\title{
4. ARTILLERISTEN UND TELEFONISTEN ABDELKRIM UND DIE ÜBERLÄUFER AUS DEN PROTEKTORATSARMEEN
}

\subsection{Die Legende von den europäischen Offizieren im Rif}

Seit Beginn des Rifkrieges machte sich zunächst in Spanien, dann in Frankreich die Auffassung breit, die militärischen Erfolge der Rifkabylen seien wesentlich - wenn nicht allein - auf europäische und vor allem deutsche Offiziere zurückzuführen, die im Hintergrund die Fäden zögen. Noch vor dem "Desaster von Annual« schrieb beispielsweise die spanische Zeitung "El Tiempo« gegen angebliche deutsche Machenschaften im Rif an. Es hieß, die Rifkabylen würden von deutschen Offizieren unterstützt, da Deutschland die Absicht habe, die Bergbauindustrie im Rif an sich zu reißen ${ }^{1}$. Die französische Nachrichtenagentur »Havas« behauptete einen Monat später, deutsche Kaufleute, die in Spanisch-Marokko lebten und am Bergbau interessiert seien, hätten den Rifkabylen Militär-Ausbilder zugesandt ${ }^{2}$. Der französische Geheimdienst betrachtete die Entwicklungen in Spanisch-Marokko als die Entfaltung eines lange vorbereiteten Plans, der von der deutschen Botschaft in Madrid geleitet würde ${ }^{3}$. Auch die englische Zeitschrift "Morocco« fragte sich, wer die Riftruppen tatsächlich anführe ${ }^{4}$.

Anfang 1925 griff die französische Presse das Thema der deutschen Ausbilder im Rif wieder auf. Aufgrund der Berichte, daß Hunderte von deutschen Offizieren und Unteroffizieren die Riftruppen anführen würden, beeilte sich das Auswärtige Amt, einer spanischen Protestnote zuvorzukommen. Es telegrafierte zur deutschen Botschaft nach Madrid: »Ob private Teilnahme an Kampfhandlungen erfolgt, ist hier nicht bekannt. Von amtlicher Unterstützung kann natürlich keine Rede sein ${ }^{5}$. Konsul Wilhelm Bohn aus Tetuan informierte die Botschaft in Paris, daß die Behauptung, Deutsche führten den Generalstab der Rifkabylen an, unsinnig sei ${ }^{6}$.

\footnotetext{
${ }^{1}$ Los alemanes se aploderan económicamente del Rif, in: El Tiempo, 16.7.1921; Spanien, Frankreich und Marokko, in: Hamburger Fremdenblatt, 27.7.1921.

${ }^{2}$ PA-AA R72041, L057268: Botschaft Paris an AA, 28.7.1921.

${ }^{3}$ ADMAE Maroc 192, 29: Bericht "Agissements insurrectionnels au Maroc français«, 21.10.1921.

${ }^{4}$ Who Leads the Rebels, in: Morocco, 6.8.1921.

${ }^{5}$ PA-AA R72044, L057803: AA an Botschaft Madrid, 7.1.1925.

${ }^{6}$ PA-AA Paris 454a: Konsulat Tetuan an Botschaft Paris, 26.2.1925.
} 
Nach dem Angriff Abdelkrims auf das französische Protektorat im April 1925 wurde der Ton französischer Presseberichte heftiger. Die Artikel sagten etwa aus, daß 540 deutsche als >Touristen per Schiff nach Tetuan und von dort ins Rif gelangt seien ${ }^{7}$ oder daß Abdelkrim hauptsächlich von deutschen Offizieren beraten werde ${ }^{8}$. Pariser Zeitungen wie »Petit Journal« oder »Écho de Paris« berichteten im Juli 1925, daß ein ehemaliger Offizier des Großen Hauptquartiers namens von Dietrich, ein Major Richter, ein Offizier namens Förster sowie ein Hauptmann von Tannenberg zu Beratern Abdelkrims avanciert seien ${ }^{9}$. Rekrutierungsbüros sollen deutsche Offiziere angeworben und nach Marokko geschickt haben ${ }^{10}$.

Der Chef des Rif-Generalstabes sei ein ehemaliger Offizier der österreichisch-ungarischen Marine namens "Aspad von Giulay Sarkantyus«, schrieb das »Bulletin du Comité de l'Afrique française «" ${ }^{11}$. Dieser allerdings hieß richtig Arpad Sarkantyus Gyulai de Nagyvarad und hatte Ungarn seit dem Ersten Weltkrieg nicht mehr verlassen ${ }^{12}$. Selbst Jacques Roger-Mathieu, der als einer der wenigen französischen Journalisten im August 1925 vor Ort im Rif war,

${ }^{7}$ Z.B. 540 stouristes allemands sont arrivés à Tetouan, in: Intransigeant, 26.5.1925; Une querelle d'allemands, in: Liberté, 8.6.1925. Der »Berliner Börsen-Courier« meldete, daß eine Verwechslung vorliege. Die ,Touristen ( seien wvermutlich die 500 deutschen Intellektuellen, die mit dem deutschen Dampfer York eine Reise nach Spanien und Portugal gemacht haben. Diese 500 deutschen Akademiker, Künstler und Gelehrte, darunter zahlreiche Frauen wie Käthe Kollwitz, sind inzwischen längst in die Heimat zurückgekehrt« [Abdel Krim und Deutschland, in: Berliner Börsen-Courier, 7.6.1925].

${ }^{8}$ PA-AA Paris 454a: Botschaft Paris an AA, 26.5.1925; Die Lage in Marokko, in: Kölnische Zeitung, 13.5.1925; Die Lage in Marokko, in: Kölnische Zeitung, 2.6.1925 (jeweils mit Bezug auf Meldungen der französischen Nachrichtenagentur "Havas«); Collaboration allemande, in: Fuvre, 13.5.1925; Les alliés d'Abd el Krim, in: Liberté, 25.5.1925; Les conseillers allemands d'Abd el Krim, in: Matin, 12.6.1925; Nos ennemis au Maroc, in: Journal, 1.6.1925; Des officiers allemands auprès d'Abd-el-Krim, in: Homme libre, 1.6.1925.

${ }^{9}$ PA-AA Paris 454a: Botschaft Paris an AA, 18.7.1925; PA-AA R30190k: Botschaft Madrid an AA, 31.7.1925; Auguste TERRIER, Les »Frères de la côte» du Rif, in: BCAF 35 (1925) S. 548-549, S. 548; René THIERRY, L'agression des Rifains contre le Maroc français, in: BCAF 35 (1925) S. 399-411, S. 409; BONNET-DEVIlLIERS, La Guerre du Rif, S. 59.

${ }^{10}$ SHAT 3H102: EMA, $2^{\mathrm{e}}$ bureau, Berichte »Action germano-riffaine«, 8.7.1925, »Ex-officiers allemands pour l'encadrement des riffains«, 16.7.1925, »L'action de l'Allemagne dans la campagne du Maroc«, 30.7.1925; CADN Tanger C38: MAE an CG Tanger, 2.10.1925. Vgl. OVED, La contribution, S. 74, S. 96, Anm. 15.

11 THIERRY, L'agression, S. 409; TerRIER, Les »Frères de la côte» 1925, S. 548. Vgl. Der Generalstabschef Abd-el-Krims. Kein Deutscher - ein ehemaliger österreichischer Marineoffizier, in: Volkszeitung, 31.7.1925; Abdel Krim's Chief of Staff, in: Manchester Guardian, 31.7.1925. Zur antideutschen Grundrichtung des "Bulletin du Comité de l'Afrique françaisex: Peter GruPP, Die Haltung des »Bulletin du Comité de l'Afrique française« gegenüber Deutschland von 1891 bis 1914, in: Francia 3 (1975) S. 393-433.

${ }_{12}$ ADMAE Maroc 130, 222: Ambassade de Budapest an MAE, 12.10.1925. 
nahm den Umstand, in Chichaouen Ausländer gesehen zu haben, zum Anlaß, die Rifarmee von einem deutschen bzw. türkischen Generalstab geleitet zu sehen $^{13}$.

Das aufgeschreckte Auswärtige Amt in Berlin beeilte sich mit Dementis. Einen von Dietrich beispielsweise hatte es in der Obersten Heeresleitung nie gegeben $^{14}$. Offiziere namens Förster oder von Tannenberg tauchten in den Ranglisten des Heeres ebenfalls nicht auf ${ }^{15}$, und Major a.D. Wolfgang Richter lebte in Breslau als Angestellter einer Bank. "Wenn die Franzosen ihre marokkanischen Niederlagen dadurch zu erklären versuchen, daß ihr gefürchteter Gegner Abd el Krim sich von deutschen Offizieren beraten lasse, so ist es für uns zwar sehr schmeichelhaft, sie müssen es nur mit etwas zutreffenderen Tatsachenbehauptungen bekräftigen«, spottete man im Auswärtigen Amt ${ }^{16}$. Genauso unzutreffend war allerdings die dort vorherrschende Ansicht, "daß diese Meldungen, ebenso wie alle anderen betreffend die Teilnahme deutscher Offiziere an den Operationen Abd-el-Krims aus der Luft gegriffen sind « ${ }^{17}$. Nicht bei einem der in der Presse oder in den Geheimdienstberichten genannten deutschen Personen kam es zu einer Verhaftung oder gar zu einer Anklage. Es handelte sich um mehr oder weniger erfundene Berichte ${ }^{18}$. Sie hoben das Ansehen Deutschlands in der arabischen Welt - da das deutsche Giftgasgeschäft mit Spanien geheim blieb - groteskerweise noch an $^{19}$.

Der Ursprung dieser und ähnlicher Behauptungen, die sich zum Teil auch gegen Großbritannien und gegen das kommunistische Rußland richteten ${ }^{20}$, waren vielfach französische Geheimdienstkreise. Aufgeschnappte Gerüchte verwandelten sich in höheren Hierarchie-Ebenen in vermeintliche Tatsachen. Das Pariser Deuxième bureau und die Rabater Direction des affaires indi-

${ }^{13}$ Jacques ROGER-MATHIEU, Cinq jours à Chechaouen. L'organisation de l'armée, entraînée et dirigée par des étrangers, in: Matin, 13.9.1925.

${ }^{14}$ PA-AA Paris 454a: AA an Botschaft Paris, 20.7.1925.

${ }^{15}$ Französische Hetze, in: Kölnische Zeitung, 4.8.1925. Vgl. AGERON, La presse parisienne, S. 23, Anm. 29; BouTBOUQALT, La Guerre du Rif, S. 113.

${ }^{16}$ PA-AA Paris 454a: AA an Botschaft Paris, 21.7.1925.

${ }^{17}$ PA-AA Paris 454a: AA an Botschaft Paris, 30.8.1925.

${ }^{18}$ OVED, La contribution, S. 79; Vincent SHEEAN, Abd el Krims europäische Helfer. Die Rolle der Ausländer im Rif, in: Neue Freie Presse, 10.11.1925.

${ }^{19}$ KUNZ, MÜLLER, Giftgas, S. 175.

${ }^{20}$ Es gab Gerüchte, daß russische Offiziere in Paris für das Rif rekrutiert worden sein sollen [AN F7, 13413: Note, 22.6.1925; dementiert in APP BA 1678: Bericht "A.S. d'engagement volontaires dans l'armée riffaine«, 11.1.1926], oder daß 15 russische Offiziere eine nach Moskau entsandte Delegation Abdelkrims zurück ins Rif begleiteten [CADN Tanger C37: Région de Fès, SR, Note, 8.1.1926]. 
gènes streuten diese mehr als zweifelhaften IInformationen، an die Presse ${ }^{21}$. Allen Berichten gemein war der Unglaube, daß die Rifkabylen ohne Anleitung und Führung von auswärtigen Experten zu ihren Militäraktionen in der Lage gewesen sein könnten ${ }^{22}$. Wenig schmeichelhaft für die französischen Militärs in Marokko war der Umstand, daß Abdelkrims Militärhelfer-zum großen Teil aus den eigenen Reihen - der Fremdenlegion und den indigenen Truppen stammten. Dies galt es zu verheimlichen und führte zu Fehlinformationen. Die Berichte dienten aber ebenso zur Kaschierung eigener militärischer Unzulänglichkeiten ${ }^{23}$ wie dazu, die französische Öffentlichkeit glauben zu machen, $\mathrm{da}$ die Feinde im Rif die gleichen seien wie die während des Weltkrieges ${ }^{24}$.

Interessenten aus Deutschland, die Abdelkrim im Kampf gegen das ungeliebte Frankreich unterstützen wollten, gab es zwar tatsächlich, aber äußerst vereinzelt, wie Briefe, die die französischen Behörden Marokkos abfangen konnten, zeigen. Im August 1925 adressierten etwa die Braunschweiger Otto Bosse und Franz Aretz einen Brief "An den Sultan der Rifkabylen Abd el Krim - Marokko « und boten ihre Dienste "als erprobte Soldaten« an, und am 13. Juli 1925 schrieben die Merseburger Wilhelm Friede und Otto Mieglitz, sich freiwillig melden zu wollen ${ }^{25}$. Derartige Post - es handelt sich um wenige Einzelfälle - dürfte Abdelkrim kaum erreicht haben.

In der Regel taten die deutschen Behörden bereits alles, um Abenteurer daran zu hindern, auch nur das Land zu verlassen. Artikel 179 des Versailler Vertrages verbot Deutschen, mit Ausnahme der französischen Fremdenlegion in fremde Kriegsdienste einzutreten ${ }^{26}$. Eine Verordnung des Sultans von Marokko aus dem Jahr 1920 untersagte Deutschen zudem das Betreten FranzösischMarokkos und der internationalen Zone von Tanger ${ }^{27}$.

${ }^{21}$ Beispiele: ADMAE Maroc 220, 82: EMA, $2^{e}$ bureau, Bericht "Officiers allemands au Maroc«, 27.5.1925; ADMAE Maroc 220, 83: EMA, $2^{\epsilon}$ bureau, Bericht »Présence d'officiers allemands au Maroc«, 1.6.1925; ADMAE Maroc 220, 108: Bericht „Présence d'officiers allemands dans 1'état-major d'Abd-el-Krim«, 20.6.1925; SHAT 3H102: EMA, $2^{\mathfrak{C}}$ bureau, Bericht œOfficiers-instructeurs et volontaires allemands envoyes dans le Rif«, 7.7.1925.

${ }^{22}$ WoOlman, Rebels in the Rif, S. 151; PENNELL, A Country, S. 130.

${ }^{23}$ RIVET, Lyautey, Bd. 3, S. 290, S. 297; BOUTBOUQALT, La Guerre du Rif, S. 32, S. 56; OVED, La gauche française, Bd. 1, S. 291; DERS., La contribution, S. 73f., S. 79; KHARCHICH, Observations, S. 228.

${ }^{24}$ BOUTBOUQALT, La Guerte du Rif, S. 56; HARRIS, France, S. 225.

${ }^{25}$ CADN Maroc DAI 199: Mappe «Saisie de la correspondance d'Abdelkrim transitant par la zone française $\ll$.

${ }^{26}$ Eckard MICHELS, Deutsche in der Fremdenlegion 1870-1965. Mythen und Realitäten, Paderborn u.a. ${ }^{3} 2000$ (Krieg in der Geschichte, 2), S. 83; PA-AA Paris 454a: AA an Botschaft Paris, 11.6.1925.

${ }^{27}$ Warnung vor Reisen nach Marokko, in: Kölnische Zeitung, 21.7.1925. 
Als Dr. Hans von Hentig, der im September 1923 in Sachsen kommunistische Aufstände gegen Aufmärsche von Adolf Hitler zu organisieren versucht hatte ${ }^{28}$, im Sommer 1925 als Korrespondent der »Frankfurter Zeitung« über Italien das Rif zu erreichen trachtete, gaben sich die deutschen Diplomaten daher alarmiert. Sie befürchteten, er könne sich politisch oder militärisch im Rif betätigen. Weil ihm das Geld ausging, kam von Hentig nicht weit ${ }^{29}$. Sein Fall veranlaßte das Auswärtige Amt, die Botschaften Madrid, Lissabon, London und Den Haag "vor der Gefahr zu warnen, daß sich abenteuerlustige Deutsche heimlich nach Marokko begeben, um dort mit den Aufständischen Verbindung aufzunehmen $\aleph^{30}$. Einigen Deutschen, die sich uneinsichtig zeigten, wurden die Auslandspässe gesperrt ${ }^{31}$. Versprengte junge Deutsche aus paramilitärischen Organisationen, die Italien als Sprungbrett fuir die Einreise ins Rif nutzen wollten, kamen nie $\mathrm{an}^{32}$.

Die französische Regierung betrachtete den Pressewirbel demzufolge relativ gelassen. Ministerpräsident Paul Painlevé gab sich im Juni 1925 überzeugt, daß die Beteiligung von Ausländern am Kampf der Rifkabylen übertrieben dargestellt würde ${ }^{33}$. Als der Staatssekretär des Auswärtigen Amts von Schubert dem französischen Botschafter de Margerie zu verstehen gab, daß die deutsche Regierung nichts mit den Abenteurern im Rif zu tun habe, erhielt er die Antwort, »daß in Paris keinerlei Verdacht dieser Art bestehe ${ }^{34}$.

Sympathisanten, die für Abdelkrim kämpfen wollten, stammten auch aus anderen Ländern. Der Schweizer Lucas Baumgartner schrieb Abdelkrim im Dezember 1924, er könne ihm auf vielfältige Art militärisch beistehen, und er schlug vor, es sei am besten, "wenn Sie mir einen Vertreter von Ihnen zur Unterhandlung zusenden möchten ${ }^{35}$. Die Bolivianer Luis Cespedes und Moise

${ }^{28}$ PA-AA R30190k: Oberreichsanwalt an Reichsminister der Justiz, 30.9.1925.

${ }^{29}$ PA-AA R30190k: Botschaft Rom an AA, 10.7.1925 und AA an Botschaft Rom, 14.7.1925; CADN Rome A453: Consulat de Triest an Ambassade de Rome, 29.7.1925.

${ }^{30}$ PA-AA R30190k: AA an Botschaften Madrid, London, Lissabon, Haag, 14.7.1925.

${ }^{31}$ PA-AA R30190k: AA an Mecklenburgisches Ministerium der Auswärtigen Angelegenheiten, 23.11.1925 und Badisches Staatsministerium an AA, 24.11.1925.

${ }^{32}$ PA-AA R30190k: Konsulat Triest an Botschaft Rom, 30.9.1925; PA-AA R30190k: Konsulat Genua an Botschaft Rom, 16.9.1925. Es gab Berichte französischer Behörden, deutsche Geheimorganisationen wie Stahlhelm, Frontbaum oder Werwolf hätten 147 Mann über Italien ins Rif schicken wollen [CADN Rome A453: Ambassade de Rome an Consulat de Triest, 26.5.1925; CADN Maroc DAI 188: MAE an CG Rabat, 31.5.1925; PA-AA R72044, L057913: Botschaft Washington an AA, 27.5.1925].

${ }^{33}$ PA-AA Paris 454a: Botschaft Paris an AA, 4.6.1925; PA-AA Paris 454a: AA an Botschaft Paris, 11.6.1925; Der Kampf in Marokko, in: Kölnische Zeitung, 15.6.1925.

${ }^{34}$ Aufzeichnung des Staatssekretärs des Auswärtigen Amts von Schubert, 18.7.1925, in: Walter BuSSMANN (Hg.), Akten zur deutschen auswärtigen Politik 1918-1945, Ser. A, Bd. 13, Göttingen 1995, Nr. 210, S. 582-584, S. 583.

${ }^{35}$ CADN Maroc DAI 195: Lucas Baumgartner an »Add-el-Krim« (sic!), 9.12.1924. Bereits im Januar 1924 hatte Baumgartner Abdelkrim einen von den französischen Behörden abgefangenen Brief geschrieben, in dem er ihm mitteilte, daß er die Angelegenheit der Rifkaby- 
Gimenez boten Abdelkrim ihre Dienste genauso $a^{36}$ wie der Ungar Franz Arkarry aus Budapest, der beim deutschen »Kolonialministerium« anfragte, wie er es bewerkstelligen könne, mit einigen Kameraden zu Abdelkrim aufzubrechen $^{37}$. Sogar der später weltberühmte amerikanische Ethnologe Carleton Coon, der sich im Herbst 1924 mit seinem Freund Gordon Browne zu Feldforschungen am Rand des Rifgebietes aufhielt, spielte mit dem Gedanken, in die Rifarmee einzutreten ${ }^{38}$. Ein Brief ihres Landsmanns Theodor Stewart aus New Orleans mit der Bitte an Abdelkrim, in die Rifarmee eintreten zu dürfen, wurde ebenfalls abgefangen ${ }^{39}$. Bei alldem handelte es sich um nicht mehr als um kuriose Einzeltaten.

\subsection{Die Rifarmee und die Protektoratstruppen}

Abdelkrims Siege von 1921 kamen durch landesübliche wharkas" (Kriegszüge) zustande. Einem Aufruf zum Kampf folgte eine sehr ungewisse Anzahl von Freiwilligen, die zur Erntezeit und zur Aussaat wieder in ihre Dörfer heimkehrten ${ }^{40}$. Schnell sahen Abdelkrim und sein Bruder Si M'hammed ein, $\mathrm{da}$ diese Methode gegen die spanische Protektoratsarmee nicht ausreichen würde. 1922 begannen sie mit der Organisation einer regulären Rifarmee, die Mitte 1923 - nach der Einnahme von über vier Millionen Peseten für die Freilassung der spanischen Gefangenen und nach der Proklamation der »RifRepublik« im selben Jahr - zum vorläufigen Abschluß kam ${ }^{41}$. Ahmed Boudra leitete das Kriegsministerium, Si M'hammed fungierte zusammen mit Generalstabschef Haddou ben Ziane el Khattabi als Oberkommandierender der Riftruppen ${ }^{42}$.

len dem Genfer Völkerbund vorgebracht habe [CADN Maroc DAI 195: Lucas Baumgartner an "Monsieur Add-el-Krim (sic!), Commandant des Rifkabyles au Rif à Schechschauen (Marocco)«, 15.1.1924].

${ }^{36}$ CADN Madrid C263: MAE an Ambassade de Madrid, 21.5.1925.

${ }^{37}$ PA-AA R70638: Franz Arkarry an »Kolonialministerium«, 22.7.1925.

${ }^{38}$ COON, Adventures, S. 29.

${ }^{39}$ CADN Maroc DAI 199: Mappe "Saisie de la correspondance d'Abdelkrim transitant par la zone française $\ll$.

${ }^{40}$ KeERNER, La Guetre du Rif espagnole, S. 145; KUNZ, MŬLLER, Giftgas, S. 56; FrAUENHOLZ, Der spanische Krieg, S. 108; VILLAIN, BrUN, Fellah ohne Faruk, S. 8.

${ }^{41}$ GODED LLOPIS, Marruecos, S. 97; HART, The Aith Waryaghar, S. 385; Fleming, Primo de Rivera and Abd-el-Krim, S. 115; VILLALOBOS, El sueño colonial, S. 138-143.

${ }^{42}$ PENNELl, La guerra del Rif, S. 182, S. 217; DERS., A Country, S. 159; KHARCHICH, La France, S. 104; WoOLMAN, Rebels in the Rif, S. 147. 
Abdelkrims Streitkräfte waren in vier Hauptgruppen aufgeteilt: a) eine kleine Anzahl organisierter Einheiten (die reguläre Rifarmee), b) schwach organisierte Gruppen befreundeter Kabylen, c) Rif-Kader zur Kontrolle unterworfener Stämme, d) Angehörige unterworfener Stämme, die zum Kriegsdienst gezwungen wurden ${ }^{43}$. Die reguläre Rifarmee bestand nur aus etwa 2000 bis 7000 Mann, die meisten davon waren Beni Ouriagheli ${ }^{44}$. Die Gesamtzahl der Truppen konnte je nach Lage durch zusätzliche Kämpfer befreundeter oder unterworfener Kabylen auf über 60000 Mann erhöht werden ${ }^{45}$. Abdelkrim beschrieb in seinen Memoiren, wie er die Einheiten seiner regulären Rifarmee verwendete: „Diese Soldaten und Offiziere wurden [...] in den Kämpfen niemals als geschlossene Einheit eingesetzt. Unter die Stämme, die ich für den Kampf an einem bestimmten Frontabschnitt in Aussicht genommen hatte, aufgeteilt, bildeten sie für diese Kern und Rahmen der militärischen Organisation ${ }^{46}$. Auf diese Weise blieb der gesamte Militärapparat im Einflußgebiet Abdelkrims stets unter dessen Kontrolle. Jederzeit waren neue Kräfte abruf-

${ }^{43}$ PRO-AIR 5, 722: Bericht »A Study of the Air Aspect of the France-Riff War 1925-1926« von Lt. D.L. Blackford (1930).

${ }^{44}$ PENNELL, A Country, S. 132. In der Literatur wie in den Quellen schwanken die Angaben über die Stärke der regulären Rifarmee erheblich: z.B. 2000 Mann [Die Hilfsquellen Abd el Krims, in: Kölnische Zeitung, 25.6.1926]; $2000-2500$ [Vincent MONTEIL, La guerre révolutionnaire, in: Abd el-Krim et la République du Rif, S. 149-152, S. 149]; 3000 [BALFOUR, Deadly Embrace, S. 194]; 5000 [NIMSCHOWSKI, Grundzüge, S. 268]; 7 000-10 000 [Robert GORDON-CANNING, Tangier and Morocco, in: Contemporary Review 127 (1924) S. 177184, S. 179]; 6000-10 000 [TOYNBEE, The Islamic World, S. 148]; $2000-5000$ [FRAUENHOLZ, Der spanische Krieg, S. 108]; 5000 [FuRNEAUX, Abdel Krim, S. 86]; 15 000-20000 [PRO-FO 371, 11908, 5, 129: Embassy of Madrid an FO, 21.5.1926 mit Bezug auf einen Bericht von Militärattaché W.W.T. Torr, 19.5.1926]; $6000-7000$ [ABDELKRIM, Memoiren, S. 93]; nie mehr als 3000 [HART, The Aith Waryaghar, S. 385]; nicht über 2500 [GABRIELLI, Abd-el-Krim, S. 48]; $3000-4000$ [ÁlVAREZ, The Betrothed of Death 2001, S. 125]; 3 000-7 000 [KHARCHICH, La France, S. 103]; $6000-7000$ [SheEAN, Personal History, S. 113]; $7000-8000$ [FRUNSE, Zivilisatoren, S. 523]; 10000 (Ende 1923) [CADN Maroc DAI 187: RG Rabat an MAE, 22.12.1923]; 6000 (Ende 1925) [Walter B. HARRIS, Abd-elKrim's Power. Organization in the Rif, in: Times, 29.12.1925]; 1926 von 6000 auf 2000 3000 reduziert [Hans A. LANGLET, How the Riffis Fight, in: Manchester Guardian, 4.5.1926].

${ }^{45}$ Auch hier gibt es sehr unterschiedliche Angaben über die Gesamtstärke: z.B. 69300 Mann (1922) [CADN Madrid C273: MAE an Ambassade de Madrid, 23.1.1922]; 65000 (1925) [HART, The Aith Waryaghar, S. 388]; 80000 [HUETZ DE LEMPS, La collaboration, S. 91; FLEMING, Primo de Rivera and Abd-el-Krim, S. 116; ÁlVAREZ, The Betrothed of Death 2001, S. 125]; 35 000-60 000 [DAOUD, Abdelkrim, S. 156]; 50 000-60 000 [FRUNSE, Zivilisatoren, S. 522]; 75000 [MONTEL, La guerre, S. 149]; 60000 [KHARCHICH, La France, S. 104; MONTJOU, La Guerre du Rif, S. 593; GABRIELLI, Abd-el-Krim, S. 49]; 100000 (Ende 1923) [CADN Maroc DAI 187: RG Rabat an MAE, 22.12.1923]; $125000 \mathrm{zu}$ Glanztagen [WOOLMAN, Rebels in the Rif, S. 149].

${ }^{46}$ ABDELKRIM, Memoiren, S. 94. Diese Angaben werden durch ein Dossier von General Dosse vom April 1926 bestätigt [SHAT 3H1557: Bericht »Réflexions suggérées par six mois de campagne contre le Riff«, 9.4.1926]. 
bar. Der französische Historiker Daniel Rivet geht so weit zu konstatieren, daß die »Rif-Republik» kein Staat mit einer Armee, sondern eine Armee mit einem Staat gewesen $\operatorname{sei}^{47}$.

Die reguläre Rifarmee war in Einheiten zu 300 bis 500 Mann eingeteilt. Jede dieser Einheiten bestand aus Untergruppierungen zu 250, 100, 50, 25 und zwölf Mann, die von Caïds angeführt wurden. Offiziere trugen einen roten, gewöhnliche Soldaten hingegen einen grünen Turban. Die wichtigsten Generäle waren Haddou Mohand Ameziane (Kommandant der Region um Kiffane im Südosten des zentralen Rifs), Ahmed Kheriro (Jebala-Region), Chaib el Yacoubi (Ostfront) und Chaib n-Moh (Ouergha-Front). In der Truppe herrschte strenge Disziplin. Die Rifarmee war eine effizient organisierte Institution, die Abdelkrim und seinem Bruder treu ergeben war ${ }^{48}$.

Abdelkrim gilt als Miterfinder der modernen Guerilla-Taktik, deren Prinzip und Strategie in der Folgezeit vom Drusenkrieg in Syrien (noch 1925) bis hin zum Unabhängigkeitskampf Algeriens oder während des Vietnam-Krieges kopiert wurden ${ }^{49}$. Seine Militärmaximen waren gute Aufklärung, Mobilität, Präzision beim Schießen sowie Ausnutzung des Geländes ${ }^{50}$. Abdelkrim und $\mathrm{Si}$ M'hammed waren keine `Draufgänger, sondern: »Die Kriegführung des Rifchefs war, militärisch betrachtet, insgesamt eher vorsichtig-realistisch, denn kühn aufs Ganze gehend «"

Die Riftruppen mieden offene Feldschlachten und bevorzugten kleine Gefechte aus dem Hinterhalt und in der Nacht, auch um den Gegnern ihre wahre Stärke nicht zu offenbaren. Selbst der Sieg von Annual 1921 kam hauptsächlich dadurch zustande, daß der spanische Posten von den umliegenden Hügeln aus beschossen worden war. Nach Überraschungsangriffen auf Blockhäuser oder Versorgungstrupps verschwanden die Riftruppen schnell wieder in den Bergen und spielten ihre hohe Beweglichkeit und ihre Kenntnis des gebirgigen

\footnotetext{
${ }^{47}$ RIVET, Lyautey, Bd. 3, S. 261; DAOUD, Abdelkrim, S. 155.

${ }^{48}$ PenNell, A Country, S. 131f.; GabrIELl, Abd-el-Krim, S. 46; FURNEAUX, Abdel Krim, S. 156; HART, The Aith Waryaghar, S. 383f.; FONTAINE, L'étrange aventure, S. 62; Vincent SHEEAN, Die Armee Abd el Krims, in: Neue Zürcher Zeitung, 8.11.1925. Zur Organisation der Rifarmee: ChTATOU, Aspectos, S. 68; WOOLMAN, Rebels in the Rif, S. 150f.; MONTJOU, La Guerre du Rif, S. 591-594; FLEMING, Primo de Rivera and Abd-el-Krim, S. 223f.; GoDED LLOPIS, Marruecos, S. 94; HART, The Aith Waryaghar, S. 387; Youssoufl, Les institutions, S. 96-99; MONTEL, La guerre, S. 149; KHARCHICH, La France, S. 103-105.

${ }^{49}$ WOLF, Les secrets, S. 114; MONTEI, La guerre, S. $151 \mathrm{f}$.

${ }^{50}$ PRO-FO 174, 303, 74: Vice Consul of Fez an CG Rabat, 27.11.1924; PRO-FO 371, 11080, 39, 155: Embassy of Madrid an FO, 23.10 .1925 mit dem Bericht des Madrider Militärattachés W.W.T. Torr "Interview with Mr. W.B. Harris, the $>$ Timesi-Correspondent at Tangier«, 10.10.1925; FRUNSE, Zivilisatoren, S. 525.

${ }^{51}$ KUNZ, MÜLLER, Giftgas, S. 120f.
} 
Geländes aus ${ }^{52}$. Der schweizerische Fremdenlegionär Werner Nef berichtete: "Diese Rebellen sind immer da, wo man sie am allerwenigsten vermutet, und dann, wenn man glaubt, sie einmal fassen zu können, dann sind sie nirgends zu finden «3. Die Rifkabylen versuchten, die Besatzung von Blockhäusern durch Umzingelung sowie durch das Abschneiden von Nachschubkonvois und von Wasserquellen zu zermürben. Das tägliche lebensgefährliche Wasserholen wurde unter spanischen Legionären »aguada " genannt ${ }^{54}$.

Diese Kampfesweise funktionierte nur in den ersten Jahren des Widerstandes. Mit dem Eintritt Frankreichs in den Rifkrieg (1925) standen den Rifkabylen zuletzt fast 500000 Mann mit modernstem Kriegsgerät gegenüber. Der militärische Druck wurde einfach zu groß, als daß ihm mit Guerilla-Taktiken zu begegnen gewesen wäres .

Spaniens Marokko-Armee orientierte sich in ihrer Gliederung am erfolgreichen französischen Vorbild. Zusätzlich zu den regulären Truppen wurden zwei neue Verbände gebildet. 1911 waren die sregulares« - bestehend aus marokkanischen Freiwilligen und spanischen Offizieren - gegründet worden. Thre Stärke wuchs rasch an und wurde zwischen 1919 (10 570 Mann) und 1925 als Folge des Rifkrieges stärker aufgestockt (16 927 Mann). Ein zweiter Schritt war die Bildung einer eigenen spanischen Fremdenlegion, der stercio de extranjeros« genannten Eliteeinheit, die anfangs ausschließlich für den Einsatz in Marokko vorgesehen war. Nach ihrer offiziellen Gründung am 28. Januar 1920 begann ab dem 31. August 1920 unter dem ersten Kommandeur José Millán Astray die Rekrutierung für den fünfjährigen Dienst. Die anfängliche Zahl von 500 Mann stieg bis Anfang 1925 auf 7967 Mann an. >Fremdenlegion، war insofern ein eher eigentümlicher Begriff, als der Anteil an Ausländern nie höher als zehn bis $20 \%$ war. Aus Lateinamerika - insbesondere Kuba - und Portugal war der Andrang besonders hoch ${ }^{56}$.

${ }^{52}$ CHTATOU, Rif Oral Tradition, S. 193; WoOlMaN, Rebels in the Rif, S. 81, S. 155, S. 184; VILlaIN, BrUN, Fellah ohne Faruk, S. 8f.; TOYNBEE, The Islamic World, S. 136; Auszug aus dem geheimen Bericht, S. 206f.

${ }^{53}$ Werner NEF, Im Kampfe gegen die Rifkabylen. Erlebnisse eines Schweizers in der Fremdenlegion während des Aufstandes im französischen Rif, Weinfelden 1927, S. 47. Vgl. KAMINSKI, Spanisch-Marokko, S. 719f.; LORENSEN, Mit der Legion, S. 417f.; SABLOTNY, Légionnaire, S. 91.

${ }^{34}$ ÁlvareZ, The Betrothed of Death 2001, S. 95, Anm. 10. Vgl. SABlotNy, Légionnaire, S. 87-89; MEYER, Dreitausend Kilometer, S. 40; ZAEPER, Unter der Glutsonne, S. 22; NEF, Im Kampfe, S. 33.

${ }^{35}$ MICHELS, Deutsche in der Fremdenlegion, S. 83; WOOLMAN, Rebels in the Rif, S. 155.

${ }^{56}$ Álvarez, The Betrothed of Death 2001, S. 7, S. 15f., S. 31f., Anm. 26; FleMING, Primo de Rivera and Abd-el-Krim, S. 213; John SCURR, The Spanish Foreign Legion, London 1985 (Men-at-Arms Series, 161), S. 4; ASPREY, War in the Shadows, S. 265; MICHELS, Deutsche in der Fremdenlegion, S. 80; VILlALOBOS, El sueño colonial, S. 123-134; LA PORTE, La atracción del imán, S. 75f.; PAYNe, Politics, S. 112-122, S. 152-157; BoYd, Praetorian Politics, S. 39, S. 172; Robert G. JENSEN, José Millán-Astray and the Nationalist \Crusade in 
Per Zeitungsannonce oder in spanischen Konsulaten und Botschaften wurden nach dem Ausbruch des Rifkrieges Soldaten angeworben ${ }^{57}$. Gerade unter der arbeitslosen Bevölkerung Europas stießen die Werbeplakate auf großes Interesse. 2500 Briten drängelten sich am 18. August 1921 vor der spanischen Botschaft in London, um sich freiwillig zu melden ${ }^{58}$. Wegen der zahlreichen Proteste in der englischen Presse und im Unterhaus sah sich der spanische Botschafter veranlaßt, die Verpflichtung von Briten auszusetzen ${ }^{59}$.

Auch in Deutschland gab es Anwerbungen - trotz des Verbotes durch Artikel 179 des Versailler Vertrages. Dies führte in Frankreich zu Befürchtungen, daß sich die deutschen Soldaten bei erneuten kriegerischen Auseinandersetzungen zwischen Frankreich und Deutschland win eine deutsche Kolonialtruppe auf nordafrikanischem Boden verwandeln würden ${ }^{60}$. Die spanische Fremdenlegion erlangte unter deutschen Arbeitslosen oder Abenteurern allerdings nicht die Aufmerksamkeit ihres französischen Vorbildes. Die starke Arbeitslosigkeit in Deutschland trieb einige hundert Deutsche - zum größten Teil ehemalige Soldaten, die nach dem Weltkrieg keine Anstellung gefunden hatten $-\mathrm{zu}$ den Rekrutierungsbüros ${ }^{61}$.

Die Hauptstelle befand sich in Hamburg, wo der spanische Vize-Konsul Amoros 1923 zahlreiche zum Teil minderjährige Deutsche für die spanische Legion gewinnen konnte, vor allem mit der falschen Behauptung, in Marokko würde eine Polizeitruppe für Sicherungsdienste aufgebaut ${ }^{62}$. Insgesamt belief sich die Anzahl der Deutschen in der spanischen Fremdenlegion im Zeitraum von 1920 bis 1930 auf 912 Mann. Dies war nach dem portugiesischen (1 085) der höchste Anteil an den insgesamt 4304 Ausländern $^{63}$.

Spain, in: Journal of Contemporary History 27 (1992) S. 425-447. Die spanische Fremdenlegion besteht noch heute unter dem Namen "La Legión «. Noch immer gilt Ramin A. Sepasgosarians Fazit: "Allem Ermessen nach hat die Anwesenheit deutscher Freiwilliger in der spanischen Fremdenlegion [...] noch keine würdigende Darstellung gefunden. [...] Eine umfassende Darstellung der deutschen Freiwilligen in der spanischen Fremdenlegion hart noch ihrer Erfüllung « [SEPASGOSARIAN, Freundschaft, S. 106f.].

${ }^{57}$ ÁlvareZ, The Betrothed of Death 2001, S. 49; HuBER, Als Fremdenlegionär, S. 4; 250 Recruited Here for Moroccan War, in: New York Times, 23.8.1921.

${ }^{58}$ Les enrôlements pour la Légion étrangère espagnole, in: Petit Journal, 19.8.1921; PRO-FO 371, 9471, 185, 77 : CG Tangier an FO, 22.2.1922 mit beiliegendem Bericht »Morocco, Annual Report $1921 \ll$, S. 9.

${ }^{59}$ Les enrôlements pour la Légion étrangère d'Espagne sont suspendus en Angleterre, in: Petit Journal, 20.8.1921; Les misères des légionnaires anglais, in: BCAF(1921) S. 421-423.

${ }^{60}$ MICHELS, Deutsche in der Fremdenlegion, S. 81.

${ }^{61}$ KUNZ, MÜLLER, Giftgas, S. 104; SABLOTNY, Légionnaire, S. 10; PA-AA R33146: Reichsinnenministerium an AA, 9.5.1921.

${ }^{62}$ Ál VAREZ, The Betrothed of Death 2001, S. 30, Anm. 26; PAYNe, Politics, S. 217; MEYer, Dreitausend Kilometer, S. 5; SABLOTNY, Légionnaire, S. 7-10.

${ }^{63}$ Mitteilung von Miguel Ballenilla an Offizier im Generalstab der Spanischen Legion in Almeria -, freundlicherweise übermittelt von José E. Álvarez, 19.9.2002. 
Erst als sich die Kommunistische Partei Deutschlands (KPD) zum »Fürsprecher deutscher Legionäre ${ }^{64}$ ernannte und seit dem Herbst 1924 in der deutschen - speziell Hamburger - Presse durch die Berichte geflohener Legionäre eine regelrechte Kampagne gegen die "Verheizung " Deutscher als "Kanonenfutter« in Marokko entbrannte ${ }^{65}$, reagierte das Auswärtige Amt in Berlin. Es brachte die spanische Botschaft dazu, die Anwerbungen in Deutschland einzustellen $^{66}$. Auf deutschen Druck hin verordnete der spanische König Alfonso XIII. sogar, daß alle unzufriedenen und heimkehrwilligen deutschen Legionäre entlassen werden sollten ${ }^{67}$. Dies geschah allenfalls vereinzelt, da die königliche Anordnung von den Offizieren in Marokko in der Regel mißachtet wurde $^{68}$. Allen voran protestierte die Anfang 1925 von Rudolf Zestermann in Hamburg gegründete Vereinigung der Angehörigen deutscher Fremdenlegionäre in Spanien vehement gegen dieses Verhalten ${ }^{69}$.

Auch Frankreich bediente sich in Marokko zusätzlicher militärischer Hilfe durch (nord-)afrikanische Soldaten. Die Protektoratsarmee bestand zum größten Teil aus tunesischen, marokkanischen, algerischen und senegalesischen Schützen-, Infanterie- und Kavallerie-Regimentern, die sich während des Ersten Weltkrieges in Europa bewährt hatten ${ }^{70}$. Nur 12000 Mann, nicht einmal ein Zehntel der vor dem Rifkrieg in Marokko stationierten Truppen (rund 140000 Mann), waren Franzosen. Eine besondere Bedeutung hatte gerade in Marokko die französische Fremdenlegion inne. 1831 gegründet, hatte sie in

\section{${ }^{64}$ SEPASGOSARIAN, Freundschaft, S. 106.}

${ }^{65}$ Z.B. Der Mord an den deutschen Erwerbslosen in der spanischen Fremdenlegion, in: Hamburger Volkszeitung, 25.8.1924; Deutsches Kanonenfutter in Marokko, in: Berliner Zeitung, 8.9.1924; Der spanischen Hölle entronnen, in: Bergedorf-Sander Volksblatt, 27.8.1924; Der spanischen Fremdenlegion entflohen, in: Mecklenburger Warte, 30.10.1924; Deutsche Erwerbslose werden dem spanischen Imperialismus als Kanonenfutter ausgeliefert, in: Rote Fahne, 6.11.1924; Deutsche in der spanischen Legion in Marokko, in: Hamburger Nachrichten, 19.11.1924; Deutsche Kämpfer in Marokko, in: Vossische Zeitung, 26.11.1924; Spanische Fremdenlegion, in: Hamburger Echo, 26.11.1924; Das Los der spanischen Fremdenlegionäre, in: Hamburger Fremdenblatt, 30.11.1924; Flucht aus der spanischen Legion! Erlebnisse eines Deutschen im Riffgebiet, in: Mecklenburger Warte, 21.12.1924; In der spanischen Fremdenlegion, in: Hamburger Correspondent, 24.1.1925; Deutsches Kanonenfutter in Marokko, in: Neue Berliner Zeitung, 2.3.1925. In ähnlicher Weise berichtete 1921 auch die englische und amerikanische Presse über die schlechte Behandlung ihrer Staatsbürger [ÁLVAREZ, The Betrothed of Death 2001, S. 70, Anm. 41].

${ }^{66}$ PA-AA R71922: Bericht »Entwurf für die Beantwortung der kommunistischen Interpellation über die spanische Fremdenlegion«, 20.10.1924. Vgl. MICHELS, Deutsche in der Fremdenlegion, S. 81; KUNZ, MŬLLER, Giftgas, S. 104. Sie datieren dies fälschlicherweise auf den Sommer 1925.

${ }^{67}$ PA-AA R71922: AA an Botschaft Madrid, 23.10.1924.

${ }^{68}$ PA-AA R71923: Aufzeichnung, 15.12.1924.

${ }^{69}$ Die Leiden der Deutschen in der spanischen Fremdenlegion, in: Hamburger Anzeiger, 10.1.1925.

${ }^{70}$ Driss MAGHRAOUI, Moroccan Colonial Soldiers. Between Selective Memory and Collective Memory, in: Arab Studies Quarterly 20 (1998) S. 21-41, S. 25-29. 
ihrer bewegten Geschichte vor allem auf Deutsche eine hohe Anziehungskraft ausgeübt - sogar zu Weltkriegszeiten. In den 1920er Jahren war der Andrang Deutscher so stark, daß ihr bis 1926 erreichter Anteil von $26 \%$ für Frankreich beängstigende Ausmaße annahm. Die Stützpunkte der Fremdenlegion in Marokko waren Meknes, Fes und Marrakesch. Ihre Truppenstärke betrug rund $13000 \mathrm{Mann}^{71}$.

\subsection{Die Anzahl und die Motive der europäischen Überläufer}

Von Anfang an bildeten indigene Deserteure der spanischen bzw. französischen Protektoratsarmeen die Basis der Riftruppen ${ }^{72}$. Schon im Sommer 1921 liefen Tausende von »regulares « - angeregt durch Abdelkrims militärische Erfolge - über. Allein im Juli 1921 waren es annähernd $5000^{73}$. Aus ihnen sortierte Abdelkrim eine kleine Gruppe europäisch trainierter Spezialisten heraus, die die Ausbildung der Riftruppen übernehmen sollten. In Annual und bei Jebel Aroui (Monte Arruit) waren zahlreiche Kanonen, Maschinengewehre und anderes modernes Militärmaterial erbeutet worden, aber kaum jemand wußte mit ihm umzugehen. Die bekanntesten dieser ersten Ausbilder waren el Matali und el Mufaddal sowie insbesondere die Südmarokkaner Si Ahmed el Soussi und Caind Mohammed Bouhout. Ahmed el Soussi bildete Artilleristen aus und kommandierte die erste MG-Abteilung, bis er im Oktober 1923 bei Sidi Ali Bou Roqba getötet wurde. Caïd Bouhout genoß im Rif wegen seiner genauen Kenntnisse der europäischen Kriegführung hohes Prestige. Er desertierte 1921 kurz vor Abdelkrims Sieg bei Annual von den »regulares« und kümmerte sich ebenfalls um die Ausbildung an MGs und an Kanonen ${ }^{74}$.

${ }^{71}$ MICHELS, Deutsche in der Fremdenlegion, S. 28, S. 88, S. 101, S. 332; PORCH, Foreign Legion, S. 383, S. 388; ClAYTON, France, S. 95-110; TOYNBEE, The Islamic World, S. 137, Anm. 2.

${ }^{n}$ GODED LLOPIS, Marruecos, S. 97.

${ }^{73}$ ÁlVAREZ, The Betrothed of Death 2001, S. 41f., S. 45. S. 64, Anm. 22; BoYD. Praetorian Politics, S. 180f.; NIMSCHOWSKI, Grundzüge, S. 264.

${ }^{74}$ Pennell, A Country, S. 130; Fleming, Primo de Rivera and Abd-el-Krim, S. 224; KHARCHICH, La France, S. 109; GABRIELLI, Abd-el-Krim, S. 46; FURNEAUX, Abdel Krim, S. 156; WOOlman, Rebels in the Rif, S. 151; Pierre LOZE, L'etat-major d'Abd el Krim, in: Petit Journal, 14.4.1926; LANGLET, How the Riffis Fight, 4.5.1926; SHAT 12J3797, 28: Vernehmung von Josef Klems vor dem 2. Kriegsgericht in Meknes, 19.6.1926; SHAT 12J3797, 61: Chef de bureau du cercle de Taza-Nord an Colonel commandant le cercle de Taza-Nord, 24.7.1926. 
Viele der unteren Offiziere, die vorher den Spaniern gedient hatten, kannten sich im Ausheben von Schützengräben und im Erstellen von Feldschanzen aus $^{75}$. Deserteure aus Ägypten, Algerien und Tunesien liefen von den Spaniern oder von der französischen Armee zu den Rifkabylen über ${ }^{76}$. Der Tunesier ben Nacer el Djaïdi, ein früherer Übersetzer der spanischen Armee, übernahm im Frühjahr 1922 die Leitung der Rif-Artillerie ${ }^{77}$. Der tunesische Deserteur Si Mohammed Drissi organisierte zur selben Zeit an der Küste vor Ajdir das Ausheben von Verteidigungsgräben ${ }^{78}$.

Im Sommer 1925 wurde sogar von unbekannten Aktivisten versucht, marokkanische Soldaten der französischen Besatzungsarmee in Deutschland für Abdelkrim anzuwerben. Poster an den Wänden der Militärbaracken forderten zum Desertieren oder zur Befehlsverweigerung auf ${ }^{79}$. 1925 kamen von 19000 im Rheingebiet stationierten afrikanischen Soldaten (Stichwort "Schwarze Schmach«) allein 18000 aus Algerien, Tunesien und Marokko. Nach Abdelkrims Angriff auf die französische Zone Marokkos wurden die meisten zur Verteidigung des Protektorates abkommandiert. Im November 1926 gab es nur noch 555 nordafrikanische Besatzungssoldaten in Deutschland ${ }^{80}$.

Das deutsche Konsulat in Tetuan teilte der Botschaft Madrid am 3. Juli 1925 mit, daß die Oldenburg-Portugiesische Dampfschiffahrtsgesellschaft (OPDG) seit geraumer Zeit auf ihren Dampfern aus Hamburg zwei bis drei marokkanische Deserteure der Besatzungsarmee, die Abdelkrim ihre Dienste anbieten wollten, mit sich führe ${ }^{81}$. Zwischen März 1923 und Februar 1925 handelte es sich allerdings um kaum mehr als 37 Fälle. Der Deutsche Hilfsverein für entlassene Gefangene und die Hamburger Polizeibehörde hatten die Deserteure

${ }^{75}$ WoOlmaN, Rebels in the Rif, S. 153f.; Du Taillis, Behind the Moorish Lines, S. 166.

${ }^{76}$ PRO-FO 371, 9470, 44, 126: CG Tangier an FO, 13.10.1923; ADMAE Maroc 219, 34: MAE an Gouverneur général de l'Algérie, 16.1.1924; L'agression des Rifains contre le Maroc français, in: BCAF 35 (1925) S. 304-308, S. 307; CADN Maroc DAI 192: RG Rabat an EMA, $2^{\circ}$ bureau, 13.11.1925.

${ }^{7}$ ADMAE Maroc 194, 216: CG Tanger an MAE, 8.7.1922.

${ }^{78}$ CADN Madrid C273: MAE an Ambassade de Madrid, 2.6.1922 mit Bezug auf den Bericht „Un voyage dans le Riff, Rapport d'un informateur« des Commissaire spécial A. Bourges, 12.5.1922.

${ }^{79}$ Pro-Rifi Propaganda in Rhineland, in: Times, 16.6.1925.

${ }^{80}$ Gerhard HöPP, Die Schuldigkeit der Mohren. Muslimische Deserteure im Deutschland der Zwischenkriegszeit 1919-1926, in: Études germano-africaines 15-16 (1997-1998) S. 192202, S. 192f. u. S. 193, Anm. 9; Hans-Jürgen LÜSEBRINK, Die marokkanischen Kolonialsoldaten (Tirailleurs) in Deutschland 1919-1923. Präsenz, Wahrnehmungsformen, Konflikte, in: POPP (Hg.), Die Sicht des Anderen, S. 53-64, S. 53f. Vgl. Gisela LEBzELTER, Die "Schwarze Schmach火. Vorurteile, Propaganda, Mythos, in: Geschichte und Gesellschaft 11 (1985) S. 37-58; Christian KoLLER, "Von Wilden aller Rassen niedergemetzelt«. Die Diskussion um die Verwendung von Kolonialtruppen in Europa zwischen Rassismus, Kolonial- und Militärpolitik 1914-1930, Stuttgart 2001 (Beiträge zur Kolonial- und Überseegeschichte, 82), S. 201-341.

${ }^{81}$ PA-AA R70638: Konsulat Tetuan an Botschaft Madrid, 3.7.1925. 
mit Genehmigung des Reichsinnenministers stets der OPDG überstellt. Thr Schicksal in Marokko blieb ungewiß. Nun aber, nach Frankreichs Verwicklung in den Rifkrieg, verweigerte das Schiffahrtsunternehmen die Übernahme mit der Begründung, daß die Deserteure Schiffe und Besatzung wegen der französischen Kriegsmarine im Mittelmeer gefährden würden. Der Generalsekretär der Liga der unterdrückten Völker, Chempakaraman Pillai, schlug daraufhin die direkte Überstellung der Deserteure an Abdelkrim vor ${ }^{82}$. Die deutsche Regierung setzte jedoch die Abschiebungen wegen befürchteter diplomatischer Konflikte mit Frankreich aus ${ }^{83}$.

Auch einige Türken kämpften auf der Seite der Rifkabylen. Im Juni 1924 hielten sich die Rifgesandten Mahmoud, Omar und Raïs Messaoud Amar alias Sibbera in der Türkei auf, um Offiziere zu rekrutieren. Ob diese jemals das Rif erreichten, ist ungewi ${ }^{84}$. Es gab immer wieder Berichte über türkische Offiziere, die das Rif aufgesucht oder Abdelkrim zum Angriff gegen Frankreich angestachelt haben sollen ${ }^{85}$. Tatsächlich hielten sich etwa 20 Türken im Rif auf. Die meisten von ihnen waren im Zuge der »Marokko-Aktion « des Ersten Weltkriegs als Verbündete Deutschlands ins Rifgebirge gekommen und dort geblieben $^{86}$. Der Türke Ahmed beriet das Kriegskabinett Abdelkrims ${ }^{87}$. Ansonsten hatten nur seine Landsleute Khalid ${ }^{88}$, Haldar Bey ${ }^{89}$ und der türkische Leutnant Aziz Ekram als Kontaktmann zum türkischen Roten Halbmond etwas mehr Bedeutung ${ }^{90}$. Im Generalstab der Rifkabylen waren keine Türken vertreten. Die übrigen verrichteten geringere Dienste. Ende 1925 beispielsweise traf der amerikanische Journalist Vincent Sheean auf den Türken Hamid Bey, von dem er berichtete: $» \mathrm{Da}$ ist auch ein türkischer Offizier, eine in sei-

${ }^{82}$ HôPP, Die Schuldigkeit, S. 198, S. 200; DERS., Frontenwechsel. Muslimische Deserteure im Ersten und Zweiten Weltkrieg und in der Zwischenkriegszeit, in: DERS., Brigitte RENWALD (Hg.), Fremdeinsätze. Afrikaner und Asiaten in europäischen Kriegen 1914-1945, Berlin 2000 (Zentrum Moderner Orient, Geisteswissenschaftliche Zentren Berlin e.V., Studien, 13), S. 129-141, S. 133f.

${ }^{83}$ PA-AA R72057: Reichsministerium des Innern an AA, 16.1.1930.

${ }^{84}$ ADMAE Maroc 199, 90: Ambassade de Constantinople an MAE, 17.9.1924; K@RNER, La Guerre du Rif espagnole, S. 151.

${ }^{85}$ PRO-FO 371, 9470, 44, 29: CG Tangier an FO, 2.9.1923; SHAT 3H1557: Région de Fès, SR, Bulletin de renseignements, 2.4.1924; SHAT 3H133: Ambassade de Madrid an MG, EMA, $2^{c}$ bureau, 8.9.1924; SHAT 3H1559: Région de Fès, SR, Bulletin de renseignements, 16.10.1924; ADMAE Maroc 199, 196: Ambassade de Constantinople an MAE, 16.10.1924; ADMAE Maroc 220, 94: Bericht »A/S d'un officier turc chez Abd el Krim«, 15.6.1925; SHAT 3H102: EMA, $2^{e}$ bureau, Bericht "Collaborateurs d'Abd el Krim«, 20.7.1925; AN F7, 13413: Bericht »Au sujet du Maroc«, 13.2.1926.

${ }^{86}$ CADN Tanger B30: MAE an CG Tanger, 27.11.1923.

${ }^{87}$ LÁZARO AVILA, La forja, S. 191.

${ }^{88}$ HART, The Aith Waryaghar, S. 387.

${ }^{89}$ SHAT 3H135: EMA, $2^{\text {e }}$ bureau, SR, Renseignements, 9.5.1927.

${ }^{90}$ ADMAE Maroc 197, 46: Bericht »La République du Rif et Angora«, 21.10.1923; CADN Tanger B30: MAE an CG Tanger, 27.11.1923. 
nem Vaterlande gründlich verrufene Person und keineswegs in irgendeiner Beziehung zu Mustafa Kemal Pascha. Dieser Mann nimmt eine untergeordnete Stellung in Ajdir ein [...]. Er hat keinerlei Beziehung zur türkischen Regierung «" .

Es gab im Rif und in der Rifarmee jedoch auch europäische Deserteure. Über sie fehlt eine gezielte Untersuchung, denn in der bisherigen Forschungsliteratur spielen sie allenfalls eine untergeordnete Rolle. Somit gehören die Deserteure des Rifkrieges ebenso zu den vernachlässigten Kapiteln einer Militärgeschichte der Neuzeit. Auch hier trifft Ulrich Bröcklings und Michael Sikoras Feststellung zu: "Desertion ist ein umstrittenes Thema, doch über die Deserteure schweigen die meisten Geschichtsbücher «" ${ }^{92}$. Veröffentlichte Erinnerungen von Fremdenlegionären - Hubert Lang zufolge »eine neue Literaturgattung ${ }^{93}$ - fanden bisher kaum Berücksichtigung.

Niemand kennt die genaue Anzahl an europäischen Deserteuren, die zu den Rifkabylen überliefen. Zunächst gilt es zu unterscheiden zwischen Deserteuren, die gefangengenommen wurden und Gefangene blieben oder nach Hause geschickt wurden, sowie denjenigen, die auf die eine oder andere Art den Rifkabylen Dienste leisteten oder in die Rifarmee eintraten. Was Letztere anbetrifft, gehen die Schätzungen in der Literatur weit auseinander - von einer Handvoll Überläufern ${ }^{94}$ über einige Dutzend ${ }^{95}$ bis hin zu $200^{96}$. Auch zeitgenössische Beobachter gingen zum Teil von einer geringen Anzahl von europäischen Militärhelfern aus. »Times«-Reporter Walter B. Harris aus Tanger, der nie selbst im Rif war, spielte die Bedeutung der europäischen Deserteure herunter ${ }^{97}$. Andere Journalisten wie der Brite George Ward Price oder die Amerikaner Paul Scott Mowrer und Vincent Sheean bekamen keine oder nur wenige Deserteure zu Gesicht ${ }^{98}$.

${ }^{91}$ SHEEAN, Abd el Krims europäische Helfer, 10.11.1925.

${ }^{92}$ Ulrich BRÖCKLING, Michael SIKORA, Einleitung, in: DIES. (Hg.), Die Armeen und ihre Deserteure. Vernachlässigte Kapitel einer Militärgeschichte der Neuzeit, Göttingen 1998, S. 7-15, S. 7. Vgl. Benjamin ZIEMANN, Fahnenflucht im deutschen Heer 1914-1918, in: Militärgeschichtliche Mitteilungen 55 (1996) S. 93-130, S. 93f.

${ }^{93}$ LANG, Die Darstellung Abd el-Krims, S. 68.

${ }^{94}$ Z.B. WoOlman, Rebels in the Rif, S. 151; HART, The Aith Waryaghar, S. 387; PENNELL, A Country, S. 130f.; MiCHELS, Deutsche in der Fremdenlegion, S. 83; FLEMNG, Primo de Rivera and Abd-el-Krim, S. 224.

${ }^{95}$ Z.B. RIVET, Lyautey, Bd. 3, S. 289f;; OVED, La contribution, S. 96, Anm. 21; DERS., La gauche française, Bd. 1, S. 293-295; John PARKER, Inside the Foreign Legion. The Sensational Story of the World's Toughest Army, London 1998, S. 85; PORCH, Foreign Legion, S. 396; CRÉMADEILLS, Le Parti communiste français, Bd. 1, S. 211.

${ }^{96}$ Nigel ThOMAS, The French Foreign Legion. London 1981, S. 71.

${ }^{97}$ HARRIS, Better Outlook, 7.6.1926; DERS., France, S. 225.

${ }^{98}$ WARD PRICE, Extra-Special Correspondent, S. 172; SHEEAN, Abd el Krims europäische Helfer, 10.11.1925; MOWRER, The House of Europe, S. 479. 
Dies hing damit zusammen, daß Abdelkrim und seinem Bruder Si M'hammed sehr daran gelegen war, deren Anzahl und Bedeutung in einem schwächeren Licht erscheinen zu lassen, um die Berichterstattung vor allem in der französischen Presse zu beruhigen ${ }^{99}$. Errungenschaften wie das Straßennetz oder das Telefonsystem und der Kampf der Rifkabylen um die Unabhängigkeit sollten der Weltöffentlichkeit als eigenständige Leistungen präsentiert werden. In einem Manifest vom 28. Januar 1925 betonte Si M'hammed daher - wider besseren Wissens -, daß kein Fremder in der Rifarmee einen Kommandoposten innehabe ${ }^{100}$. Selbst nach dem Ende des Rifkrieges meinte Abdelkrim noch wahrheitswidrig: "Über die Zahl der Deserteure in meiner Armee hat man übertriebene Gerüchte verbreitet. Es waren in Wirklichkeit kaum fünfzig « ${ }^{101}$. Spanischen wie französischen Militärs kam es ebenfalls darauf an, höhere Desertionszahlen zu kaschieren. Nur 43 europäische Deserteure im Dienste Abdelkrims - sieben Franzosen, 33 meist deutsche Deserteure aus der französischen Fremdenlegion sowie drei Deserteure aus der spanischen Fremdenlegion - zählte etwa ein zusammenfassender Bericht des französischen Generals Daugan vom 19. Juli 1926 auf $^{102}$.

Die Realität sah anders aus. Anhand des Studiums von deutschen, britischen und französischen Quellen sowie der Auswertung von Sekundärliteratur lassen sich allein 68 europäische sowie ein amerikanischer Überläufer aus der spanischen bzw. französischen Protektoratsarmee namentlich identifizieren ${ }^{103}$. Von einigen ist nur ihr arabischer Kampfname bekannt. 28 lassen sich der französischen Fremdenlegion zuordnen, 25 der spanischen Fremdenlegion, acht dem französischen Bataillon d'Afrique (Rest unbekannt). Acht identifizierte Überläufer stammten aus Frankreich, vier aus Spanien, zwei aus Italien, jeweils einer aus Serbien, Ungarn, Finnland, Österreich, den Niederlanden, den USA, der Tschechoslowakei und der Schweiz (Rest unbekannt). Fast zwei Drittel von ihnen (41) waren Deutsche - eine sehr aussagekräftige Zahl, die bestätigt, was Abdelkrim in seinen »Memoiren« berichtete: »Diese Deserteure gehörten den verschiedensten Nationen an, die meisten waren Deutsche aus der Fremdenlegion ${ }^{104}$.

Die Dunkelziffer und damit die wirkliche Zahl der Überläufer war sehr wahrscheinlich höher. Einige Zahlenangaben deuten dies an, wobei zusätzlich berücksichtigt werden muß, daß sie Momentaufnahmen waren. 60 deutsche Überläufer aus der französischen Fremdenlegion zählte ein Informant im Som-

\footnotetext{
${ }^{99}$ Morocco, in: The Round Table 60 (1925) S. 717-731, S. 724; FraUenholz, Der spanische Krieg, S. 109; HARRIS, Better Outlook, 7.6.1926.

${ }^{100}$ WARD PRICE, Extra-Special Correspondent, S. 172; A Riff Manifesto. Aim an Autonomous Moslem State, in: Manchester Guardian, 12.2.1925.

${ }^{101}$ ABDELKRIM, Memoiren, S. 96.

102 OVED, La gauche française, Bd. 1, S. 293f., S. 458, Anm. 56.

${ }^{103}$ Siehe die Liste im Anhang 8.1, S. 365-376.

${ }^{104}$ ABDELKRIM, Memoiren, S. 96.
} 
mer $1922^{105}$. Insbesondere 1924 stieg die Anzahl der übergelaufenen Deserteure wegen der Offensive der Rifkabylen in Richtung Chichaouen und wegen der Vorbereitungen für den Kampf gegen Französisch-Marokko sprunghaft an. Allein 50 deutsche Artilleristen aus beiden Fremdenlegionen waren Anfang 1925 in der Bucht von Alhucemas stationiert ${ }^{106} .79$ Deutsche zählte ein anderer französischer Bericht auf ${ }^{107}$, und selbst das deutsche Konsulat in Tetuan berichtete im August 1925 von 80 Deutschen in Ajdir ${ }^{108}$. El Haj Mohammed Boumghait, ein ehemaliger Angestellter der deutschen Mannesmann-Brüder, gab im Juli 1925 an, daß sich im gesamten Rif 150 Deutsche aufhalten wür$\operatorname{den}^{109}$. Diese Zahl nannte auch Vincent Sheean, aber seinen Informationen zufolge handelte es sich um die Gesamtzahl aller Deutschen für die Jahre 1923 bis $1925^{110}$.

Angesichts des vorliegenden sehr unterschiedlichen Zahlenmaterials ist also nur eine sehr vorsichtige Schätzung möglich. Hiernach dienten Abdelkrim meines Erachtens im Zeitraum von 1921 bis 1926 mindestens 150 europäische Überläufer aus den Protektoratsarmeen, von denen der Großteil aus Deutschland stammte und sich fast die Hälfte identifizieren läßt.

Die Überläufer im Rif waren keine neuartige Erscheinung. In ganz Marokko hatte die französische Fremdenlegion besonders in den Jahren 1920 bis 1921 mit der Problematik Fahnenflucht zu kämpfen. Hundert Legionäre desertierten beispielsweise im Jahr 1920 bei Ouezzane in der Nähe des Rifgebirges, und es gab vor allem im Atlasgebirge Bündnisse zwischen Deserteuren und aufständischen Kabylen. 1924 wurde die französische Fremdenlegion von der Nordgrenze des Protektorats zurückgezogen. Damit sollte auch verhindert werden, daß Legionäre zu Abdelkrim überlaufen konnten. Berichte bezeichneten die Anzahl der Desertionsfalle als schwerwiegend. Dieser Abzug der Fremdenlegion hatte auch unmittelbar mit Abdelkrims anfänglichen militärischen Erfolgen im Zuge des Angriffs auf Französisch-Marokko im Frühjahr 1925 zu $\operatorname{tun}^{111}$. Als die Fremdenlegion wieder vorgezogen wurde, kam es im Juni 1925 gleich wieder zu zahlreichen Desertionen ${ }^{112}$.

${ }^{105}$ ADMAE Maroc 194, 216: CG Tanger an MAE, 8.7.1922 mit Bezug auf einen Bericht des ehemaligen Spanisch-Übersetzers Ahmed Touhami Cherradi.

${ }^{106}$ CADN Maroc DAI 188: Note, 16.1.1925 mit Bezug auf Aussagen des spanischen Deserteurs Enrique Larrea Gonzalez.

${ }^{107}$ ADMAE Maroc 99, 244: Bericht »Renseignements sur Abd el Krim et sur la contrebande d'armes au Maroc«, 2.9.1925.

${ }^{108}$ PA-AA Paris 454a: Konsulat Tetuan an Botschaft Madrid, 14.8.1925.

${ }^{109}$ CADN Tanger C39: Tabor de police $\mathrm{N}^{0} 1$, Note, 24.7.1925 mit Bezug auf eine Aussage von El Haj Mohammed Boumghaït.

${ }^{110}$ SHEEAN, Abd el Krims europäische Helfer, 10.11.1925. Vgl. LANG, Die Darstellung Abd el-Krims, S. 68.

${ }^{111}$ PORCH, Foreign Legion, S. 393-397.

112 James WeLlard, The French Foreign Legion. London 1974, S. 95; ZAEPER, Unter der Glutsonne, S. 24; NEF, Im Kampfe, S. 49. 
Die Grenze zwischen den Protektoratszonen diente als Fluchtziel für Deserteure aus beiden Fremdenlegionen. Die Fahnenflüchtigen aus der französischen Fremdenlegion flohen meist in Richtung Norden zur spanischen Zone, diejenigen aus der spanischen Fremdenlegion zog es in die andere Richtung. Gleich nach dem Ausbruch des Rifkrieges nahmen die Desertionen aus der spanischen Fremdenlegion in Richtung Französisch-Marokko kräftig zu, was Spanien zu einer Protestnote veranlaßte ${ }^{113}$. Dies dauerte an, bis die Regierungen Spaniens und Frankreichs im Sommer 1925 einen gegenseitigen Auslieferungsvertrag für geflohene Legionäre abschlossen ${ }^{114}$.

Gerade für Soldaten der spanischen Fremdenlegion gab es viele Gründe zu desertieren. Sie war eine Todesfalle, in der während der Rifrebellion über ein Drittel aller Mannschaftsdienstgrade getötet oder verwundet wurde ( 7655 von $19923=38,4 \%)^{115}$. Viele Legionäre glaubten, bei der Anwerbung betrogen worden zu sein, da ihnen erklärt worden war, sich für einen "Sicherungsdienst« oder für die spanische Schutzpolizei in Marokko zu verpflichten ${ }^{116}$. Dieses Gefühl verstärkte sich aufgrund willkürlicher Disziplinarmaßnahmen - Stockschläge, Fußtritte, Strafkompanien, Rippenstöße, Erschießungen ${ }^{117}$ zum festen Willen, »diesen jammervollen Verhältnissen ${ }^{118}$ zu entkommen. Im Sommer 1924 habe es Hunderte von Deserteuren gegeben, berichtete Zeitzeuge Richard Sablotny. Nur wenige hätten sich retten können, da ihnen Kopfgeldjäger auf den Fersen gewesen seien ${ }^{119}$. Auf die Ergreifung von Deserteuren wurde eine Prämie ausgesetzt - 500 Peseten für lebende, 1000 Peseten für tote Flüchtlinge ${ }^{120}$. Schlimmste Strafen bis hin zur sofortigen Erschießung drohten ${ }^{121}$.

${ }^{113}$ CADN Madrid C271: MAE an Ambassade de Madrid, 28.9.1921. José Álvarez erwähnt das Thema Desertion in der spanischen Fremdenlegion weder in seiner Dissertation "The Betrothed of Death" von 1995 noch in der Version von 2001.

${ }^{114}$ PA-AA R87858: Botschaft Paris an AA, 19.9.1924; PA-AA R71923: Polizeibehörde Hamburg an AA, 19.12.1924 mit Bezug auf eine Aussage von Hans Raab; Fritz KLOSE, Marschier oder krepier! Leiden und Laster der Legion, Berlin 1932, S. 146; SABLOTNY, Légionnaire, S. 221, S. 232; MEYER, Dreitausend Kilometer, S. 59f., S. 62, S. 110; SEHRING, Auf den Schlachtfeldern, S. 31.

115 ÁlVAREZ, The Betrothed of Death 2001, S. 236.

${ }^{116}$ HUBER, Als Fremdenlegionär, S. 18; MEYER, Dreitausend Kilometer, S. 5, S. 13f.

${ }^{117}$ PRO-FO 371, 7066, 184, 166: Consul of Tetuan an CG Tangier, 12.1.1921; HUBER, Als Fremdenlegionär, S. 24, S. 26; DEGENKOLBE, Vom Schusterjungen, S. 26f.; MEYER, Dreitausend Kilometer, S. 19f., S. 24f., S. 28f.; SABLOTNY, Légionnaire, S. 34-42, S. 63f., S. 68f., S. 90, S. 96f., S. 102, S. 167-170, S. 215.

${ }^{118}$ MEYER, Dreitausend Kilometer, S. 5.

${ }^{119}$ SABLOTNY, Légionnaire, S. 219.

${ }^{120}$ PRO-FO 371, 7067, 184, 240: Consul of Tetuan an CG Tangier, 4.7.1921; HuBER, Als Fremdenlegionär, S. 27; SABLOTNY, Légionnaire, S. 72-74, S. 90, S. 95. Auch in der französischen Fremdenlegion gab es für jeden tot oder lebendig zurückgebrachten Deserteur 50 Francs Prämie [ZAEPER, Unter der Glutsonne, S. 24].

${ }^{121}$ HUBER, Als Fremdenlegionär, S. 27; SEHRING, Auf den Schlachtfeldern, S. 31. 
Nicht jeder Deserteur wurde im Rif willkommen geheißen. Deutsche jedoch hatten wesentlich weniger zu befürchten. Dem Schweizer Albert Huber (spanische Fremdenlegion) riet ein Mitverschwörer 1921, sich im Rif als Deutscher zu erkennen zu geben. Auf diese Weise werde ihm nichts geschehen ${ }^{122}$. Die Passion Abdelkrims für Deutsche rührte noch von Weltkriegstagen her, als er zusammen mit seinem Vater die Partei Deutschlands ergriffen hatte ${ }^{123}$. An den Wänden seines Hauptquartiers sollen Bilder von Kaiser Wilhelm II., Kaiser Franz Joseph I. und einiger deutscher Heeresführer gehangen haben ${ }^{124}$. Auch andere Deserteure berichteten von Abdelkrims bevorzugter Behandlung der Deutschen ${ }^{125}$.

Die Rifarmee benötigte Fachleute. Es lag nahe, unter den Legionen Propaganda für Abdelkrims Sache zu betreiben und insbesondere deutsche Deserteure abzuwerben, wie es Albert Bartels alias »Si Hermann« schon während des Ersten Weltkrieges für die deutsche »Marokko-Aktion« versucht hatte. Möglicherweise wollte Abdelkrim diese Deutschen für seinen lange vorher geplanten Angriff gegen den Erzfeind Französisch-Marokko instrumentalisieren. 1924 begannen regelrechte Rekrutierungsbestrebungen zunächst in der spanischen Fremdenlegion.

Als mehr und mehr Deserteure im Rif eintrafen, ließ Abdelkrim bevorzugt bei Deutschen Befragungen durchführen. Dabei ließ er ihnen in der Regel die Wahl zwischen der Rifarmee oder dem Aufenthalt in einem Gefangenenlager, bis eine Rückkehrpassage nach Tanger möglich war ${ }^{126}$. Dem deutschen Deserteur Wilhelm Sommer von der spanischen Fremdenlegion teilte Abdelkrim mit, daß es verstärkte Anstrengungen gebe, kompetente Ausländer zu finden, die den Rifkabylen die Handhabung moderner Waffen beibringen sollten ${ }^{127}$. Wer den Rifkabylen zusätzlich Gewehre übergab, wurde wesentlich vertrau-

${ }^{122}$ HUBER, Als Fremdenlegionär, S. 34.

${ }^{123}$ Siehe hierzu Kapitel 2, S. 33-36.

${ }^{124}$ DEGENKOLBE, Erlebnisse, 7.3.1926; SEHRING, Auf den Schlachtfeldern, S. 58.

${ }^{125}$ PA-AA R70844: Preußisches Innenministerium an AA, 6.2.1928 mit Bezug auf eine Vernehmung von Johann Kummer, 4.1.1928; PA-AA R71927: Preußisches Innenministerium an AA, 27.2.1926 mit Bezug auf Aussagen von Alois Fleischer, 19.12.1925; CADN Maroc DAI 192: EMA, $2^{e}$ bureau an RG Rabat, 19.1.1925 mit dem auf der Befragung deutscher Deserteure basierenden Bericht »Légion étrangère espagnole au Maroc«.

${ }^{126} \mathrm{Vgl}$. etwa die Befragung von Martin Reinhold durch Abdelkrim im Frühjahr 1924 [SHAT 3H1154: $2^{e}$ bureau, Aknoul, Bericht »Procès-verbal d'interrogatoire de l'ex-légionnaire Martin Reinhold surnommé Ali«, 24.10.1925], die Beobachtungen Heinrich Biesters [PAAA R71922: Hamburger Senatskommission für die Reichs- und Auswärtigen Angelegenheiten an AA, 4.12.1924], die Aussagen von Hugo Oswald und Heinrich Halwald [CADN Maroc DAI 192: Berichte "Déclaration du déserteur espagnol Hugo Oswald«, 18.5.1925, und "Déclaration du déserteur Heinrich Halwald«, 18.5.1925] oder die Aussagen Walter vom Scheidts [PA-AA R70840: Preußisches Innenministerium an AA, 14.2.1927].

${ }^{127}$ SHAT 3H102: Bericht „Extrait de l'interrogatoire d'un déserteur de nationalité allemande de la Légion étrangère espagnole«, 19.2.1925. 
ensvoller behandelt ${ }^{128}$. Im Juni 1924 ließ Abdelkrim 22 Deserteure aus der französischen Fremdenlegion befragen. Nur Walter vom Scheidt und Jakob Sauer liefen zur Rifarmee über. Die übrigen wurden nach Tanger gebracht, wo sie allerdings von den dortigen Sicherheitsbehörden aufgegriffen und verhaftet wurden ${ }^{129}$.

Im Mai und Juni 1924 nahmen die Rifkabylen Kontakt zu deutschen Legionären auf, die in Ben Tieb, dem östlichen Hauptquartier der spanischen Fremdenlegion, stationiert waren ${ }^{130}$. Unter den Deutschen rumorte es seit langem. Die Unzufriedenheit über die Verhältnisse war groß. Plötzlich kam das Gerücht auf, daß alle Deutschen am 17. Juni 1924 entlassen werden sollten, was diese mit Jubel begrüßten. Doch am Stichtag passierte nichts. Augenzeuge Franz Sehring berichtete: »Man kann sich nun wohl die große Niedergeschlagenheit und Wut bei uns Deutschen vorstellen. Immer und immer wieder hoffen, und nie wurde die Befreiung Tatsache ${ }^{131}$.

Der Plan der Aufrührer sah vor, daß Deutsche in der Nacht vom 23. zum 24. Juni 1924 einen Strohhaufen im Lager anzünden, drei Schüsse als Zeichen für die umliegenden Rifkabylen abgeben und sich in der daraus folgenden Verwirrung des Munitionslagers bemächtigen sollten. Zusammen mit eindringenden Riftruppen sollte dann die spanische Besatzung überwältigt werden, um mit Hilfe der erbeuteten Artillerie von Ben Tieb aus benachbarte Posten zu erobern. Doch aus dem »Komplott von Ben Tieb» wurde nichts. Kurz vor der Ausführung wurde der Plan von einem Deutschen verraten. Es erfolgten 38 bis 40 Verhaftungen. Drei angebliche, in Wahrheit völlig unbeteiligte >Rädelsführer - die Deutschen Pohlmann, Otto Hilger und Bornemann - wurden noch am 24. Juni 1924 erschossen. Vier weitere - Herbert von Kassel, Franz Masthoff, Georg Demmel und Adolf Achtermann - wurden nach Malaga gebracht und $\mathrm{zu} 20$ Jahren Zuchthaus verurteilt ${ }^{132}$, am 28 . Januar 1927 jedoch vom

${ }^{128}$ SABLOTNY, Légionnaire, S. 267.

${ }^{129}$ PA-AA R70840: Preußisches Innenministerium an AA, 14.2.1927 mit Bezug auf Aussagen von Walter vom Scheidt.

${ }^{130} \mathrm{Zu}$ den Zuständen im Lager Ben Tieb: SABLOTNY, Légionnaire, S. 84-87.

${ }^{131}$ SEHRING, Auf den Schlachtfeldern, S. 36f.

132 SABLOTNY, Légionnaire, S. 173-180, S. 183-190; Der Mord an den deutschen Erwerbslosen in der spanischen Fremdenlegion, in: Hamburger Volkszeitung, 25.8.1924; Primo de Rivera erschießt deutsche Legionäre, in: Rote Fahne, 9.9.1924; Deutsches Kanonenfutter in Marokko, in: Berliner Zeitung, 8.9.1924; PA-AA R72043, L057566: Konsulat Tetuan an Botschaft Madrid, 22.7.1924; PA-AA R71923: Konsulat Tetuan an Botschaft Madrid, 25.11.1924; PA-AA R71922: Konsulat Malaga an Botschaft Madrid, 14.10.1924; CADN Madrid C275: Ambassade de Madrid an MAE, 7.7.1924 mit dem Bericht »Le nouveau problème méditerranéen et ses dangers pour la Frances. 
Kriegsgericht Melilla wieder freigesprochen ${ }^{133}$. Noch im März 1925 erkundigte sich Abdelkrim beim Deserteur Kurt Degenkolbe nach den deutschen Gefangenen von Ben Tieb, die er befreien wollte ${ }^{134}$.

Seit dem Frühjahr 1925 wurde die Desertionspropaganda der Rifkabylen im Zuge der Offensive gegen die französische Marokkozone auch innerhalb der französischen Fremdenlegion verstärkt. Zwei Deutsche, Josef Klems alias Caïd el Haj alemán und Leonhard Gehbauer, tippten zusammen mit Kurt Degenkolbe auf der einzigen Schreibmaschine des Rifs Flugblätter in deutscher Sprache, die an den Frontlinien verteilt wurden ${ }^{135}$. Gehbauer stellte den deutschen Landsleuten die Freiheit in Aussicht und fragte, warum sie noch für Frankreich kämpften, wenn sie doch im Rif mit Freuden empfangen würden. Dort sei das Wort »allemand" ein Wort der Freiheit. Allen Deserteuren werde freigestellt, im Rif zu bleiben oder über Tanger nach Deutschland zurückzukehren. Verbunden war der Appell mit der Aufforderung, Waffen und Munition mitzubringen ${ }^{136}$. Auf ähnliche Weise appellierte Klems an seine Landsleute: "Wollt ihr wirklich den verhaßten Franzosen als Kanonenfutter dienen, wo sich hier eine rettende Hand bietet? [...] Werft den französischen Zwang von euch ${ }^{137}$. Der Erfolg war eher mäßig. Im Mai 1925 desertierten gerade 50 Legionäre ${ }^{138}$. Josef Klems zufolge liefen insgesamt nur 100 Deserteure mit ihren Waffen und ihrer Munition über - weitaus weniger, als Abdelkrim erwartet hatte ${ }^{139}$.

Die von den Rifkabylen und ihren Sympathisanten in Tanger organisierte Rückkehrmöglichkeit von Deserteuren in ihre Heimat wirkte für viele Fremdenlegionäre verlockend, wenn auch Abdelkrims Ziel einer Ausdünnung der gegnerischen Streitkräfte nie erreicht wurde. Die Grenze zur internationalen

${ }^{133}$ PA-AA R71923: Botschaft Madrid an AA, 18.2.1927.

${ }^{134}$ DEGENKOLBE, Vom Schusterjungen, S. 76.

${ }^{135}$ SHAT 12J3797, 28: Vernehmung von Josef Klems vor dem 2. Kriegsgericht Meknes, 19.6.1926; ADMAE Maroc 220, 66: EMA, $2^{e}$ bureau, Bericht "Propagande allemande au Maroc«, 20.5.1925; ADMAE Maroc 129, 13: RG Rabat an MAE, 19.6.1925; SHAT 12J3797: Bericht »Rapport sur l'affaire du caporal Klems Josef«, 23.12.1926; Roy BAKER, Penal Battalion, London 1934, S. 31; Ex-Légionnaire, Hell Hounds, S. 36; PORCH, Foreign Legion, S. 396. Eckhard Michels geht in seiner Arbeit über "Deutsche in der Fremdenlegion « $\left({ }^{3} 2000\right)$ auf dieses Thema nicht ein.

${ }^{136}$ Deux des tracts germano-soviétiques jetés par les Riffains dans nos lignes, in: Éclair, 14.6.1925.

${ }^{137}$ SHAT 12J3797: (Grammatikalisch verbesserter, DS) Desertionsaufruf von Josef Klems o.D. [ca. Juni 1925]. Vgl. Rafael LOPEZ RIENDA, Abd-el-Krim contra Francia. Impresiones de un cronista de guerra, Madrid 1925, S. 59.

138 ADMAE Maroc 220, 66: EMA, $2^{\circ}$ bureau, Bericht "Propagande allemande au Maroc«, 20.5.1925.

${ }^{139}$ SHAT 12J3797, 28: Vernehmung von Josef Klems vor dem 2. Kriegsgericht Meknes, 19.6.1926. Der amerikanische Journalist Vincent Sheean meinte, Klems sei »für die meisten Desertionen aus der französischen und spanischen Fremdenlegion « verantwortlich gewesen [SHEEAN, Abd el Krims europäische Helfer, 10.11.1925]. 
Zone von Tanger war $\mathrm{zu}$ dieser Zeit aufgrund der mangelnden Bewachung durch Spaniens Armee noch mehr als durchlässig. Der amerikanische Journalist Vincent Sheean konnte im Januar 1925 selbst miterleben, wie eine Karawane der Rifkabylen von 400 Männern und Frauen unbemerkt durch die spanischen Linien schlüpfte ${ }^{140}$. Der erste Konvoi mit Deserteuren und Überläufern, die Abdelkrim entlassen hatte, wurde im Oktober 1924 in Richtung Tanger geschickt. 25 ehemalige Soldaten der spanischen Fremdenlegion erreichten am 23. Oktober 1924 die Tanger-Zone ${ }^{141}$. Es handelte sich um Spanier, Italiener und Ungarn sowie fünf Franzosen, den Holländer Henrik Scarurek, einen Norweger und zwölf deutsche Deserteure, die dem niederländischen Konsul von Tanger übergeben werden sollten ${ }^{142}$.

Unter den Deutschen befanden sich unter anderem Richard Sablotny, Hans Somm, Hans Ebeling und Walter Hensel ${ }^{143}$. Nur drei Deutsche - Hans Stappers, Heinrich Schröer und Peter Wolfekam - erreichten das niederländische Konsulat $^{144}$. Da Deutschland aufgrund des Versailler Vertrages keinen eigenen Vertreter in Tanger haben durfte, hatte das Auswärtige Amt mit den Niederlanden vereinbart, daß deren Konsul die deutschen Interessen wahrnehmen sollte $^{145}$. Deutsche Deserteure, die Abdelkrim nach Tanger schickte, gaben sich des öfteren als holländische Staatsbürger aus, um zum Generalkonsul der Niederlande vorgelassen zu werden ${ }^{146}$. Walter Meyer, ein Deserteur aus der spanischen Fremdenlegion, berichtete in seinen Erinnerungen, daß die Ehefrau des Generalkonsuls ihn mit dem Auto bis kurz vor Tetuan gefahren habe, damit er von dort aus mit einer neuen Identität als Holländer Frederik Steenbergh per Schiffsverbindung nach Malaga gelangen konnte ${ }^{147}$. Einige ausländische Konsuln schützten die in Tanger ankommenden Deserteure heimlich und schickten sie zu deutschen, niederländischen oder belgischen Häfen ${ }^{148}$.

Andere - wie Heinrich Biester, Alfred Knüppel, Hans Ebeling, Otto Alt oder Richard Sablotny - wurden im Oktober 1924 von Tangerer Sicherheitsbehörden verhört und anschließend mit dem französischen Dampfer "Abda«

${ }^{140}$ Vincent SHEEAN, Dashes Through Spanish Lines, in: Chicago Tribune, 15.2.1925.

${ }^{141}$ Some of Abdel Krim's Prisoners Arrive in Tangier, in: Al-Moghreb al Aksa \& Tangier Gazette, 25.10.1924; CADN Madrid C275: MAE an Ambassade de Madrid, 24.11.1924; SHEEAN, »Robin Hood«, S. 979; DERS., An American, S. $252 \mathrm{f}$.

142 PA-AA R71922: Aufzeichnung, 30.10.1924; CADN Madrid C275: MAE an Ambassade de Madrid, 21.11.1924 mit Bezug auf einen Bericht der Tabor de police $\mathrm{N}^{\circ} 1$ Tanger, 28.10.1924.

${ }^{143}$ SABLOTNY, Légionnaire, S. 276-309.

${ }^{144}$ PA-AA R71922: Niederländische Gesandtschaft Berlin an AA, 22.11.1924.

${ }^{145}$ PA-AA R71127: AA an Generalkonsulat Zürich, 31.1.1925.

${ }^{146}$ CADN Tanger C37: Tabor de police $\mathrm{N}^{\circ} 1$, Bericht $»$ Note sur les agissements du consulat général des Pays-Bas de Tanger «, 2.12.1925.

${ }_{147}$ MEYER, Dreitausend Kilometer, S. 139f., S. 147-149, S. 156f.

${ }^{148}$ SHEEAN, Abd el Krims europäische Helfer, 10.11.1925. 
nach Marseille verschifft ${ }^{149}$. Eine Gruppe von 20 deutschen Deserteuren aus der französischen Fremdenlegion fiel etwa im gleichen Zeitraum der Tangerer "Tabor de police $\mathrm{N}^{\circ} 1 \ll$ in die Hände ${ }^{150}$.

Von Abdelkrim rentlassener Deserteure bekamen etwas Geld und einen Passierschein in arabischer Sprache ausgehändigt ${ }^{151}$. Kurt Degenkolbe alias Caïd Abdullah erhielt im Frühjahr 1925 von Abdelkrim und Außenminister Azerkane die Berechtigung, jederzeit die Gefangenenlager zu betreten und jeden nichtspanischen bzw. nichtfranzösischen Gefangenen in die Heimat zu entlas$\operatorname{sen}^{152}$. Deserteure der spanischen Fremdenlegion wurden außerdem mit einem Passierschein Abdelkrims in Richtung Französisch-Marokko geschickt. Noch im Mai 1925 fing die französische Armee zwölf Deutsche $a b^{153}$.

Dann jedoch war der Weg wegen des Angriffs der Rifkabylen auf die französische Zone Marokkos versperrt, und auch der Schleichweg nach Tanger wurde von den Spaniern entdeckt. Die Deserteure saßen im Rif fest und mußten zwischen Frontdienst oder längerer Gefangenschaft wählen. Erst Anfang Juli 1925 wurde bei Regaïa eine neue Passage nach Tanger gefunden. Kurt Degenkolbe schickte Ende Juni 1925 noch fünf deutsche (Paul Hohenwald, Karl Millfahrt, Max Varras, Robert Schadach und Albert Müller) und den italienischen Deserteur Carlos Cuarenti aus der spanischen Fremdenlegion sowie etwas später auch Anton Gangkors und einige andere Deutsche - darunter Walter Meyer - nach Tanger. Paul Hohenwald und Walter Meyer schafften die Rückkehr nach Deutschland, während die meisten anderen in Tanger verhaftet wurden. Kurze Zeit darauf machte sich Degenkolbe selbst zusammen mit Hellmuth Greve über Chichaouen auf den Weg. Unterwegs schlossen sich ihm noch einige aus der spanischen Fremdenlegion desertierte Portugiesen

${ }^{149}$ SABLOTNY, Légionnaire, S. 304-309; PA-AA R71922: Hamburger Senatskommission für die Reichs- und Auswärtigen Angelegenheiten an AA, 4.12.1924 mit Bezug auf eine Vernehmung von Heinrich Biester.

${ }^{150}$ PA-AA R70840: Preußisches Innenministerium an AA, 14.2.1927 mit Bezug auf Aussagen von Walter vom Scheidt.

${ }^{151}$ CADN Maroc DAI 192: Bericht «Déclaration du déserteur espagnol Hugo Oswald«,

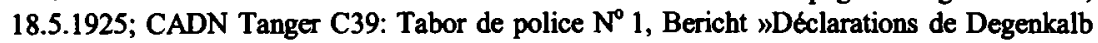
Kurt, déserteur de la légion espagnole au Maroc«, 15.7.1925; PA-AA R71927: Regierungspräsident Düsseldorf an AA, 29.12.1925 mit Bezug auf Aussagen von Alois Fleischer; MEYER, Dreitausend Kilometer, S. 106, S. 118, S. 130; DEGENKOLBE, Vom Schusterjungen, S. 79; Charles MERCER, Legion of Strangers. The Vivid History of an Unique Military Tradition - The Foreign Legion, London u.a. 1964, S. 238.

is2 DeGENKolbE, Vom Schusterjungen, S. 95f. Diese Angaben wurden von Hellmuth Greve in einem Brief an seinen in Hamburg lebenden Vater bestätigt [PA-AA R71925: Konsulat Tetuan an Botschaft Madrid, 29.6.1925].

${ }^{153}$ CADN Maroc DAI 188: Territoire de Taza, Cercle de Guercif, SR, Bericht »Déclarations du nommé Valfredi Giovanni«, 14.1.1925; CADN Maroc DAI 192: Berichte »Déclaration du deserteur espagnol Hugo Oswald«, 18.5.1925, "Déclaration du déserteur Heinrich Halwald«, 18.5.1925. 
$a^{154}$. Deutsche Deserteure aus der französischen Fremdenlegion wurden auBerdem nach Tetuan zum dortigen deutschen Konsulat geschickt. Von August bis Anfang Oktober 1925 waren es insgesamt 30 Mann $^{155}$.

Anfang Oktober 1925 entschloß sich Abdelkrim, alle deutschen, italienischen, englischen und amerikanischen Kriegsgefangenen in die Freiheit zu entlassen, darunter etliche Deserteure. Als Faustpfand gegen Frankreich und Spanien behielt er lediglich französische und spanische Soldaten in Gefangenschaft ${ }^{156}$. Ein französischer Bericht unterstellte Abdelkrim den Versuch, das Wohlwollen von den Herkunftsländern der freigelassenen Gefangenen zu erlangen ${ }^{157}$. Wahrscheinlicher ist jedoch, daß er sie loswerden wollte. Der nächste Winter stand bevor, und die spanischen und französischen Blockademaßnahmen hatten den Nachschub an Lebensmitteln unterbunden. Überflüssige Esser mußten verschwinden. Abdelkrims Vertrauen in die Zuverlässigkeit der Überläufer, die in seiner Rifarmee gekämpft hatten, war mittlerweile wegen der gelungenen Landungsaktion der spanischen Armee in der Bucht von Alhucemas gesunken. Wer von ihnen gehen wollte, erhielt einen Passierschein nach Tanger ${ }^{158}$. Über 100 Mann machten sich in kleinen Gruppen auf den Weg nach Tanger, wo sie fast ausnahmslos festgenommen wurden ${ }^{159}$.

Insgesamt entkamen nur wenige dem Netz der Sicherheitsdienste in Tan$\operatorname{ger}^{160}$. Dies betraf auch eine Reihe von Deutschen, die auf eine Heimkehr über Tanger hofften. Um den 16. Oktober 1925 wurde Walter Toussier, ein Deserteur aus der spanischen Fremdenlegion, verhaftet ${ }^{161}$. In der Nacht vom

${ }^{154}$ MEYER, Dreitausend Kilometer, S. 120-122, S. 124-127, S. 134f.; DEGENKOLBE, Vom Schusterjungen, S. 98-100, S. 110, S. 114f.; CADN Tanger C39: Tabor de police $\mathrm{N}^{\circ} 1$, Bericht »Déclarations de Degenkalb Kurt«, 15.7.1925; CADN Tanger C39: Tabor de police $\mathrm{N}^{\circ}$ 1, Note, 1.7.1925 und 15.7.1925; CADN Maroc DAI 192: Tabor de police $\mathrm{N}^{\circ} 1$ Tanger an DAI Rabat, 11.7.1925.

${ }^{155}$ PA-AA Madrid 136: Konsulat Tetuan an Botschaft Madrid, 4.10.1925; CADN Tanger C39: Consulat de Tétouan, Note, 21.9.1925; CADN Tanger C39: Tabor de police $\mathrm{N}^{\circ} 1$, Note, 7.8.1925.

${ }^{156}$ CADN Tanger C38: Tabor de police $\mathrm{N}^{\circ} 1$, Bulletin de renseignements, 23.10.1925; CADN Maroc DAI 192: Tabor de police $\mathrm{N}^{\circ} 1$ Tanger an DAI Rabat, 2.11.1925 mit Bezug auf eine Befragung von Fritz Weinard, 30.10.1925.

${ }^{157}$ CADN Tanger C37: Bericht »Renseignements sur le Riff", 8.12.1925.

${ }^{158}$ PA-AA R71927: Regierungspräsident Düsseldorf an AA, 29.12.1925 mit Bezug auf eine Aussage von Alois Fleischer, 19.12.1925; MEYER, Dreitausend Kilometer, S. 130.

${ }^{159}$ CADN Maroc DAI 192: Tabor de police $\mathrm{N}^{\circ} 1$ Tanger an DAI Rabat, 2.11.1925 mit Bezug auf ein Verhör von Karl Naumann, 30.10.1925; SHAT 3H442: Bericht »Interrogatoires sommaires de 2 caporaux et 1 tirailleur [...] qui se sont présentes au port de Souk es Sebt le 17 novembre matin«, 18.11.1925; ADMAE Maroc 138, 61: Bericht "Déclaration du Caporal Kiffani Abd el Kader«, 11.6.1926; CADN Maroc DAI 192: Tabor de police $\mathrm{N}^{\circ} 1$ Tanger an DAI Rabat, 2.11.1925 mit Bezug auf eine Befragung von Fritz Weinard, 30.10.1925; TERRIER, Les »Frères de la côte« 1925, S. 549.

${ }_{160}$ MERCER, Legion, S. 239; SHEEAN, Abd el Krims europäische Helfer, 10.11.1925.

${ }^{161}$ CADN Maroc DAI 192: Tabor de police $N^{\circ}$, Bericht "Interrogatoire d'un déserteur de la légion étrangère espagnole, de nationalité allemande«, 16.10.1925. 
22. zum 23. Oktober 1925 versuchten Jakob Gumpler, Leonhard Gehbauer und Georg Streit, den amerikanischen Konsul Blake zu überreden, sie in die Heimat nach Deutschland bringen zu lassen. Doch Blake übergab die drei der französischen Polizei. Am 23. Oktober 1925 wurden der Franzose Louis Bourhis, der Abdelkrim auf vielfältige Weise gedient hatte, der Amerikaner Wesley Williams und der Deutsche Peter »Kruschtn festgenommen $^{162}$. Wenige Tage später ereilte die wie Rifkabylen gekleideten Karl Naumann, Walter Hending und Fritz Weinard das gleiche Schicksal ${ }^{163}$. Heinrich Hoffmann, Alois Fleischer, Joseph Reuter und Jakob Putz sowie die Portugiesen Manuel Armindo und Augusto Antonio wurden im November 1925 verhaftet $^{164}$.

1926 gelang nur noch wenigen Deserteuren die Flucht in die Heimat. Gegen Ende des Rifkrieges teilte Abdelkrim keine Passierscheine mehr aus. Wer in der Hoffnung zu den Rifkabylen desertierte, eine Passage nach Tanger zu erhalten, der endete im Gefangenenlager und wurde im Mai 1926 an die Sieger ausgeliefert ${ }^{165}$. Willy Blum, Karl Scholl und Erich Schmitt, die über Melilla nach Deutschland heimkehren wollten, desertierten am 1. Mai 1926 im Sektor Taza. Sie fanden sich genauso im Gefangenenlager wieder wie etwa Alfred Heintz, Wilhelm »Uftreing«, Karl Müller, Walter Ebert, Karl Lemmel, Hans Kempken oder Gottlieb Deuble. Sie waren allesamt aus der französischen Fremdenlegion desertiert und wurden nach ihrer Übergabe an das französische Militär Ende 1926 zu mehrmonatigen Gefängnisstrafen verurteilt ${ }^{166}$.

Wenn Abdelkrim in den letzten Kriegstagen im Mai 1926 für einen Deserteur keine Verwendung mehr hatte, ließ er ihn, auch wenn er sich schon längere Zeit im Rif aufgehalten und für ihn gekämpft hatte, in ein Gefangenenlager bringen ${ }^{167}$. Unter den Kriegsgefangenen, die Abdelkrim an Spanien übergab, befanden sich keine Deutschen mehr. Sie waren im Kampf getötet worden, durch Krankheit gestorben oder nach Tanger bzw. nach Französisch-Marokko geflüchtet ${ }^{168}$. Die meisten Deserteure, die Abdelkrim gedient hatten, waren zum Kriegsende hin in alle Richtungen verstreut ${ }^{169}$.

${ }^{162}$ CADN Tanger C38: Tabor de police $\mathrm{N}^{\circ}$ 1, Note, 23.10.1925 und 24.10.1925.

${ }^{163}$ CADN Maroc DAI 192: Tabor de police $\mathrm{N}^{\circ} 1$ Tanger an DAI Rabat, 2.11.1925; CADN Tanger C39: Tabor de police $N^{\circ} 1$, Note, 31.10.1925.

${ }^{164}$ PA-AA R71927: Regierungspräsident Düsseldorf an AA, 29.12.1925 mit Bezug auf eine Aussage von Alois Fleischer und Heinrich Hoffmann, 19.12.1925; CADN Tanger C39: Tabor de police $\mathrm{N}^{0} 1$, Bericht »Déserteurs venant du Riff«, 22.11.1925.

${ }^{165}$ CADN Tanger C40: Tabor de police $\mathrm{N}^{\circ} 1$ Tanger an S.E. le mendoub de S.M. chérifienne Tanger, 25.3.1926; PA-AA R71927: Preußisches Imnenministerium an AA, 6.7.1926.

${ }_{166}$ PA-AA R70857: Antoine Paoli an Botschaft Paris, 1.7.1926 und 9.12.1926, Botschaft Paris an AA, 3.6.1926, 15.11.1926 und 16.11.1926.

${ }^{167}$ PARENT, Au Riff, S. $580 f$.

${ }^{168}$ PA-AA R71927: Botschaft Madrid an AA, 9.7.1926.

${ }^{169}$ Auguste Terrier, Les »Frères de la côte« du Rif, in: BCAF 37 (1927) S. 46f.; SHAT 12J3797: Chef de bureau du cercle de Taza-Nord an Colonel commandant le cercle de TazaNord, 24.7.1926; PRO-FO 371, 11909, 5, 214: Embassy of Madrid an FO, 2.6.1926. 
Johann Kummer, ein Deserteur aus der französischen Fremdenlegion, hatte das Pech, bei seiner Flucht von spanischen Truppen aufgegriffen zu werden. Sie stellten ihn vor die Wahl, entweder an die Franzosen ausgeliefert zu werden oder in die spanische Fremdenlegion einzutreten. Bis ihm die Flucht nach Deutschland gelang, kämpfte Kummer nun auf spanischer Seite gegen die letzten aufständischen Rifkabylen ${ }^{170}$. Walter vom Scheidts Flucht in Richtung Mittelmeerküste endete im Militärgefängnis von Tetuan. Erst als das dortige deutsche Konsulat intervenierte, durfte vom Scheidt im November 1926 nach Deutschland zurückkehren ${ }^{171}$. Da die Kämpfe in Spanisch-Marokko bis 1927 andauerten, blieb die Problematik von Desertionen weiter bestehen. Heimlich schaffte die deutsche Botschaft in Madrid deutsche Deserteure aus der spanischen Fremdenlegion zurück in die Heimat. Im Dezember 1926 meldete sie nach Berlin, daß das Wort »Deserteur« nun durch »Praktikant» ersetzt werde, um diese Maßnahme gegenüber den spanischen Behörden zu verschleiern ${ }^{172}$.

Die meisten europäischen Überläufer wollten den Fremdenlegionen oder Protektoratsarmeen entfliehen, um einen Weg zurück in die Heimat zu finden. Diesen Weg zeigte ihnen Abdelkrim durch seine Desertions-Flugblätter, die eine Heimführung über Tanger propagierten. Was aber motivierte Deserteure, sich Abdelkrims Rifarmee anzuschließen oder ihm auf andere Weise behilflich zu sein? Einige wie der Schweizer Albert Huber und sein deutscher Kamerad Wilhelm fühlten sich unter Druck gesetzt und gaben seiner Offerte nach: $» \mathrm{Da}$ wir wohl merkten, daß, so freundlich das Anerbieten gemacht wurde, es doch wie ein Befehl aufgefaßt werden mußte, erklärten wir uns sofort einverstanden ${ }^{173}$.

Vereinzelt mag es unter Legionären Gedanken der Sympathie für den Freiheitskampf der Rifkabylen gegeben haben, wie etwa beim Schweizer Werner Nef, der dann doch nicht wagte zu desertieren ${ }^{174}$. Franz Sehring sinnierte in seinen Erinnerungen: "Die Rifkabylen [...] haben aber ein Anrecht auf das Land, denn weit über ein Jahrhundert wohnen sie schon dort « ${ }^{175}$. Derartige Äußerungen dienten in der Regel nur als Kontrast gegen die Hervorhebung der Grausamkeit der spanischen Eroberer ${ }^{176}$. Die wenigsten wollten gezielt zu den

${ }^{170}$ PA-AA R70844: Preußisches Innenministerium an AA, 6.2.1928 mit Bezug auf eine Vernehmung von Johann Kummer, 4.1.1928.

${ }^{171}$ PA-AA R70840: Preußisches Innenministerium an AA, 14.2.1927 mit Bezug auf Aussagen von Walter vom Scheidt.

17 PA-AA R71928: Botschaft Madrid an AA, 27.12.1926.

${ }^{173}$ HUBER, Als Fremdenlegionär, S. 45.

${ }^{174}$ NEF, Im Kampfe, S. 48f.

${ }^{175}$ SEHRING, Auf den Schlachtfeldern, S. 4.

${ }^{176}$ FAATH, Das Bild Marokkos, S. 87. 
Rifkabylen überlaufen wie der Deutsche Ernst Löhndorff aus der französischen Fremdenlegion: »Wir haben schon viel von [...] Abd-el-Krim gehört, er soll Europäer um sich haben; vielleicht kann er uns gebrauchen « ${ }^{177}$. Andere wollten den zum Teil unerträglichen Zuständen in den Gefangenenlagern des Rifs entfliehen und boten ihre Dienste an ${ }^{178}$.

Abdelkrim wollte insbesondere deutsche Deserteure in seine Rifarmee integrieren. Sie wurden daher unter den Gefangenen beider Legionen gezielt herausgesucht. 1925 ließ Abdelkrim das Gerücht streuen, daß Deutschland und die Türkei Frankreich den Krieg erklärt hätten und dem Rif beistehen würden. Er versuchte, deutsche Fremdenlegionäre mit diesen Hinweisen zum Kampf gegen den alten Erzfeind aufzustacheln ${ }^{179}$. Abdelkrim stellte seinen Kämpfern Überläufer als Vorhut der Deutschen vor ${ }^{180}$. Ihre Anwesenheit diente im Rif also auch dazu, den Rifkabylen Mut zu machen. Sie sollten glauben, daß sie nicht alleine stünden. Mehrere Male präsentierte Abdelkrim seinen Truppen Deserteure als technische Berater ${ }^{181}$. Jeder gefangene deutsche Deserteur, der in Verhören nützliche Talente erwähnte, wurde gefragt, ob er in die Rifarmee eintreten wolle. Auf diese Weise kam Abdelkrim, wie Vincent Sheean beobachtete, "zu seinen besten Artilleristen und zu seinen besten Technikern ${ }^{182}$.

Viele Deutsche fühlten sich geschmeichelt, wenn Abdelkrim sich freute, »daß die Sammelstelle aller Deutschen bei ihm wäre ${ }^{183}$. Alois Fleischer, ein Deserteur aus der spanischen Fremdenlegion, berichtete, daß Abdelkrim sein Bedauern über die zahlreichen gefallenen deutschen Legionäre ausgedrückt habe. Er habe stets seine Liebe für das Deutsche betont, und seine Anhänger seien froh gewesen, wenn sich Deutsche unter ihnen befunden hätten ${ }^{184}$. Es gab auch Deserteure wie beispielsweise Karl Naumann (französische Fremdenlegion), die sich weigerten, in den Rifdienst einzutreten, weil auf der Gegenseite ebenfalls Deutsche kämpften ${ }^{185}$. Innerhalb der französischen Fremdenlegion herrschte durchaus eine feindliche Stimmung gegenüber den Über-

${ }^{177}$ Ernst F. LöHNDORFF, Afrika weint. Tagebuch eines Legionärs, Bremen 1930, S. 187. Löhndorff erreichte das Rif allerdings nicht.

${ }^{178}$ SABLOTNY, Légionnaire, S. 264-268.

${ }^{179}$ MEYER, Dreitausend Kilometer, S. 129; CADN Maroc DAI 192: Bericht »Déclaration du déserteur espagnol Hugo Oswald«, 18.5.1925.

${ }^{180}$ PENNELL, A Country, S. 203. Dieses Gerücht wurde auch vom deutschen Deserteur Josef Klems alias Caïd el Haj alemán in Umlauf gebracht [SHAT 12J3797: Bericht "Déclarations de Si Mohamed Jaouen Ameziane«, 28.7.1926].

${ }^{181}$ LOZE, L'état-major, 14.4.1926.

${ }^{182}$ SHEEAN, Abd el Krims europäische Helfer, 10.11.1925.

${ }^{183}$ MEYER, Dreitausend Kilometer, S. 128.

${ }^{184}$ PA-AA R71927. Preußisches Innenministerium an AA, 27.2.1926 mit Bezug auf eine Aussage Alois Fleischers, 19.12.1925.

${ }^{185}$ CADN Maroc DAI 192: Tabor de police $\mathrm{N}^{\circ} 1$ Tanger an DAI Rabat, 2.11 .1925 mit Bezug auf ein Verhör von Karl Naumann, 30.10.1925. 
läufern ${ }^{186}$. Max Köster berichtete: „Wir waren [...] ausserordentlich ungehalten, weil mancher Legionär durch die zu Abdul Krim übergelaufenen Legionäre sein Leben hatte lassen müssen ${ }^{187}$.

Abdelkrim versuchte, einzelne Überläufer zur Steigerung ihrer Motivation in einflußreicheren Stellungen im Rif heimisch werden zu lassen. Walter vom Scheidt alias Abdelkader, einer der wenigen europäischen Kommandeure der Rifarmee, heiratete Ende 1925 die vierzehnjährige Tochter eines Caïds und erhielt ein Haus mit Land, Kühen, Schafen, Ziegen und Geflügel. Der Deutsche berichtete, es habe im Rif gutes Essen und Trinken gegeben, und er sei "auch reichlich mit Geld versehen « worden: "Ich wäre noch nicht nach Deutschland zurückgekehrt, wenn ich nicht wegen des französischen Einmarsches hätte flüchten müssen ${ }^{188}$. Kurt Degenkolbe alias Caïd Abdullah, einer der einflußreichsten Überläufer in Abdelkrims Hauptquartier, trat zum Islam über und erhielt 150 Peseten für seine Einkleidung ${ }^{189}$. Er durfte sich seine Ehefrau aus 15 Kabylenmädchen aussuchen: »Ein Wink (von Abdelkrim), und ich hatte das für eine Heirat in Marokko Notwendige, nämlich den Esel, Getreide und Geld. Darauf suchte ich mir die aus, die ich für die Schönste hielt, Abdelkrim verband uns und bezahlte das Hochzeitsmahl ${ }^{190}$.

Auch Martin Reinhold wurde von Außenminister Azerkane für seine Heirat mit einer Frau aus Izemouren mit Geld ausgestattet ${ }^{191}$. Josef Klems, der wichtigste Militärberater von Si M'hammed, erhielt zum Einstieg 1000 Peseten ${ }^{192}$. Er verheiratete sich gleich mehrmals und wurde Vater eines Sohnes. Ihm wurden ein Haus, Landgüter und ein Pferd zur Verfügung gestellt ${ }^{193}$. Auch andere Deserteure oder Militärberater verheirateten sich, erhielten neue Namen, kleideten sich nach Landesart oder nahmen die örtlichen Gewohnheiten an ${ }^{194}$. Die

${ }^{186}$ PA-AA R70857: Antoine Paoli an Botschaft Paris, 9.7.1926.

${ }^{187}$ PA-AA R70843: Preußisches Innenministerium an AA, 21.10.1927 mit Bezug auf eine Aussage des ehemaligen französischen Fremdenlegionärs Max Köster, 20.8.1927.

${ }^{188}$ PA-AA R70840: Preußisches Innenministerium an AA, 14.2.1927 mit Bezug auf Aussagen von Walter vom Scheidt.

${ }^{189}$ DEGENKOLBE, Vom Schusterjungen, S. 79.

${ }^{190}$ DERS., Erlebnisse, 7.3.1926.

${ }^{191}$ SHAT 3H1 154: Bericht „Procès-verbal d'interrogatoire de l'ex-légionnaire Martin Reinhold surnommé Ali«, 24.10.1925.

${ }^{192}$ PA-AA R70870: Botschaft Paris an AA, 21.6.1926 mit beiliegendem französischem Erlebnisbericht von Josef Klems (betitelt "Affaire Klems «).

${ }^{193}$ SHAT 12J3797: Bericht "Rapport sur l'affaire Klems Josef«, 23.12.1926; SHEEAN, An American, S. 275f.

${ }^{194}$ ADMAE Maroc 138, 82: Bericht "Interrogatoire de Haïmou Tayeb«, 7.6.1926; SHAT 3H443: Commandant superieur des troupes du Maroc, EMA, $2^{e}$ bureau, Fès: Bericht terrogatoire du sergeant Ben Ameur Tahar«, 29.12.1925; SHAT 3H1154: Bericht "Procesverbal d'interrogatoire du tirailleur Larbi Mohammed«, 15.10.1925; Foreigners Aid Abd-elKrim, in: New York Times, 13.5.1925; Collaboration allemande, in: Euvre, 13.5.1925. 
arabischen Kampfnamen dienten aus Abdelkrims Sicht wohl auch dazu, die Anwesenheit von europäischen Soldaten im Rif zu verschleiern. Abenteuerlust oder eine Spur orientalische Romantik mögen diese Leute angetrieben haben. Die meisten schätzte der Augenzeuge Vincent Sheean, ein Reporter der »Chicago Tribune«, als reine Glücksritter ein ${ }^{195}$.

Auch im Rif zeigte sich also ein Phänomen, das »die Geschichte der europäisch-überseeischen Beziehungen bis in die Gegenwart hinein begleitet hat " ${ }^{196}$ - nämlich das der Überläufer, die der Faszination einer ihnen fremden Welt erlagen und dort eine neue Heimat fanden. Allerdings beschränkte sich die Faszination im Fall des Rifkrieges auf dessen Dauer.

\subsection{Die Aufgabenfelder der Überläufer}

Abdelkrim benötigte vor allem Helfer mit technischem Sachverstand. Dringend erforderlich waren von Anfang an schnelle Kommunikationsverbindungen - die Etablierung eines Telefonnetzes und die Errichtung eines Straßensystems. Dies diente sowohl militärischen Zwecken als auch der internen Kontrolle des Rifstaates, denn Zentralismus prägte sowohl die innere Struktur der »Rif-Republik» als auch die militärischen Entscheidungsprozesse ${ }^{197}$. Diese technischen Aufgaben bewältigten in der Regel europäische Überläufer oder Gefangene. Wo es vorher nichts Vergleichbares gab, errichteten sie Teilbereiche einer Infrastruktur, in denen sich die Rifkabylen nicht allein helfen konnten.

Der Spanier Antonio Rojano und der Deutsche Walter Noah, beides Deserteure aus der spanischen Fremdenlegion, erstellten die Grundstrukturen eines Telefonnetzes $^{198}$. 1921 war Rojano bei Alhucemas desertiert und gefangenge-

${ }^{195}$ SHEEAN, My Meeting, S. 848.

${ }^{196}$ Urs BITTERLI, Die , Wildenc und die >Zivilisiertenc. Grundzüge einer Geistes- und Kulturgeschichte der europäisch-überseeischen Begegnung, München 1976, S. 87.

${ }_{197}$ PENNEL, Morocco since 1830, S. 193.

${ }^{198}$ Charles Richard Pennell hat in seinen Arbeiten das Telefonnetz im Rif bereits beschrieben, ohne allerdings den Einsatz der europäischen Überläufer herauszustreichen. Hier erfolgt eine Verfeinerung seiner Ergebnisse, insbesondere was die Linienführung, die Anzahl der Stationen oder den besonderen Einfluß europäischer Helfer anbetrift, auf die Pennell kaum eingeht [PENnell, A Country, S. 141-143, S. 150f.; PENnel, La guerra del Rif, S. 198200]. 
nommen worden. Freiwillig blieb er im Rif $^{199}$. Er reparierte zunächst defekte Waffen, später ebenso Motoren und Autos ${ }^{200}$. Es ist auch eine simple Konstruktionszeichnung für ein Schiff namens »Aixdir« überliefert, auf der nicht viel mehr als die Umrisse eines Bootes mit einem Führerhäuschen an Deck zu erkennen $\operatorname{sind}^{201}$.

Erst im Laufe des Jahres 1923 begann Rojano auf Befehl von Si M'hammed mit ernsthaften Arbeiten am Telefonsystem ${ }^{202}$. Zusammen mit Deserteuren der spanischen Fremdenlegion machte er sich ans Werk. Vor allem benutzten sie erbeutetes spanisches Material ${ }^{203}$. Die Rifkabylen besorgten außerdem aus Algerien, Tanger und Großbritannien Nachschub an Feldtelefonen oder Telefondraht $^{204}$. Zunächst wurde das Hauptquartier in Ajdir mit Abdelkrims Wohnhaus in Ait Kamara telefonisch verbunden, und bis Dezember 1923 gab es zahlreiche weitere Linien. Der spanische Deserteur Manuel Santo leitete den Bau der Verbindung zwischen Targuist und Ajdir ${ }^{205}$. Als die Rifkabylen ihren Einflußbereich 1924 nach Westen ausdehnten, folgte unmittelbar die Errichtung von Telefonlinien ${ }^{206}$. Von Aït Kamara aus führten Telefondrähte in alle Richtungen ${ }^{207}$. Dort entstand eine moderne Zentralstation, wo Hunderte von Ohren lauschten, wenn abends gegen $17 \mathrm{Uhr}$ das Kommuniqué der MelillaFront eintraf, dem eine Stunde später der Bericht von der Westfront folgte ${ }^{208}$.

Antonio Rojano erwarb sich einen Ruf als technischer Leiter des Telefondienstes im Rif ${ }^{209}$. Jeder nannte ihn »Antonio el mecánico«. Unterstützung erhielt er von einem Engländer namens John Bevan, der während seines Be-

${ }^{199}$ GABRIELLI, Abd-el-Krim, S. 51; CADN Madrid C275: MAE an Ambassade de Madrid, 24.11.1924; PENNELL, A Country, S. 150; LOZE, L'état-major, 14.4.1926; WOOLMAN, Rebels in the Rif, S. 153. Richard Sablotny zufolge fiel Rojano beim Schmuggel von Eiern und Hühnern in die Hände der Rifkabylen [SABLOTNY, Légionnaire, S. 266].

${ }^{200}$ CADN Maroc DAI 198: Bericht „Declarations de Si El Hassan El Kadiri«, 26.6.1926; SHAT 3H1561: EMA, $2^{\circ}$ bureau, Fè, Bericht »Renseignements divers fournis par Antonio Palma«, 1.1.1926.

${ }^{201}$ ADMAE Maroc 114, 164: Konstruktionszeichnung für das Schiff »Aixdir«.

${ }^{202}$ HART, The Aith Waryaghar, S. 387; WOOLMAN, Rebels in the Rif, S. 153.

${ }^{203}$ KHARCHICH, La France, S. 112; Gabrielli, Abd-el-Krim, S. 51; Paul S. MowRER, Une visite chez Abd el Krim, adversaire de l'Espagne, in: L'Europe nouvelle 13 (1924) S. 15221524, S. 1522; RUE, News, S. 269.

${ }^{204}$ SHEEAN, An American, S. 109; DERS., Im Rif, in: Neue Zürcher Zeitung, 29.9.1925; DERS., Im Hauptquartier der Rifarmee. Durch die Feuerlinien zu Abd-el-Krim, in: Berliner Tageblatt, 2.10.1925; DAOUD, Abdelkrim, S. 153.

${ }^{205}$ SHAT 3H443: Région de Taza, Poste d'Hassi Ouenzga, SR, Bericht »Feuille de renseignements sur le Riff (d'après les impressions de voyage du docteur Marion-Gallois)«, 4.12.1923; KHARCHICH, La France, S. 112.

${ }^{206}$ PENNELl, A Country, S. 141-143; Hoisington, Lyautey, S. 192.

${ }^{207}$ WARD PRICE, Extra-Special Correspondent, S. 168; DERS., First News from the Riff, in: Daily Mail, 24.4.1924.

${ }^{208}$ CADN Maroc DAI 187: RG Rabat an MAE 22.12.1923.

${ }^{209}$ GABRIELLI, Abd-el-Krim, S. 51; DAOUD, Abdelkrim, S. 153. 
suches von Mai bis August 1923 eigentlich nach Bodenschätzen suchen wollte. Mehreren völlig voneinander unabhängigen Berichten zufolge war er an der Entwicklung des Kommunikationsnetzes im Rif beteiligt ${ }^{210}$. Ein Franzose aus Casablanca namens Labbe reparierte 1923 Telefonlinien für Abdelkrim ${ }^{211}$.

Betrieben wurden die Telefonstationen von Jungen oder Jugendlichen, denen Rojano die Bedienung und Wartung beigebracht hatte ${ }^{212}$. Rifkabylen, die im algerischen Telefondienst tätig gewesen waren, standen dem Spanier zur Seite $^{213}$. Die Krankenpflegerin Mlle Ponzo, die im Dezember 1923 Abdelkrims kranke Schwester pflegte, schwärmte von der Perfektion des Telefonnetzes ${ }^{214}$. Eine Einschätzung, die Rifbesucher Gerald Spencer Pryse ein Jahr später teilte: "Ihr System der Feldtelefone ist bewundernswert ${ }^{215}$.

Im August 1924 begannen zehn europäische Überläufer mit der Arbeit, Sidi Ali Bou Roqba ans Netz anzuschließen ${ }^{216}$. Andere Deserteure hielten die Telefone instand oder bedienten sie ${ }^{217}$. "TTelefone sind derzeit an so vielen Orten wie möglich installiert«, konstatierte Abdelkrims Berater Robert GordonCanning in der Augustausgabe der "Contemporary Review« von $1924^{218}$. Stolz präsentierten die Rifkabylen dem amerikanischen Journalisten Paul Scott Mowrer von den »Chicago Daily News« im Oktober 1924 ihr Telefonnetz. Auf seinem Weg von Taourirt aus wurden ihm möglichst viele Stationen gezeigt, um ihm die gute Organisation des Rifstaates zu demonstrieren ${ }^{219}$.

${ }^{210}$ ADMAE Maroc 133, 100: Bericht »La question riffaine vue de la méditerranéeর von Daniel Bourmancé-Say, 28.5.1925; WARD PRICE, Extra-Special Correspondent, S. 172 (bezieht sich auf Aussagen von Si M'hammed); SHAT 3H134: Ambassade de Madrid, Attaché militaire an MG, EMA, $2^{\mathrm{C}}$ bureau, 27.3.1924. Siehe zu Bevan auch Kapitel 6, S. 273, S. $295 f .$, S. 320.

211 SHAT 3H1102: SR, Bericht »Liste de personnes à surveiller « O.D. (1924).

${ }^{212}$ PENNELL, A Country, S. 131 (Pennell reduziert die Bedeutung Rojanos auf diese Einweisungen); BALFOUR, Deadly Embrace, S. 359; HART, The Aith Waryaghar, S. 387; GABRIELLI, Abd-el-Krim, S. 51; Walter B. HARRIS, Better Outlook in Morocco, in: Times, 7.6.1926; LANDAU, Moroccan Drama, S. 124; LANGLET, Riff, S. 182; LE GUILLERME, CH. »402«, S. 162.

${ }^{213}$ MERCER, Legion, S. 235.

${ }^{214}$ FONTAINE, L'étrange aventure, S. 62.

${ }^{215}$ SPENCER PRYSE, Through the Lines, S. 640. Vgl. HARRIS, Conditions in the Rif, 3.12.1924.

${ }^{216}$ SHAT 3H1103: Contrôle civil de Taourirt, Bulletin de renseignements, 18.8.1924 und 19.8.1924.

${ }^{217}$ PRO-FO 174, 303, 74: Consulate of Fez an RG Rabat, 27.11.1924; PORCH, Foreign Legion, S. 395f.

${ }_{218}$ GORDON-CANNING, Tangier, S. 179. Siehe zu Gordon-Cannings Beraterfunktion Kapitel 6, S. 316-346.

${ }^{219}$ MOWRER, The House of Europe, S. 464-467; SHAT 3H102: Bericht »Notes au sujet du voyage de M. Scott Mowrer dans le Riff« o.D. [Oktober 1924]; SHAT 3H1557: Contrôle civil de Taourirt, Bulletin de renseignements, 17.10.1924. 
Doch der Stern von Antonio Rojano begann zu sinken. Léon Gabrielli, der Kontrollbeamte von Taourirt und ein guter Kenner der Verhältnisse im Rif, schätzte ihn ohnehin als Blender ohne sonderlichen Wert ein ${ }^{220}$. Rojano kam in ein Gefangenenlager. Er wurde ständig überwacht und konnte sich ohne Eskorte nirgendwohin bewegen. Der Grund hierfür und sein weiteres Schicksal sind nicht bekannt ${ }^{221}$.

Bis Ende 1924 gingen von Ajdir grob vier Hauptlinien aus bzw. sie befanden sich im $\mathrm{Bau}^{222}$ : a) nach Westen an der Küste entlang (Beni-Bou-Ifrah-ElJebha-Amtar-Oued-Lau) in Richtung Dar Raï und Regaïa in der Nähe der internationalen Zone von Tanger ${ }^{23}$, b) über Targuist in Richtung Chichaouen und von dort nach Süden in Richtung Ouezzane und Taounat ${ }^{224}$, c) über Targuist, Taberrant und Beni Berber in Richtung Mediouna ${ }^{225}$, d) in Richtung Osten über Muzimma, Chaib Meghar, Annual, Tizi Azza, Tafersit nach Midar und von dort nach Süden in Richtung Sidi Ali Bou Roqba, Aknoul und Sa$\mathrm{ka}^{226}$. Anfang 1925 wurde die Strecke von den Jebala nach Chichaouen in Angriff genommen. Von dort aus wurde eine Linie nach Norden Richtung Beni Mecouar gezogen. Nachdem Tangerer Sympathisanten Nachschubmaterial be-

${ }^{220}$ GABRIELLI, Abd-el-Krim, S. 51; CADN Maroc DAI 191: Bericht "Renseignements Gabrielli sur le Riff, Renseignements d'ordre militaire«, 19.9.1925; CADN Maroc DAI 188: DAI, Bericht »Note sur le »Maghzen، Riffain« o.D. [Dezember 1925].

${ }^{221}$ SHAT 3H1561: EMA, $2^{e}$ bureau, Fè, Bericht "Renseignements divers fournis par Antonio Palma«, 1.1.1926; SABLOTNY, Legionnaire, S. 266.

${ }^{222}$ Grundlegend zum Telefonnetz: PENNELL, A Country, S. 142; DERS., La guerra del Rif, S. 199; JACQUES, L'aventure riffaine, S. 3f.; LADREIT DE LACHARRIÈRE, Le rêve, S. 184; SheEAN, An American, S. 109; DeRS., My Meeting, S. 845; DerS., War in Africa, S. 260; DERS., Riff Laughs, 13.2.1925; DERS., Im Hauptquartier, 2.10.1925; HARRIS, France, S. 209; DERS., Rifi Reports. Fighting Near Tetuan, in: Times, 9.9.1925; DERS., Abd-elKrim's Power, 29.12.1925; WARD PRICE, Extra-Special Correspondent, S. 168, S. 172; DERS., First News, 24.4.1924; BONNET-DEVILliERS, La Guerre du Rif, S. 65, S. 69; RUE, News, S. 274f.; DERS., Tribune, 23.6.1925.

${ }^{223}$ SABLOTNY, Légionnaire, S. 279; SPENCER PRYSE, Through the Lines, S. 473, S. 621; CADN Madrid C275: MAE an Ambassade de Madrid, 24.11.1924; CADN Maroc DAI 188: Territoire de Taza, Cercle de Guercif, SR, Renseignements, 6.3.1925; CADN Maroc DAI 192: Tabor de police $\mathrm{N}^{\circ} 1$ Tanger an DAI, 11.7.1925; CADN Tanger C39: Tabor de police $\mathbf{N}^{\circ} 1$, Note, 24.7.1925 und 4.8.1925; TNLA, BNS, 1, Williams: Walter Harris an Harold Williams, 25.7.1925.

${ }^{224}$ PA-AA Paris 454a: Konsulat Tetuan an Botschaft Madrid, 14.8.1925; CADN Maroc DAI 188: Territoire de Taza, Cercle de Guercif, SR, Renseignements, 6.3.1925.

${ }^{225}$ GODED LLOPIS, Marruecos, S. 89.

${ }^{226}$ SHAT 3H1558: Bericht »Répertoire des organisations riffaines relevées au 10 décembre 1924 sur le front nord du territoire de Taza« o.D.; SHAT 3H1103: Contrôle civil de Taourirt, Bulletin de renseignements, 7.12.1925; CADN Maroc DAI 188: Territoire de Taza, Cercle de Guercif, SR, Renseignements, 6.3.1925. 
sorgt hatten, konnte die Linie nicht nur bis zum Sommer 1925 fertiggestellt, sondern auch praktisch bis zur Grenze der internationalen Zone von Tanger verlängert werden ${ }^{227}$. An dieser Arbeit waren fünf deutsche Überläufer maßgeblich beteiligt ${ }^{228}$.

Im Hauptquartier in Ajdir liefen alle Drähte in einer großen Schalttafel der Firma Ericsson zusammen ${ }^{229}$. Glaubt man einem Bericht der deutschen Zeitschrift »Radio-Umschau«, dann verfügte Abdelkrim 1925 über rund 30 RadioSende- und Empfangsapparate. Hiernach war er über die neuesten Heeresberichte der Spanier und Franzosen ständig auf dem Laufenden. Die Kavallerie habe über stoßfeste drahtlose Sattelapparate verfügt, hieß es. Im Hauptquartier in Ajdir standen laut der »Radio-Umschauk eine umfangreiche Antennenanlage und ein großer »Mehrröhren-Apparat modernster Konstruktion und deutschen Fabrikats ${ }^{230}$.

Mitte August 1925 nahm der französische Journalist Jacques Roger-Mathieu die Linie zwischen Bougabech und Dar Raï in Augenschein: "Die Installation befindet sich in den Anfängen [...], aber die Kommunikationsverbindung ist sehr sicher ${ }^{231}$. Walter Harris, der "Times«-Korrespondent in Tanger, schrieb in einem Brief an seinen Chef Harold Williams: „Es wird Sie amüsieren zu hören, daß Abdelkrims Telefon nun von Ajdir im Rif bis an die Grenze der Tangerzone funktioniert. Es erleichert alles, und ich kann wesentlich einfacher mit ihm kommunizieren ${ }^{232}$ Die Stationen vor der Grenze zur französischen Zone wurden im Frühjahr 1925 immer zahlreicher, denn Abdelkrim bereitete sich auf militärische Maßnahmen vor. Marschall Lyautey betrachtete dies mit wachsender Sorge ${ }^{233}$. Die Linie zwischen Chaouia und Sidi Ali Bou Roqba sowie die Verbindung nach Ajdir wurden fertiggestellt. Aknoul wurde ange-

${ }^{227}$ PENNELL, A Country, S. 177; CADN Tanger C39: Tabor de police $\mathrm{N}^{\circ} 1$ Note, 24.7.1925; PRO-FO 371, 11078, 39: Embajada de Londres an FO, 20.7.1925; CADN Madrid C263: CG Tanger an MAE, 1.8.1925.

${ }^{228}$ CADN Tanger C39: Tabor de police $\mathrm{N}^{\circ} 1$, Note, 1.8.1925.

${ }^{229}$ NARA 881.00, 1057: American Agency and Consulate General of Tangier an Secretary of State, 20.5.1925.

${ }^{230}$ Abd el Krims Nachrichtendienst durch Radio, in: Radio-Umschau 2 (1925) S. 13491351, S. 1350. Vgl. insbesondere BONNET-DEVILLIERS, La Guerre du Rif, S. 59; RUE, Tribune, 23.6.1925. Zum Chiffre-System der Rifkabylen: FONTAINE, L'étrange aventure, S. 211-216.

${ }^{231}$ Jacques ROGER-MATHIEU, Les trois étapes de Msouha à Chechaouen. L'initiation aux particularites de la vie rifaine, in: Matin, 8.9.1925.

${ }_{232}$ TNLA, BNS, 1, Williams: Walter Harris an Harold Williams, 25.7.1925.

${ }^{233}$ Hubert JACQUES, L'aventure riffaine et ses dessous politiques, Paris 1927, S. 63. 
schlossen und eine Verlängerung nach Saka gebaut ${ }^{234}$. Im Mai 1925 waren alle Frontabschnitte im Süden der "Rif-Republik» mit dem Hauptquartier Si M'hammeds in Targuist verbunden ${ }^{235}$.

An der Fertigstellung dieser Anschlußpunkte hat auch der Deutsche Josef Klems alias Caïd el Haj alemán mitgewirkt ${ }^{236}$. Im März 1925 leitete er zudem die Verlegung einer Telefonleitung zwischen Chichaouen und Ajdir durch spanische Gefangene ${ }^{237}$. Andere deutsche Überläufer wie Paul Hohenwald, Karl Millfahrt und Max Varras wurden für Arbeiten am Telefonsystem eingesetzt $^{238}$ - ebenso der Spanier Enric Carbonell ${ }^{239}$. Deserteure reparierten bei Beni Berber Telefonleitungen ${ }^{240}$. Vier andere kümmerten sich in Sidi Abdallah ben Youssef monatelang um die Instandhaltung der Anlage ${ }^{241}$. Sechs Europäer verbanden Chichaouen mit Souk el Tlata ${ }^{242}$. Karl Ohme alias Caïd Abdeslem fungierte als Telefonist für Abdelkrim und Caïd Haddou ${ }^{243}$. Der Telefondienst war unter den Deserteuren wesentlich beliebter als etwa die schwere Arbeit im Straßenbau ${ }^{244}$.

Antonio Rojanos Nachfolger wurde der Deutsche Walter Noah ${ }^{245}$, der im Mai 1925 bei Melilla aus der spanischen Fremdenlegion desertierte. Während des Ersten Weltkrieges hatte er als Telefonist an der russischen Front gedient. Nun verpflichtete Abdelkrim den Spezialisten dafür, weitere Stationen vor al-

${ }^{234}$ SHAT 3H1558: Bericht "Répertoire des organisations riffaines relevées au 10 décembre 1924 sur le front nord du territoire de Tazau, 10.12.1924; SHAT 3H1557: Contrôle civil de Taourirt, Bulletin de renseignements, 13.11.1924.

${ }^{235}$ CADN Tanger C38: CG Tanger an RG Rabat, 15.5.1925.

${ }^{236}$ WoOlman, Rebels in the Rif, S. 153; VaIdon, Tangier, S. 198; Fleming, Primo de Rivera and Abd-el-Krim, S. 225; Georges R. MANUE, La fin d'un aventurier. Le légionnaire déserteur Klems, qui fut chef d'etat-major du rebelle marocain Abd el Krim, vogue actuellement vers le bagne de la Guayane, in: Dépêche coloniale et maritime, 21.2.1930. Siehe zu Klems vor allem auch S. 135-154.

${ }^{237}$ MEYER, Dreitausend Kilometer, S. 103.

${ }^{238}$ CADN Maroc DAI 192: Tabor de police $\mathrm{N}^{\circ} 1$ Tanger an DAI Rabat, 11.7.1925.

${ }^{239}$ BosQue CoMA, Prisioneto, S. 26.

${ }^{240}$ SHAT 3H442: Bericht »Déclarations du caporal Harteinstein Réné« o.D. [1926].

${ }^{241}$ PARENT, Au Riff, S. 76.

${ }^{242}$ PRO-FO 371, 11078, 39, 128: Embajada de Londres an FO, 20.7.1925.

${ }^{243}$ SHAT 3H442: Bericht „Déclarations du soldat Florio Louis«, 8.6.1926; ADMAE Maroc 138, 136: Bericht »Déclarations du Caporal Baldy Fernand«, 8.6.1926; ADMAE Maroc 138, 133: Bericht »Déclarations du caporal Gomis Julio», 8.6.1926.

${ }^{244}$ SHAT 3H102: Bericht Note au sujet du voyage de M. Scott Mowrer dans le Riff« o.D. [Oktober 1924].

${ }^{245}$ Auch Walter Noahs Name wird in der Literatur vereinzelt falsch wiedergegeben: „Otto Noja« [WoOLMAN, Rebels in the Rif, S. 151; GoDED LlOPIS, Marruecos, S. 89]; „Otto Noya [ [José M. CaMpos MarTíneZ, Abd-el-Krim y el Protectorado, Malaga 2000 (Colección Africa propia, 18), S. 220]. Hans Langlet zufolge kam Noah aus Tilsit [LANGLET, Riff, S. 225], Kurt Degenkolbe zufolge aus Danzig [DEGENKOLBE, Vom Schusterjungen, S. 71]. Walter Meyer hingegen nennt Königsberg als Geburtsort [MEYER, Dreitausend Kilometer, S. 114]. 
lem in Richtung Französisch-Marokko zu errichten sowie die empfindlichen Telefonapparate instand $\mathrm{zu}$ halten und $\mathrm{zu}$ reparieren. Noah avancierte $\mathrm{zu}$ einem der wichtigsten Helfer bei der Errichtung des Telefonnetzes ${ }^{246}$. Der Reporter Vincent Sheean traf den Deutschen im Oktober 1925 und veröffentlichte eine enthusiastische Beschreibung: »Der wichtigste [...] Deutsche ist meiner Meinung nach der ausgezeichnete Telephonist Walter Noah. [...] Er errichtete ein leistungsfähiges Telephonsystem, das sich über die ganze französische Front erstreckt und dem mehr als die Hälfte aller Erfolge der Rifleute während dieses Sommers zu verdanken ist. Ohne dieses Netzwerk von Feldtelephonen, das sich von Uezzan bis zur Ostfront erstreckt, wäre Sidi Mohammed (Si M'hammed) nie imstande gewesen, die Operationen auf dem ganzen Kriegsgebiet zu leiten $\aleph^{247}$. Im Frühjahr 1926 hielt sich Walter Noah noch in Chichaouen auf, doch dann verliert sich seine Spur im Zuge des spanischen Vormarsches ${ }^{248}$.

Ende 1925 konstatierte der gut informierte Walter Harris in der "Times«, daß Abdelkrims Telefonnetz über die meisten Gebiete des Rifs verteilt war $^{249}$. Insgesamt gab es zuletzt etwa 77 Telefonstationen, die sich - abgesehen von der Südverbindung - meist in aufgegebenen spanischen Blockhäusern befan$\operatorname{den}^{250}$. Es war ein schlichtes System. Nicht alle Leitungen waren mit Isolatoren und Masten ausgestattet. Vielfach mußten sie in Ermangelung von $\mathrm{Holz}$ einfach auf dem Boden verlegt werden ${ }^{251}$. Trotz einiger Störungen galt das Netz jedoch als ungemein effizient ${ }^{252}$.

${ }^{246}$ LANGLET, Riff, S. 234; MEYER, Dreitausend Kilometer, S. 114-116; GODED LLOPIS, Marruecos, S. 89; LOZE, L'état-major, 14.4.1926; PENNELL, A Country, S. 131f.; LANG, Die Darstellung Abd el-Krims, S. 68; WoOLMAN, Rebels in the Rif, S. 151.

${ }^{247}$ SHEEAN, Abd el Krims europäische Helfer, 10.11.1925. Vgl. DEGENKOLBE, Vom Schusterjungen, S. 71.

${ }^{248}$ LANGLeT, Riff, S. 225f.; Goded LloPIS, Marruecos, S. 89; PA-AA R70840: Preußisches Innenministerium an AA, 14.2.1927 mit Bezug auf Aussagen von Walter vom Scheidt. Es gibt einen Bericht eines ehemaligen spanischen Fremdenlegionärs, daß Noah in spanischer Gefangenschaft getötet worden sei [PA-AA R71927: Preußisches Innenministerium an AA, 7.3.1926 mit Bezug auf eine Aussage von Emil Kahl]. Dem widerspricht ein Artikel in der "Temps« im Juni 1926, der aussagte, daß Noah noch nicht gefaßt worden sei [PA-AA R70870: Botschaft Paris an AA, 10.6.1926].

${ }^{249}$ HARRIS, Abd-el-Krim's Power, 29.12.1925.

${ }^{250}$ Goded Llopis, Marruecos, S. 89; SALAS LARRAZÁbal, Protectorado, S. 149f.; Le GuILLERME, CH. »402«, S. 162; Un central téléphonique dans une caverne du Rif, in: Petit Journal, 22.2.1926.

${ }^{251}$ PaReNT, Au Riff, S. 50f.; Le Gulllerme, CH. $\$ 402 \lll$, S. 162; DaOUd, Abdelkrim, S. 153.

${ }^{252}$ ASPREY, War in the Shadows, S. 273; PENNELl, Exito y fracaso, S. 33; FleMING, Primo de Rivera and Abd-el-Krim, S. 225; WoolmaN, Rebels in the Rif, S. 153; CADN Maroc DAI 192: Tabor de police $N^{\circ} 1$ Tanger an DAI Rabat, 11.7.1925 mit Bezug auf eine Befragung von Paul Hohenwald. 
Neben dem Telefonsystem verfügten die Rifkabylen über vier Telegrafenstationen. Eine befand sich seit April 1924 bei Iger Aïch westlich von Morro Nuevo. Sie stammte aus Großbritannien ${ }^{253}$. Später wurden drei weitere Empfangsgeräte, mit denen Abdelkrim das französische Militär ausspionierte, von Deserteuren der spanischen Fremdenlegion errichtet ${ }^{254}$.

Dieses Netz an Feldtelefonen und Telegrafie hatte für Belange der internen Kontrolle, aber vor allem in militärischer Hinsicht immense Bedeutung ${ }^{255}$. Von Ajdir oder Targuist aus waren alle Winkel des Einflußbereichs Abdelkrims jederzeit zu erreichen, um etwa eine Konzentration von Truppen oder Truppenverschiebungen herbeizuführen. Die Hauptquartiere waren ständig über die neueste Lage informiert. Von dort aus konnten Abdelkrim und Si M'hammed alle Bewegungen ihrer Truppen per Telefon leiten ${ }^{256}$. Die Anlagen wurden ausgiebig genutzt. Der amerikanische Reporter Paul Scott Mowrer amüsierte sich darüber, daß das Telefon im Rif fast mehr genutzt werde als in europäischen Ländern ${ }^{257}$.

Neueste politische Entwicklungen erreichten Abdelkrim auf dem schnellsten Weg. Die Ergebnisse der von Frankreich und Spanien abgehaltenen Madrider Konferenz vom Juni 1925 erfuhr er über das von den Überläufern errichtete Telefonnetz ${ }^{258}$. Deren Bedeutung hob vor allem der amerikanische Reporter Vincent Sheean hervor: »Beide, Artillerie wie Telephon, waren unschätzbare Elemente für die Erringung einer ganzen Reihe von Siegen der Rifs, aber der bedeutungsvollste aller mechanischen Faktoren ist das Telephon, und dessen Wirksamkeit hängt praktisch noch mehr von der Arbeit der europäischen Helfer [...] ab als selbst die der Artillerie ${ }^{259}$. Ab dem 21. Mai 1926 jedoch gab es aufgrund des Vormarsches der alliierten Truppen und der Sabotage spanischer Spione keine funktionierende Telefonverbindung mehr. Die restlichen Tage bis zur Kapitulation Abdelkrims mußten sich die Rifkabylen wie seit jeher auf Laufboten (rekkas) verlassen ${ }^{260}$.

${ }^{253}$ Charles A.P. GARDINER, My Escape in Lifeboat from Spanish Bombs, in: Illustrated Sunday Herald, 2.8.1925; GODED LLOPIS, Marruecos, S. 89; FONTAINE, L'étrange aventure, S. 65, S. 86; SHAT 3H146: Consulado de Oujda an Alto comisario de Tetuan, 9.9.1924; CADN Maroc DAl: Consulado de Oujda an Alto comisario de Tetuan, 13.9.1924; PRO-FO 371, 10583, 783, 18: Embajada de Londres an FO, 14.6.1924; CADN Maroc DAI: Bericht "Déclarations de Si El Hassan El Kadiri«, 26.6.1926.

${ }^{254}$ DUMAS, Abd-el-Krim, S. 28f; LADREIT DE LACHARRIËRE, Le rêve, S. 184.

${ }^{255}$ PENNELL, A Country, S. 141.

${ }^{256}$ YOUSSOUFI, Les institutions, S. 98; LANG, Die Darstellung Abd el-Krims, S. 68; TOYNBEE, The Islamic World, S. 136; SABLOTNY, Légionnaire, S. 264; SHEEAN, My Meeting, S. 845; LANGLET, Life, 1.5.1926; DERS., How the Riffis Fight, 4.5.1926; RUE, News, S. 275. ${ }^{257}$ MOWRER, Une visite, S. 1522.

${ }^{258}$ PRO-FO 371, 11079, 39, 140: Embassy of Madrid an FO, 18.7.1925 mit einem Bericht von Militärattache W.W.T. Torr, 17.7.1925.

${ }^{259}$ SHEEAN, Abd el Krims europäische Helfer, 10.11.1925.

${ }^{260}$ PARENT, Au Riff, S. 94. 
Auch das von Abdelkrim konzipierte Straßennetz diente vornehmlich militärischen Zwecken. Ausgebaute Straßen ermöglichten insbesondere für die erbeutete Artillerie schnellere Bewegungen ${ }^{261}$. Sie wurden ebenso für die Verwirklichung der wirtschaftlichen Pläne Abdelkrims angelegt und waren ein Propagandamittel, um nach innen wie nach außen den Eindruck von Modernität zu vermitteln. Im Februar 1923 lockte Abdelkrim die Bewohner der Ghomara für den Fall, daß sie sich ihm unterwerfen würden, mit dem schnellen Bau von Straßen ${ }^{262}$.

Als Zeichen für seine Progressivität beauftragte der technikverliebte Abdelkrim Caïd Haddou im Verlaufe des Jahres 1923 damit, in Algerien drei Autos für ihn zu kaufen - einen Renault, einen Turcat-Méry und einen Ford. Garagen in Azghar, Bouham und Targuist dienten zu ihrer Unterbringung ${ }^{263}$. Chauffeure saßen am Steuer, wenn Abdelkrim täglich die Strecke zwischen seinem Wohnort Aït Kamara und Ajdir zurücklegte ${ }^{264}$. Einer von ihnen war der Algerier Hammou aus Oujda ${ }^{265}$. Nicht jeder wurde akzeptiert. Die Bewerbung des Franzosen Lorthios aus Missour wurde trotz seiner fünfjährigen Erfahrung als Fahrer abgewiesen ${ }^{266}$. Als einzige Europäer durften die Überläufer Antonio Palmeri und Henrik Scarurek Abdelkrims Ford steuern ${ }^{267}$.

Die Wagen waren häufig defekt und mußten repariert werden ${ }^{268}$. Der Tschechoslowake Ferdinand Niessel, ein Deserteur aus der spanischen Fremdenlegion, war für Abdelkrims Renault zuständig ${ }^{269}$. Hammadi, ein Cousin von Caïd Haddou, versuchte sich ebenso als Kfz-Mechaniker wie die Deserteure

${ }^{261}$ Salas LarrazÁbal, Protectorado, S. 149; Last Riff Reserves Called into Action, in: New York Times, 31.8.1925.

${ }^{262}$ PRO-FO 371, 9469, 44, 115: Consul of Tetuan an CG Tangier, 8.2.1923; PENNELL, A Country, S. 141.

${ }^{263}$ FLEMING, Primo de Rivera and Abd-el-Krim, S. 225; Goded LlopIS, Marruecos, S. 102; WoOlman, Rebels in the Rif, S. 152; SABLOTNY, Légionnaire, S. 272f.; BosQue COMA, Prisionero, S. 26; ADMAE Maroc 133, 117: Bericht "Notes et remarques sur la question riffaine« o.D. von Daniel Bourmancé-Say; CADN Madrid C275: MAE an Ambassade de Madrid, 24.11.1924; CADN Maroc DAI 192: Bericht »Rapport du Docteur Mosnier«, 1.6.1926; NARA 881.00, 1057: American Agency and Consulate General of Tangier an Secretary of State, 20.5.1925.

${ }^{264}$ MEYER, Dreitausend Kilometer, S. 117; DEGENKOLBE, Erlebnisse, 7.3.1926.

${ }^{265}$ MOWRER, The House of Europe, S. 474; SPENCER PRYSE, Through the Lines, S. 465; FLEMING, Primo de Rivera and Abd-el-Krim, S. 225; CADN Madrid C275: MAE an Ambassade de Madrid, 24.11.1924.

${ }^{266}$ CADN Maroc DAI 190: Lorthios an Caïd Haddou, 5.7.1924.

${ }^{267}$ CADN Madrid C275: MAE an Ambassade de Madrid, 24.11.1924; CADN Maroc DAI 199: EMA, $2^{\complement}$ bureau an RG Rabat, 6.7.1926.

${ }^{268}$ CADN Maroc DAI 197: Région d'Oujda, Renseignements, 20.12.1924.

${ }^{269}$ CADN Maroc DAI 188: Territoire de Taza, Cercle de Guercif, SR, Renseignements, 6.3.1925. 
Antonio Rojano oder Franz Koberstein ${ }^{270}$. Ersatzteile wie Reifen, Scheinwerfer oder Benzin wurden in der Regel aus Algerien beschafft ${ }^{271}$, ab 1925 aus Tange $^{272}$. Der US-Amerikaner Alexander Friedmann bedrängte Abdelkrim im Januar 1925 in einem Brief, daß die »Rif-Republik« nicht nur Autos, sondern auch Motorräder und Fahrräder benötige ${ }^{273}$. Ali Luh, der Rif-Agent in Tanger, versuchte, den Emir des Rifs aufgrund einer Zeitungsannonce davon zu überzeugen, amerikanische Autos zu kaufen ${ }^{274}$. Zuletzt war Abdelkrim wegen Benzinmangels nicht mehr in der Lage, seine Fahrzeuge zu benutzen. Er versteckte sie in Beni Bou Ifrah. Im Mai 1926 wurden sie von den Franzosen konfisziert $^{275}$. Ansonsten besaß im Rif nur noch Caïd Haddou ein weiteres Auto, einen Ford. Seine Fahrkünste waren berüchtigt ${ }^{276}$.

Die erste Straße zwischen Ajdir und Ait Kamara - Abdelkrims Wohnort wurde von den spanischen Gefangenen von Annual und Jebel Aroui aus dem Jahre 1921 errichtet. Sie hieß daher "Straße der Gefangenen« (pista de los prisioneros) ${ }^{277}$. Als ausgebildeter Bergbauingenieur war Si M'hammed hier noch selbst der Bauleiter. Die Franzosen A. Bourges und Carlo de Carli, die im Mai 1922 das Rif aufsuchten, bekamen die Arbeiten zu Gesicht. Sie berichteten davon, daß Si M'hammed den spanischen General Navarro, der ebenfalls mitschaufeln mußte, fragte, wie die Arbeit vorangehe, worauf dieser geantwortet habe, ein Spanier sei kein Faulpelz. Si M'hammed habe entgegnet, daß Spanier erstmalig seit dem ersten Aufeinandertreffen etwas für das Rif tun würden ${ }^{278}$. Auch die weiteren Straßen wurden in der Regel von den Gefange-

${ }^{270}$ GABRIELLI, Abd-el-Krim, S. 14; SHAT 3H1561: EMA, 2e bureau, Bericht »Renseignements divers fournis par Antonio Palma«, 1.1.1926; SHAT 3H442: Bericht »Déclarations du soldat Florio Louis« O.D. [1926].

${ }^{271}$ SHAT 3H1559: Commissariat de la région d'Oujda, Renseignements, 30.10.1923; SHAT 3H1102: Territoire de Taza, Cercle de Guercif, SR, Feuille de renseignements, 12.1.1924 und 15.1.1924; CADN Maroc DAI 195: RG Rabat an Chef de la région d'Oujda, 5.11.1924; LE GUILLERME, CH. $\bowtie 402 \ll, ~ S . ~ 96$.

${ }^{272}$ CADN Tanger C39: Tabor de police $\mathrm{N}^{\circ}$ 1, Note, 15.7.1925; ADMAE Maroc 134, 2: CG Tanger an MAE, 2.4.1926.

${ }^{273}$ CADN Maroc DAI 195: Alexander Friedmann an "To His Majesty Abdel Krim, Ajdir, Morocco«, 24.1.1925.

${ }^{274}$ Vincent SHEEAN, Eye to Eye with the Barbary Pirate, Raisuli. Impressions of the Most Evil Old Chief in Morocco after his Capture by Abd el-Krim, in: Asia 25 (1925) S. 10711079, S. 1078.

${ }^{275}$ CADN Tanger C38: CG Tanger an RG Rabat, 3.3.1926; SHAT 3H442: Note de renseignements o.D. [Mitte 1926]; WOOLMAN, Rebels in the Rif, S. 152.

${ }^{276}$ FONTAINE, L'étrange aventure, S. 62; RUE, News, S. $283 \mathrm{f}$.

${ }^{277}$ GODED LLOPIS, Marruecos, S. 90. Vgl. ShEeAN, Personal History, S. 114; DeRS., My Meeting, S. 848; PARENT, Au Riff, S. 579; MOWRER, The House of Europe, S. 468; TOYNBEE, The Islamic World, S. 146; SABLOTNY, Légionnaire, S. 254.

${ }^{278}$ CADN Madrid C273: MAE an Ambassade de Madrid, 2.6.1922 mit dem Bericht 》Un voyage dans le Riff, Rapport d'un informateur« von A. Bourges, 12.5.1922. 
nen errichtet ${ }^{279}$. Es handelte sich um tägliche Knochenarbeit, die vom Morgen bis in die Nacht andauerte. Es gab ein Brot pro Tag und Wasser. Häufig kam es zu Mißhandlungen. Niemand kennt die Anzahl der Todesfälle ${ }^{280}$.

Abdelkrim nutzte gezielt aus, daß der Straßenbau zu den ureigenen Aufgabengebieten von Fremdenlegionären oder von Soldaten der Protektoratsarmeen gehörte. Überläufer leiteten daher schon früh die Bauarbeiten, die $\mathrm{Ge}-$ fangenen führten sie durch. Im Juli 1922 befanden sich etwa 60 Deutsche im Rif, die für die Überwachung und Leitung der Straßenbauarbeiten eingesetzt wurden. Es handelte sich zumeist um Überläufer aus der französischen Fremdenlegion ${ }^{281}$. Die Arbeit lohnte sich, denn wer eine Zeit lang im Straßenbau tätig war, erhielt für die Heimkehr Geld und einen Passierschein nach Tan$\operatorname{ger}^{282}$.

Spanische Gefangene und europäische Überläufer bauten 1924 bis 1925 die Straße von Ajdir über Targuist in Richtung Chichaouen und Tetuan. Vier deutsche Deserteure waren neben dem Einheimischen Sadiq ben el Shadli, der in Frankreich im Straßenbau tätig gewesen war, an der Leitung der Arbeiten beteiligt. Die Strecke trug wegen ihrer hervorragenden Qualität den Namen »die große Straße der Automobile« (le grand chemin des automobiles) ${ }^{283}$. Ende 1924 waren im Süden die Straßen zwischen Sidi Ali Bou Roqba und Aknoul, Saka sowie Aïn Zohra in Arbeit ${ }^{284}$. Nach der Eroberung von Chichaouen wurde eine Verbindung über Talambout nach Oued Lau errichtet. Ein deutscher Ingenieur befehligte dabei 300 spanische Gefangene ${ }^{285}$.

$\mathrm{Zu}$ dieser Zeit wurde beschlossen, eine zumeist aus deutschen Deserteuren bestehende Einheit für den Straßenbau aufzustellen. Sie war in der Nähe von Abdelkrims Wohnort Aï Kamara stationiert. Der Truppe gehörten unter anderem die Deutschen Richard Sablotny, Karl Ritter und Hans Ebeling an. $\mathrm{Zu}$ sammen mit 180 spanischen Gefangenen errichteten sie die Straße von Aït Kamara in Richtung Süden ${ }^{286}$. Vincent Sheean traf Anfang 1925 in Ajdir vier

\footnotetext{
${ }^{279}$ PenNell, A Country, S. 141; BosQue Coma, Prisionero, S. 26.

${ }^{280}$ MEYER, Dreitausend Kilometer, S. 108; CADN Tanger C39: Tabor de police $\mathrm{N}^{\circ} 1, \mathrm{Be}-$ richt "Déclarations de Degenkalb Kurt«, 15.7.1925.
}

${ }^{281}$ ADMAE Maroc 194, 216: CG Tanger an MAE, 8.7.1922 mit Bezug auf einen Bericht von Ahmed Et Touhami Cherradi, 7.7.1922.

${ }^{282}$ MERCER, Legion, S. 238; SABLOTNY, Légionnaire, S. $275 f$.

${ }^{283}$ CADN Tanger C39: Tabor de police $\mathrm{N}^{\circ} 1$, Bericht „Déclarations de Degenkalb Kurt«, 15.7.1925; BOSQUE COMA, Prisionero, S. 26; PENNELl, A Country, S. 141; GODED LLOPIS, Marruecos, S. 90; SPENCER PRYSE, Through the Lines, S. 443; SHAT 3H1557: Contrôle civil de Taourirt, Bulletin de renseignements, 17.10.1924; CADN Maroc DAI 188: Territoire de Taza, Cercle de Guercif, SR, Renseignements, 6.3.1925; PA-AA Paris 454a: Konsulat Tetuan an Botschaft Madrid, 14.8.1925.

${ }^{284}$ SHAT 3H1558: Bericht "Répertoire des organisations riffaines relevées au 10 décembre 1924 sur le front nord du territoire de Taza«, 10.12.1924.

${ }^{285}$ PENNELL, A Country, S. 177; CADN Tanger C38: CG Tanger an RG Rabat, 1.5.1925.

${ }^{286}$ SABLOTNY, Legionnaire, S. 271f., S. 275; MOWRER, The House of Europe, S. 472. 
deutsche Deserteure der spanischen Fremdenlegion, die wegen ihrer Ingenieurkenntnisse mit Straßenbau beauftragt waren und denen 1800 Gefangene unterstanden ${ }^{287}$. Spanische und französische Gefangene bauten drei Straßen, die Ajdir mit der Bucht von Alhucemas und dem Süden des Beni-OuriaghelGebietes in Richtung Sidi Ali Bou Roqba verbanden ${ }^{288}$. Karl Naumann und Walter Hending, Deserteure aus der französischen Fremdenlegion, arbeiteten 1925 an der Strecke Targuist-Ajdir ${ }^{289}$.

Als einen der Leiter im Straßenbau finden wir Walter Hüntjens wieder, der Anfang Oktober 1924 im Auftrag der British Red Crescent Society ins Rif gekommen und wegen seiner mangelnden Medizinkenntnisse als Leiter des Hospitals in Chichaouen abgesetzt worden war. Er wurde El Mohandis genannt und war für den Straßen- und Brückenbau zuständig. Zusätzlich hatte Hüntjens topographische Arbeiten zu verrichten ${ }^{290}$. Als die in Tanger wartende Ehefrau bis Anfang 1926 noch immer keine Nachricht von ihrem Mann erhalten hatte, versuchte sie vergeblich, zusammen mit dem schwedischen Journalisten Hans Langlet ins Rif aufzubrechen ${ }^{291}$. Abdelkrim ließ ihr 1000 Peseten zukommen ${ }^{292}$.

Nach einem Streit mit einem Gefährten von Caïd Haddou kam Hüntjens gegen Ende des Rifkrieges in das Gefangenenlager bei Tamasint, wo er an Fieber erkrankte ${ }^{293}$. Er wurde von spanischen Truppen gefangengenommen ${ }^{294}$, kam aber schnell wieder frei. Hüntjens erhielt 100 Peseten Belohnung, weil er spanischen Gefangenen geholfen hatte. Er arbeitete im Elektrizitätswerk von

${ }^{287}$ SHEEAN, Riffis Fight, 12.2.1925; CADN Maroc Direction de l'intérieur 842: Tabor de police $\mathrm{N}^{\circ} 1$, Note, 8.2.1925.

${ }^{288}$ FLEMING, Primo de Rivera and Abd-el-Krim, S. 225; BONNET-DEviLLIERS, La Guerre du Rif, S. 69; GODED LLOPIS, Marruecos, S. 90.

${ }^{289}$ CADN Maroc DAI 192: Tabor de police $\mathrm{N}^{\circ} 1$ Tanger an DAI Rabat, 2.11.1925.

${ }^{290}$ CADN Tanger C40: Tabor de police $\mathrm{N}^{\circ} 1$, Bericht $»$ Renseignements donnés par Abdelkrim el Hadj Ali el Bokkoyi«, 5.3.1926; CADN Tanger C40: Tabor de police $\mathrm{N}^{\circ}$ 1, Information, 5.4.1926; CADN Maroc DAI 191: Bericht $»$ Renseignements Gabrielli sur le Riff, Renseignements d'ordre militaire«, 19.9.1925; SHAT 3H442: Bericht »Interrogatoire de Djelloul Ben Sliman«, 7.6.1926; ADMAE Maroc 138, 82: Bericht »Interrogatoire de Haïmou Tyab«, 7.6.1926; SHAT 3H1561: Bericht »Interrogatoire de Mouloud Ben Belaïd«, 4.6.1926; SHAT 3H1154: EMA, 2 ${ }^{\mathrm{e}}$ bureau, Aknoul, Bericht »Procès-verbal d'interrogatoire de trois convoyeurs du train des equipages prisonniers des riffains«, 15.10.1925; LOZE, L'etat-major, 14.4.1926; GABRIELLI, Abd-el-Krim, S. 180. Siehe zu Hüntjens Kapitel 3, S. $75 f$.

${ }^{291}$ ADMAE 135, 141: Tabor de police $\mathrm{N}^{\circ}$ 1, Renseignements, 18.1.1926.

${ }^{292}$ CADN Tanger C40: Tabor de police $\mathrm{N}^{\circ}$ 1, Information, 5.4.1926.

${ }^{293}$ CADN Maroc DAI 199: EMA, $2^{\circ}$ bureau an RG Rabat, 6.7.1926 mit dem Bericht »Note sur les renseignements fournis par le légionnaire Klems du $2^{e}$ étranger et leur exploitation o.D.; ADMAE Maroc 134, 57: Ambassade de Stockholm an MAE, 5.5.1926 mit Bezug auf einen Bericht von Hans Langlet in "Dagens Nyheter火, 25.4.1926.

${ }^{294}$ PENNELl, A Country, S. 154, Anm. 47; GODED LlOPIS, Marruocos, S. 90; CAMPOS MARTíNEZ, Abd-el-Krim, S. 223. Doktor Mosnier behauptete, Hüntjens sei in Ceuta gestorben [CADN Maroc DAI 192: Bericht »Rapport du Docteur Mosnier«, 1.6.1926]. 
Villa Sanjurjo, bis er am 31. März 1927 wegen seiner Unterstützung der Rifkabylen erneut verhaftet wurde und auf Befehl von General Goded Llopis standrechtlich erschossen werden sollte. Ein Hauptmann der Guardia Civil weigerte sich, den Befehl auszuführen. Hüntjens wurde nach Ceuta gebracht, wo ein Verfahren eröffnet wurde, dessen Ausgang jedoch nicht bekannt ist ${ }^{295}$.

Auch nach der Landung der spanischen Truppen in der Bucht von Alhucemas im September 1925 wurden weitere Straßen errichtet. Von Targuist aus sollten neue Verbindungen nach M'Tioua, Beni Zeroual, Ghafsai, Taouerda, Marnissa, Beni Itefft und Beni Bou Ifrah entstehen ${ }^{296}$. Und noch im Februar 1926 wurden Straßenbauarbeiten zwischen Annual und Souk el Sabt begonnen. Die Qualität dieses Netzwerks an Straßen genügte keinem europäischen Standard. Es handelte sich vielfach um ausgebesserte Pfade oder Wege ${ }^{297}$. Allerdings, Abdelkrim war nicht nur der erste, der das Wegenetz im Rif ausbauen ließ, sondern er legte den Grundstein für das noch heute gültige StraBensystem in diesem Gebiet.

Ein anderes Aufgabenfeld für Deserteure war die Ausbildung der Rifarmee. Schon vor den ersten Siegen von Annual und Jebel Aroui im Jahre 1921 stellte Abdelkrim mit dem Schweizer Albert Huber und dem Deutschen "Wilhelm» die ersten europäischen Deserteure ein, die seine Leute militärisch weiterbilden sollten. Sie formierten eine Schützentruppe von $50 \mathrm{Mann}$, die sie während der folgenden Kämpfe anführten ${ }^{298}$. MG-Kompanien und Artillerieabteilungen sollten zukünftig die wesentlichen Tätigkeitsfelder europäischer - vor allem deutscher - Überläufer sein. "Die Bedienung der Geschütze und Maschinengewehre geschieht meistens durch Deutsche«, berichtete der deutsche Deserteur Alois Fleischer ${ }^{299}$.

In diesen Bereichen kannten sich die Rifkämpfer weniger bis gar nicht aus. Dieses Problem bestand für Abdelkrim über die Jahre hinweg weiter. Im April 1923 forderte sein Bruder Si M'hammed in Zusammenhang mit einem Wirtschaftsvertrag mit dem Engländer Charles Gardiner insgesamt 26 Ausbilder für seine Artillerie $a^{300}$. Noch im Sommer 1925 bestätigte ein Offizier Abdel-

${ }^{295}$ PA-AA Madrid 138: Konsulat Tetuan an Botschaft Madrid, 4.7.1927.

${ }^{206}$ BONNET-DEVILLIERS, La Guerre du Rif, S. 66, S. 69; Abd el Krims Kampfvorbereitungen, in: Kölnische Zeitung, 5.11.1925; Alfredo MOREA, La guerra marochina vista dal campo di Abd-el-Krim, in: Vocce repubblicana, 4.11.1925.

${ }^{297}$ PENNELL, A Country, S. 141, S. 202.

${ }^{298}$ HUBER, Als Fremdenlegionär, S. 45-53.

${ }^{299}$ PA-AA R71927: Regierungspräsident Düsseldorf an AA, 29.12.1925 mit Bezug auf eine Aussage von Alois Fleischer.

${ }^{300}$ ADMAE Maroc 111, 25: Vertrag zwischen Rifregienung und Charles Gardiner, 30.4.1923 (englische Übersetzung); KHARCHICH, La France, S. 454f. 
krims dem Sonderberichterstatter der Zeitung »Euvre«, daß es sehr schwierig sei, genügend Leute zu finden, die das zur Verfügung stehende Material bedienen könnten ${ }^{301}$.

Die Riftruppen hatten 1921 bis 1924 einige hundert Hotchkiss-MGs von den Spaniern erbeutet ${ }^{302}$. Allein im Frühjahr 1925 kamen 200 Beute-MGs von den Franzosen hinzu ${ }^{303}$. Zunächst kümmerte sich der Südmarokkaner Caïd Mohammed Bouhout um die Ausbildung an den Waffen ${ }^{304}$. Im Zuge der Organisation einer regulären Rifarmee (1923-1924) übernahm Si Ahmed el Soussi das Kommando über die MG-Abteilung ${ }^{305}$. Mindestens 20 Deserteure - zumeist Deutsche - wurden vom Sommer 1924 bis zum Frühjahr 1925 als MGSchützen engagiert ${ }^{306}$. Ein Deutscher war später der neue Kommandant der MG-Kompanie ${ }^{307}$. Kurt Degenkolbe berichtete, daß Abdelkrim deutsche Deserteure im Mai 1924 gezielt gefragt habe, ob sie mit Maschinengewehren umgehen könnten. Sie dienten ihm ein Jahr lang als MG-Schützen ${ }^{308}$. Einer dieser Deutschen war Martin Reinhold, ein Deserteur aus der französischen Fremdenlegion. Er wurde zusammen mit den anderen im September 1924 bei der Eroberung von Chichaouen eingesetzt. Den Winter verbrachten sie mit der Reparatur beschädigter Maschinengewehre ${ }^{309}$.

Ein Deserteur aus der französischen Armee befehligte im Sommer 1925 die MG-Abteilungen in Chichaouen. Es handelte sich um den Franzosen Durand alias Caïd Saïd, einen Deserteur aus dem Bataillon d'Afrique, der genauso wie sein Kamerad Louis Bourhis von 1924 bis 1925 für Abdelkrim als MG-Schütze kämpfte ${ }^{310}$. Vier Deutsche hielten sich im Januar 1925 bei der MG-Truppe

${ }^{301}$ Die Kämpfe in Marokko, in: Kölnische Zeitung, 8.6.1925.

${ }^{302}$ WOOLMAN, Rebels in the Rif, S. 153.

${ }^{303}$ PORCH, Foreign Legion, S. 399.

${ }^{304}$ SHAT 12J3797, 28: Vernehmung von Josef Klems vor dem 2. Kriegsgericht Meknes, 19.6.1926.

${ }^{305}$ FLEMING, Primo de Rivera and Abd-el-Krim, S. 224.

${ }^{306}$ SHAT 3H1 103: Contrôle civil de Taourirt, Bulletin de renseignements, 28.4.1925; CADN Maroc DAI 191: Bericht »Renseignements Gabrielli sur le Riff, Renseignements d'ordre militaire«, 19.9.1925; PORCH, Foreign Legion, S. 395f.; SHEEAN, My Meeting, S. 848; BONNET-DEVILLIERS, La Guerre du Rif, S. 59.

${ }^{307}$ ABDELKRIM, Memoiren, S. 96.

${ }^{308}$ CADN Tanger C39: Tabor de police $N^{\circ} 1$, Bericht »Déclarations de Degenkalb Kurt«, 15.7.1925.

${ }^{309}$ SHAT 3H1154: Bericht "Procès-verbal d'interrogatoire de l'ex-légionnaire Martin Reinhold surnommé Alik, 24.10.1925; PRO-FO 174, 303, 74: Vice Consul of Fez an CG Rabat, 27.11.1924 mit Bezug auf einen Rif-Informanten.

${ }^{310}$ SHAT 3H1557: Territoire de Taza, Cercle de Guercif, SR, Bericht »Renseignements fournis sur le Riff «, 8.2.1925; SHAT 3H1558: Commandant du cercle de Guercif an Commandant le territoire de Taza, 6.5.1925; SHAT 3H102: EMA, $2^{\mathrm{e}}$ bureau, Bericht »Renseignements divers - Marock, 3.9.1925; CADN Tanger C37: EMA, $2^{\mathrm{C}}$ bureau, Note, 13.8.1925; CADN Tanger C38: Tabor de police $\mathrm{N}^{\circ} 1$, Note, 23.10.1925. 
in der Nähe von Kiffane auf ${ }^{31}$. Richard Sablotny aus der spanischen Fremdenlegion bediente Ende 1924 in den Verteidigungsstellungen um Ajdir für kurze Zeit ein Maschinengewehr. Die dort stationierten Rifsoldaten erzählten ihm, ihre Ausbildung von europäischen Überläufern erhalten zu haben ${ }^{312}$.

Im Frühjahr 1925 stießen mindestens zwölf deutsche Deserteure neu zur MG-Abteilung hinzu. Ein Ungar, der im Rif Abdullah genannt wurde, wies sie den MG-Kompanien $\mathrm{zu}^{313}$. Im Laufe des Jahres erhöhte sich die Zahl durch weitere deutsche Überläufer aus der spanischen Fremdenlegion ${ }^{314}$. Alois Fleischer war einer von ihnen. Nach seiner Desertion am 10. Mai 1925 kämpfte er zunächst im Zuge der Offensive gegen Französisch-Marokko vier Monate gegen französische Truppen, dann anderthalb Monate gegen die Spanier. Heinrich Hoffmann und Peter »Kruschtn« kämpften 1925 sieben Monate lang als MG-Schützen ${ }^{315}$.

Deutsche wurden vor allem direkt vor Ajdir zum Schutz der Bucht von Alhucemas an Maschinengewehren eingesetzt ${ }^{316}$. Der Deutsche Fritz Weinard und der Amerikaner Wesley Williams - beide aus der französischen Fremdenlegion - richteten von August bis Oktober 1925 unter der Leitung des Deutschen Karl Ohme alias Caïd Abdeslem an der Mittelmeerküste Blockhäuser für MG-Stellungen ein ${ }^{317}$. 100 französische Gefangene mußten ihnen dabei helfen. Als Ajdir nach der Landung der Spanier bedroht wurde, half Weinard Anfang Oktober 1925, Kanonen und Maschinengewehre etwa 25 Kilometer weit ins Hinterland zu schaffen ${ }^{318}$. Die deutschen Verteidiger der Bucht brachten den Spaniern mit ihren MGs hohe Verluste bei. Karl Schneider, ein Deserteur aus der spanischen Fremdenlegion, wurde deshalb nach seiner Gefangennahme am 7. November 1925 von spanischen Einheiten erschossen ${ }^{319}$.

${ }^{311}$ SHEEAN, My Meeting, S. 848.

${ }^{312}$ SABLOTNY, Légionnaire, S. 270.

${ }^{313}$ CADN Tanger C39: Tabor de police $\mathrm{N}^{\circ}$ 1, Bericht "Déclarations de Degenkalb Kurt«, 15.7.1925.

${ }^{314}$ DeGEnKolbE, Vom Schusterjungen, S. 109f.; MEYER, Dreitausend Kilometer, S. 129; Les Allemands au camp riffain, in: Écho du Maroc, 28.7.1925.

${ }^{315}$ PA-AA R71927: Regierungspräsident Düsseldorf an AA, 29.12.1925 mit Bezug auf Aussagen von Alois Fleischer und Heinrich Hoffmann; CADN Tanger C38: Tabor de police $\mathrm{N}^{\circ} 1$, Note, 23.10.1925.

${ }^{316}$ CADN Maroc DAI 188: Tabor de police $\mathrm{N}^{\circ} 1$, Note, 16.1.1925 mit Bezug auf Aussagen des spanischen Deserteurs Enrique Larrea Gonzalez.

${ }^{317}$ ADMAE Maroc 100, 101: Bericht »Interrogatoire d'un déserteur de la légion française, de retour de chez les Riffains«, 30.10.1925; Les Allemands Ohme, ex-caïd Abdeslem, et Koberstein, poursuivi pour désertion, sont condamnés à vingt ans de travaux forcés, in: Écho du Maroc, 4.2.1927. Siehe zu Ohme auch Kapitel 3, S. 87f.

${ }^{318}$ CADN Maroc DAI 192: Tabor de police $\mathrm{N}^{\circ} 1$ Tanger an DAI Rabat, 2.11 .1925 mit Bezug auf ein Verhör von Fritz Weinard, 30.10.1925; SHEEAN, Abd el Krims europäische Helfer, 10.11.1925; DERS., Personal History, S. 160.

${ }^{319}$ PA-AA R71927: Konsulat Tetuan an Botschaft Madrid, 13.4.1926. 
Unterricht erhielten die Rifkabylen auch im Handgranatenwerfen. Walter Meyer beobachtete dabei im Hauptquartier des Rifs einen ungarischen Deserteur aus der französischen Fremdenlegion ${ }^{320}$. Die Handgranaten bastelten sich die Rifkabylen in der Regel aus nicht explodierten Fliegerbomben. In Tamasint existierte eine Werkstatt unter der Leitung von M'Alem Temsamani. Im Rif lebende jüdische Goldschmiede stellten sich auf die Erzeugung von Granaten um. Der Sprengstoff einer 200-Kilogramm-Bombe ergab etwa 450 bis 470 Handgranaten, die aus spanischen Sardinendosen gefertigt wurden ${ }^{321}$. 1480 dieser einheimischen Handgranaten stellten die spanischen Truppen nach dem Rifkrieg sicher ${ }^{322}$.

Europäische Überläufer wiesen die Rifkabylen ebenso in das Ausheben von Schützengräben und Unterständen ein. Franzosen erinnerte das Grabensystem an den den deutschen Gegner im Ersten Weltkrieg ${ }^{323}$. Larry Rue, ein amerikanischer Journalist, der im Juni 1925 das Rif besuchte, staunte über das gut getarnte System von Unterständen, die über das gesamte Rif verteilt waren. $\mathrm{Zu}$ meist sollen Deutsche die Anweisungen zu deren Bau erteilt haben ${ }^{324}$. Ein Finne namens Klayno leitete Gefangene an der französischen Front im Sektor Bibane an, Schützengräben auszuheben ${ }^{325}$. Auch indigene Deserteure aus den französischen und spanischen Protektoratsarmeen kannten sich mit diesen Defensivtechniken aus ${ }^{326}$.

Die reguläre Rifarmee, deren Hauptkontingent stets in Targuist und Ajdir stationiert war, wurde - wie der amerikanische Journalist Vincent Sheean beobachtete - von deutschen Überläufern im Drill unterwiesen ${ }^{327}$. Die deutschen Offiziere Hauptmann Grauert und Leutnant Jeschonnek, die sich von April bis Juni 1925 im Zuge der deutschen Giftgaslieferungen vor Ort über Spaniens Marokkoarmee informierten, berichteten über Abdelkrims Hauptquartier: »In seinem Lager halten sich Offiziere aller Nationen auf, die das prachtvolle

\footnotetext{
${ }^{320}$ MEYER, Dreitausend Kilometer, S. 123f.

${ }^{321}$ ABDELKRIM, Memoiren, S. 95f.; Ina GARDINER, How Abd-el-Krim Rules the Riffians, in: Illustrated Sunday Herald, 16.8.1925; Der Riffkrieg und die Juden Marokkos, in: Leipziger Jüdische Zeitung 4 (1925) H. 30, S. 1f.; KHARCHICH, La France, S. 110; WOOLMAN, Rebels in the Rif, S. 153; DaOUD, Abdelkrim, S. 157; PENNELL, A Country, S. 151; LANGLET, Abdel Krim's Views, 29.4.1926; Auszug aus dem geheimen Bericht, S. 206; MOWRER, Une visite, S. 1522f.; DERS., The House of Europe, S. 468f.

322 ESPAÑA, La actuación, S. 364.

${ }^{323}$ BONNET-DEVILLIERS, La Guerre du Rif, S. 64; LEGEY, Ce que j'ai vu, S. 22.

${ }^{324}$ RuE, News, S. 270. Vgl. GABRIELLI, Abd-el-Krim, S. 51; MOWRER, The House of Europe, S. 469; HARRIS, Better Outlook, 7.6.1926; SABLOTNY, Légionnaire, S. 271.

${ }^{325}$ CADN Tanger C37: Région de Fè, SR, Renseignements, 24.9.1925.

${ }^{326}$ WOOLMAN, Rebels in the Rif, S. $153 \mathrm{f}$.

${ }^{327}$ SHEEAN, My Meeting, S. 848; DeRS., An American, S. 230. Vgl. LA GARDE, The Moroccan War, 15.9.1923; SABLOTNY, Légionnaire, S. 270; RUE, News, S. 286; MOWRER, The House of Europe, S. 474; WOOLMAN, Rebels in the Rif, S. 151; BALFOUR, Deadly Embrace, S. 360 .
} 
ihnen zur Verfügung stehende Menschenmaterial für die moderne Kampfführung schulen und regelrechte Felddienstübungen abhalten. Zahlreiche Überläufer sowohl der spanischen wie der französischen Fremdenlegion dienen ihm als willkommenes Lehrpersonal ${ }^{328}$.

Die Artilleristen der Rifarmee waren ebenfalls häufig Deutsche. In den Jahren 1921 und 1922 waren die Rifkabylen oft nicht in der Lage, die von den Spaniern erbeuteten Kanonen zu bedienen ${ }^{329}$. Zunächst übernahmen indigene Deserteure wie Bomoz, Caïd Mohammed Bouhout, el Matali, el Mufaddal oder der Tunesier Ben Nacer el Djaïdi die Leitung der Rif-Artillerie ${ }^{330}$. Ein Deserteur aus der französischen Fremdenlegion namens Listani führte die Artillerie beim Angriff auf Igheriben im Juli $1921 \mathrm{an}^{331}$. Etwa eine Handvoll deutscher Überläufer aus der französischen Fremdenlegion bedienten 1921 Geschütze beim Beschuß der spanischen Festung in der Bucht von Alhucemas oder im Zuge der Gefechte nach dem Sieg Abdelkrims bei Annual ${ }^{332}$. Gefangene spanische Offiziere wurden getötet, weil sie sich geweigert hatten, Rifkabylen an den erbeuteten Kanonen auszubilden ${ }^{333}$.

1922 leistete der Schweizer Albert Huber Instruktionsdienste ${ }^{334}$. Der größte Erfolg der Artilleristen war lange Zeit die Versenkung des spanischen Postdampfers »Juan de Juanes« in der Bucht von Alhucemas (19. März 1922) ${ }^{335}$. Der französische Journalist Jean du Taillis beobachtete am 1. April 1922 eine Artillerieeinheit bei Dar Driouch, die unter dem Kommando von Mohammed Barnoussi stand: »Der Anführer der Artillerie war ein alter Bekannter von mir, ein früherer Leutnant im Militär von Sultan Abdelaziz, der als der >Mann mit der siegreichen Kanone bekannt war ${ }^{336}$.

${ }^{328}$ Auszug aus dem geheimen Bericht, S. 205f.

${ }^{329}$ MERCER, Legion, S. 235; KHARCHICH, La France, S. 109.

${ }^{330}$ SHAT 12J3797, 28: Vemehmung von Josef Klems vor dem 2. Kriegsgericht in Meknes, 19.6.1926; ADMAE Maroc 194, 216: CG Tanger an MAE, 8.7.1922; PENNELL, La guerra del Rif, S. 186f.; GODED LLOPIS, Marruecos, S. 98; CAMPOS MARTÍNEZ, Abd-el-Krim, S. 223; FURNEAUX, Abdel Krim, S. 115.

${ }^{331}$ LA PORTE, La atracción del imán, S. 112, Anm. 78.

332 PRO-FO 371, 7067, 184, 228: CG Tangier an FO, 27.6.1921; PRO-FO 371, 7067, 184, 229: Consul of Tetuan an CG Tangier, 21.6.1921; PRO-FO 371, 7067, 184, 13: CG Tangier an FO, 26.7.1921; Daniel BOURMANCÉ-SAY, La population de Melilla massacre les musulmans, in: Écho de Paris, 30.7.1921.

${ }^{333}$ Henri de KERILLIS, A Prisoner of the Moors, in: The Living Age 317 (1923) S. 398-401, S. 399.

${ }^{334}$ HUBER, Als Fremdenlegionär, S. 68.

${ }^{335}$ ÁlVAREZ, The Betrothed of Death 2001, S. 97, Anm. 13; WoOLMAN, Rebels in the Rif, S. 105; KeERNER, La Guerre du Rif espagnole, S. 145; LA PORTE, La atracción del imán, S. 113; CAMPOS MARTINEZ, Abd-el-Krim, S. 131 f;; MOWRER, The House of Europe, S. 467; OTEYZA, Abd-el-Krim, S. 137.

${ }^{336}$ Du TAlLLIS, Behind the Moorish Lines, S. 166. 
Erst 1923 bildete sich eine reine Artillerie-Einheit, als ein serbischer Deserteur aus der spanischen Fremdenlegion deren Kommando übernahm. Sein wahrer Name ist nicht bekannt. Im ganzen Rif wurde er als Abdallah Serbiano bzw. als »der serbische Hauptmann« (El Capitán Serbiano) berühmt ${ }^{337}$. Dem Oberkommandierenden der Rifarmee Si M'hammed diente er als Militärberater $^{338}$. In Azghar wies er die Rifkabylen zusammen mit sechs Deutschen in die Bedienung der erbeuteten Kanonen und Maschinengewehre ein ${ }^{339}$. Er fotografierte spanische Posten und Kasernen, fertigte Karten der spanischen Linien bei Chichaouen an und konzipierte Angriffspläne. Bei Ajdir richtete er eine Luftabwehrstellung ein und schoß sogar spanische Flugzeuge $a^{340}$. Ein englischer Besucher des Rifs, John Bevan, war im Sommer 1923 sehr angetan von den Schußleistungen der von Abdallah Serbiano ausgebildeten Rifartillerie ${ }^{341}$.

Als am 17. August 1923 Tifarauin, das Abdelkrim gern in ein zweites Annual verwandeln wollte, von 9000 Rifkämpfern angegriffen wurde, beteiligte sich auch die neue Artillerieeinheit. Der Angriff schlug fehl, weil die spanische Luftwaffe den seltenen Fall einer Truppenkonzentration der Rifkabylen ausnutzte und ein Blutbad anrichtete ${ }^{342}$. Anfang Oktober 1923 tüftelte Abdallah Serbiano eine Möglichkeit aus, den spanischen Posten Tizi Azza zu erobern. Ein unterirdischer Graben sollte bis unter das Lager gezogen werden, um dort eine Sprengladung zu zünden. Der Plan wurde jedoch aufgedeckt. Abdallah Serbianos neuer Auftrag war, die Verteidigung der Bucht von Alhucemas vorzubereiten. Abdelkrim hatte in spanischen Zeitungen von den Plänen einer eventuellen Landung spanischer Truppen gelesen. Sein serbischer Gehilfe ließ Schützengräben ziehen und Stellungen für Maschinengewehre sowie für 50 Geschütze anlegen ${ }^{343}$.

Der Algerienfranzose Dr. Yves Marion-Gallois, der im November 1923 zusammen mit der Hebamme Mlle Ponzo Abdelkrims Schwester behandelte, traf in Ajdir auf Abdallah Serbiano, der bei ihm den Eindruck erweckte, der Chef des Rif-Generalstabes zu $\operatorname{sein}^{344}$. Dies war übertrieben, aber die Einschätzung

${ }^{337}$ In der Literatur wird Abdallah Serbiano nur beiläufig erwähnt [WOOLMAN, Rebels in the Rif, S. 151; PENNELL, A Country, S. 131; HART, The Aith Waryaghar, S. 387; FURNEAUX, Abdel Krim, S. 86; GODED LLOPIS, Marruecos, S. 98].

${ }^{338}$ CADN Berlin B497: CG Tanger an MAE, 10.8.1923.

${ }^{339}$ HART, The Aith Waryaghar, S. 387.

${ }^{340}$ CADN Maroc DAI 198: Bericht „Déclarations de Si el Hassan el Kadiri«, 26.6.1926; LANGLET, How the Riffis Fight, 4.5.1926.

${ }_{341}$ PRO-FO 371, 9470, 44, 29: CG Tangier an FO, 2.9.1923.

342 ÁlvareZ, The Betrothed of Death 2001, S. 107f., Anm. 63.

${ }^{343}$ SHAT 3H1159: Commissariat de la sûreté régionale Oujda, Renseignement, 15.10.1923 und 22.10.1923; CADN Maroc DAI 187: RG Rabat an MAE, 22.12.1923; MOWRER, Une visite, S. 1524.

${ }^{344}$ SHAT 3H1559: Région de Taza, Poste d'Hassi Ouenzga, SR, Bericht »Feuille de Renseignements sur le Riff (d'après les impressions de voyage du docteur Marion-Gallois)«, 4.12.1923. 
des Arztes zeigt, daß der Einfluß des serbischen Überläufers im Rif groß gewesen sein muß. Dies bestätigen die Aussagen anderer Augenzeugen wie etwa von Abdelkrims Sekretär Si el Hassan el Kadiri. Am Anfang des Sommers 1924 wurde der Kommandeur der Rif-Artillerie während eines spanischen Luftangriffes auf Ajdir getötet ${ }^{345}$. Für kurze Zeit wurde Hans Ebeling, ein deutscher Deserteur aus der spanischen Fremdenlegion, wegen seiner Artillerie-Erfahrung aus dem Ersten Weltkrieg als Waffeninstrukteur eingesetzt. Ihm standen ein weiterer Deserteur und der Deutsche Walter Hensel zur Seite ${ }^{346}$.

\subsection{Abdelkrims Militärberater Josef Klems alias Caïd el Haj alemán}

Abdallah Serbianos Nachfolger wurde der Deutsche Josef Klems ${ }^{347}$, der als Caïd el Haj alemán zum bedeutendsten Militärberater Abdelkrims avancier$\mathrm{te}^{348}$ und eine wesentliche Rolle als Artilleriechef sowie als Anführer einer rein aus Überläufern bestehenden Einheit innerhalb der Rifarmee einnahm ${ }^{349}$.

${ }^{345}$ CADN Maroc DAI 198: Bericht "Déclarations de Si el Hassan el Kadiri«, 26.6.1926 (Mai oder Juni 1924); CADN Tanger C40: Tabor de police $N^{\circ} 1$, Bericht »Renseignements donnés par Abdelkrim el Hadj Ali el Bokkoyi«, 5.3.1926; GODED LLOPIS, Marruecos, S. 98; HARRIS, Better Outlook, 7.6.1926; WoOLMAN, Rebels in the Rif, S. 151; PENNELL, A Country, S. 132.

${ }^{346}$ SABLOTNY, Légionnaire, S. 268f.

${ }^{347}$ Klems' Name wird in der Literatur gelegentlich falsch wiedergegeben: z.B. "Otto Klems" [John LafFIN, The French Foreign Legion, London 1974, S. 101, Alexander MILES, Devil's Island. Colony of the Damned, Berkeley 1988, S. 179]; »Peter Klems « [Michel PIERRE, La terre de la grande punition. Histoire des bagnes de Guyane, Paris 1982, S. 291; René BeLBENOîT, Dry Guillotine. Fifteen Years among the Living Dead, Maidstone 1973 (Nachdr. d. Ausg. New York 1938), S. 152]; »Klemps« [ABDELKRIM, Memoiren, S. 96; GODED LLOPIS, Marruecos, S. 88; OVED, La gauche française, Bd. 1, S. 293]; »Rüdiger Klems« [Peter HORNUNG, Die Legion. Europas letzte Söldner, München 1981, S. 184 (seine Angaben über Klems entbehren jeder Grundlage und werden hier nicht berücksichtigt)]; $\gg$ Joseph Klemms “ [Fleming, Primo de Rivera and Abd-el-Krim, S. 225; HART, The Aith Waryaghar, S. 387; WOOLMAN, Rebels in the Rif, S. 151]; wKlem» [LADREIT DE LACHARRIËRE, Le rêve, S. 446].

${ }^{348}$ FLEMING, Primo de Rivera and Abd-el-Krim, S. 225; LE GuILLERME, CH. »402«, S. 199; George WARD PRICE, In Morocco with the Legion, London 1934, S. 245; SABLOTNY, Légionnaire, S. 268; GODED LLOPIS, Marruecos, S. 88; Tony GERAGHTY, La Légion. »Marche ou crève«, Paris 1988, S. 158; CRÉMADEILLS, Le Parti communiste français, Bd. 1, S. 210; Pierre MOnTagnoN, Histoire de la Légion de 1931 à nos jours, Paris 1999, S. 195; MiCHELS, Deutsche in der Fremdenlegion, S. 83.

${ }^{349}$ Philippe BRUSSAC, La Légion étrangère, Paris 1955 (Les grandes réussites françaises, 4), S. 104; MERCER, Legion, S. 234. Zu Unrecht minimieren Rupert Furneaux und David Woolman Klems' Rolle im Rif auf Handlangerdienste [FURNEAUX, Abdel Krim, S. 86; WOOLMAN, Rebels in the Rif, S. 184; VAIDON (d.i. Woolman), Tangier, S. 198]. 
Seine Geschichte verdient deshalb etwas mehr Beachtung. Zudem ist sein Leben in der bisherigen Literatur nie eingehender erforscht worden. Nicht nur im Rif avancierte Klems zu einer legendären Figur, über die Gedichte und Lieder geschrieben wurden ${ }^{350}$. Auch in der französischen Fremdenlegion, aus der er desertierte, gilt er bis heute als der berühmteste Deserteur ${ }^{351}$. Zeitgenossen feierten ihn als $»$ Robin Hood ${ }^{352}$ oder als $»$ Scharnhorst des Rifs ${ }^{353}$. Für spätere Bewunderer war er ein deutscher "Lawrence von Arabien ${ }^{354}$. Paul Christopher Wren schrieb über Klems' Leben die Kurzgeschichte »Odo Klemmens ${ }^{355}$. Paolo Zappa fertigte einen ganzen Roman (»Il sergente Klems $«$ ) an, der 1971 mit Peter Strauss in der Titelrolle verfilmt wurde ${ }^{356}$. In Sigmund Rombergs Musicalerfolg "The Desert Song« von 1927 basierte die Hauptfigur "Red Shadow « auf der Lebensgeschichte von Josef Klems ${ }^{337}$.

Josef Franz Klems wurde am 25. April 1893 in Düsseldorf geboren. Er wuchs in kleinen Verhältnissen auf und arbeitete als Kutscher und Rechtsanwaltsgehilfe. Wegen Diebstahl und Unterschlagung wurde er 1911 und 1912 zweimal von den Strafkammern Düsseldorf und Köln zu mehrmonatigen Haftstrafen verurteilt. Im Oktober 1913 trat er als Musketier in das deutsche Heer ein (12. Kompanie des Infanterie-Regiments 98 in der 33. Division), aus der er acht Monate später im Juni 1914 desertierte $^{358}$. Am 12. Juni 1914 tauchte

${ }^{350}$ Hugh MCLEave, The Damned Die Hard. The Story of the French Foreign Legion, Farnborough 1974, S. 170; LANG, Die Darstellung Abd el-Krims, S. 68; SHEEAN, »Robin Hood", S. 969f.; DERS., An American, S. 226f.; MEYER, Dreitausend Kilometer, S. 104; SABLOTNY, Légionnaire, S. 268.

${ }_{351}$ PORCH, Foreign Legion, S. 396; GeRAGHTY, La Légion, S. 157; PENNELL, A Country, S. 132; MaNue, La fin, 21.2.1930; Pietre MAC ORLAN, La Légion etrangetre, Paris 1933, S. 98.

${ }^{352}$ SheEAN, Personal History, S. 117; DerS., An American, S. 226.

${ }^{353}$ MOWRER, The House of Europe, S. 483.

${ }^{334}$ PIERRE, La terre, S. 292; MLES, Devil's Island, S. 179.

${ }^{355}$ Fleming, Primo de Rivera and Abd-el-Krim, S. 225; Woolman, Rebels in the Rif, S. 151.

${ }^{356}$ Paolo ZAPPA, Il sergente Klems, Mailand 1941; Spielfilm »Il sergente Klems« (dt. "Marschbefehl zur Hölle«), Italien 1971, Regie: Sergio Grieco. Sowohl Buch als auch Film sind nicht nur von mangelnder Qualität, sondern haben auch mit dem historischen Josef Klems nicht viel gemein.

${ }^{337}$ ShEEAN, Personal History, S. 119, Anm. 5; FuRNEAUX, Abdel Krim, S. 143f.; McLEAVE, The Damned, S. 172; VAIDON, Tangier, S. 198; LAFFIN, Foreign Legion, S. 104; GERAGHTY, La Légion, S. 161; Roy C. ANDERSON, Devils, Not Men. The History of the French Foreign Legion, London 1987, S. 63; WOOLMAN, Rebels in the Rif, S. 151; FLEMING, Primo de Rivera and Abd-el-Krim, S. 225.

${ }^{358}$ PA-AA R70857: Preußisches Innenministerium an AA, 12.10.1926; PA-AA R70871: Preußisches Justizministerium an AA, 15.12.1930; PA-AA R70871: Reichsarchiv Potsdam an AA, 13.12.1930 mit Bezug auf die Truppenstammrolle von Josef Klems. Dem amerikanischen Journalisten Vincent Sheean erzählte Klems später die erfundene Geschichte, er sei mit einer ungarischen Tänzerin nach Paris durchgebrannt. Daraufhin sei er als Teppichverkäufer in den Orient aufgebrochen [SHEEAN, An American, S. 256f.]. 
Klems in der Militär-Unterintendantur von Verdun auf und trat der französischen Fremdenlegion bei. Er erhielt die Matrikelnummer $9073^{359}$. Klems wurde der Compagnie montée des 2. Fremdenregiments zugeteilt. Den Ersten Weltkrieg verbrachte er zunächst in Algerien, dann ab dem 10. Juli $1916 \mathrm{im}$ Raum Meknes in Marokko. Am 3. Februar 1920 verlängerte Klems seine Dienstzeit um weitere fünf Jahre, und am 1. Januar 1922 wurde er zum Unteroffizier befördert ${ }^{360}$. Sein Vorgesetzter Capitaine Cattin berichtete über Klems, daß sein Dienst nie zu beanstanden gewesen sei, aber er beschrieb ihn auch als extrem reizbar, mißtrauisch und selbstgefallig ${ }^{361}$.

Klems war nicht der deutsche Super-Soldat, wie er in der Literatur bisweilen dargestellt wird $^{362}$. Er war seit 1917 eine Art Geschäftsführer, Quartiermacher und Kantinenchef, der für die Küche Nachschub besorgte. Wegen falscher Abrechnungen wurde der Deutsche am 4. März 1922 zum Gefreiten degradiert und zur 6. Kompanie des 2. Fremdenregiments nach Missour versetzt. Doch wegen guter Führung wurde Klems schon am 11. August 1922 wieder zur Beförderung vorgeschlagen ${ }^{363}$.

Im Sommer 1922 erhielt der Deutsche die Nachricht, daß einer seiner Brüder in der Heimat wegen antifranzösischer Propaganda verurteilt worden war $^{364}$. Er war so aufgebracht, daß er Anordnungen eines Vorgesetzten, in der Offiziersmesse Schaufelarbeiten zu verrichten, nicht befolgte. Sein Kompaniechef beschränkte die Bestrafung auf einige Tage Stubenarrest, da er Klems wieder als Unteroffizier einsetzen wollte. Doch dieser fühlte sich schikaniert und desertierte am 24. August 1922 mit einem Gewehr und zahlreicher Munition. Als Grund für seine Flucht gab er später einen Trübsinnsanfall (coup de

${ }^{359}$ SHAT 12J3797, 43: Bericht Notice sur le nommé Joseph Klems, déserteur du $2^{e}$ régiment étranger et sur son rôle dans les rangs des nos ennemisu, 5.12.1926.

${ }^{360}$ SHAT 12J3797, 19: Bericht „État signalétique et de services d'un homme de troupe: Klems, Joseph« o.D.; Georges BLOND, Histoire de la Légion étrangère 1831-1981, Paris 1981, S. 204; GERAGHTY, La Légion, S. 157.

${ }^{361}$ SHAT 12J3797, 37: Région de Fès, Territoire de Midelt, Cercle de Missour, Bericht „Compte rendu Capitaine Cattin«, 4.12.1924.

${ }^{362}$ Z.B. Geraghty, La Légion, S. 157; MCLeave, The Damned, S. 169; Ward Price, In Morocco, S. 246.

${ }^{363}$ SHAT 12J3797: Bericht »Rapport sur l'affaire du caporal Klems Joseph«, 23.12.1926; SHAT 12J3797, 19: Bericht "État signalétique et de services d'un homme de troupe: Klems, Joseph« o.D.; TERRIER, Les "Frères de la côte« 1926, S. 306, Anm. 1; MANUE, La fin, 21.2.1930; MAC ORLAN, La Légion, S. 96; MOWRER, The House of Europe, S. 480; WoOLMAN, Rebels in the Rif, S. 152.

364 SHAT 12J3797, 83: Région de Taza, Cercle d'Outat, SR, Bericht "Compte rendu du Colonel Martin«, 1.10.1922; MCLEAVE, The Damned, S. 170. Im Mai 1924 unterschrieb Klems einen Brief an einen scheinbar desertionswilligen Deutschen mit: „Ein Deutscher, der seinen Vater und Bruder rächt« [SHAT 12J3797, 38: Desertionsaufruf von Josef Klems aus Tamghilt o.D. (Mai 1924)]. 
cafard) an, die übliche Begründung von Deserteuren der französischen Fremdenlegion. Klems wollte ursprünglich versuchen, über Melilla oder Tanger nach Deutschland zurückzukehren ${ }^{365}$.

Nordwestlich von Missour wurde der Flüchtling von den Aït Baza, einer Teilfraktion der Aït Seghrouchen, gefangengenommen. Dem Tod entkam er nur durch die Intervention von Moulay M'hammed, dem Anführer der Aït Seghrouchen. Dieser erkannte den Nutzen eines Deserteurs aus der feindlichen französischen Fremdenlegion und wies Klems an, seinem Sohn Moulay Ali zu dienen. Als Beweis für seine Treue drang der Deutsche in der Nacht vom 17. auf den 18. September 1922 in seinen alten Posten bei Missour ein und entwendete vier Gewehre. Etwa sechs Monate hielt sich Klems bei den Aït Seghrouchen auf, doch als sich Moulay Ali dem französischen Militär unterwerfen mußte, floh er im Frühjahr $1923 \mathrm{zu}$ den benachbarten Marmoucha und Beni Ouaraïn in der Gegend von Taza. Ihn begleiteten dabei zwei weitere Deserteure aus der französischen Fremdenlegion. Mehrere Monate lebte Klems bei den Ait Ali Ou Zekri, einer Teilfraktion der Aït Temana. Er reparierte ein erbeutetes Maschinengewehr und feuerte damit am 9. Juni 1923 bei Bou Khamouj auf ehemalige Kameraden seiner früheren Legions-Kompanie. Auch am Kampf von Aït Makhlouf nahm Klems teil. Mit seinen Begleitern Amar Ou Aqqa Ou Bouzehar und Mohand Ou Saìd Ou Berraho belauerte er den Posten von Tazouta. Nachts streifte er seine Legionärskleidung wieder über, schlich sich ins Lager und entwendete ein Gewehr. Wenig später stahl er eine ganze Rinderherde ${ }^{366}$.

Klems begann in der Folgezeit einen regelrechten »Privatkrieg gegen die Franzosen $\aleph^{367}$ und erlangte in der gesamten Fes-Taza-Region als El Haj alemán einen hohen Bekanntheitsgrad ${ }^{368}$. Doch der Druck der französischen Militäraktionen gegen die Bevölkerung des Atlasgebirges war zu groß. Nach der Schlacht von El Mers am 24. Juni 1923 stand die Unterwerfung der Marmou-

${ }^{365}$ SHAT 12J3797, 27: Vernehmung von Josef Klems vor dem 2. Kriegsgericht Meknes, 19.6.1927; SHAT 12J3797, 29: Vernehmung von Josef Klems vor dem 2. Kriegsgericht Meknes, 22.6.1927; SHAT 12J3797, 23: Vernehmung von Josef Klems vor dem 2. Kriegsgericht Meknes, 8.6.1927; SHAT 12J3797, 3: Bericht "Rapport du Capitain Boissenin«, 27.8.1922; MANUE, La fin, 21.2.1930; MAC ORLAN, La Légion, S. 96.

${ }^{366}$ SHAT 12J3797, 83: Région de Taza, Cercle d'Outat, SR, Bericht »Compte rendu du Colonel Martin«, 1.10.1922; SHAT 12J3797, 43: Bericht »Notice sur le nommé Joseph Klems«, 5.12.1926; SHAT 12J3797, 84: Région de Fes, Territoire de Midelt, Cercle de Missour, Affaires indigènes, Bureau des Marmoucha an Substitut commissaire rapporteur près de conseil de guerre, 1.10.1926; SHAT 12J3797: Bericht "Rapport sur l'affaire du caporal Klems Joseph «, 23.12.1926; SHAT 12J3797, 90: Befragung von Fqir Hamed ou Sissou und Taleb Mohand Ameziane, Ait Temana, 10.11.1926; PA-AA R70870: Botschaft Paris an AA, 21.6.1926 mit beiliegendem Bericht »Affaire Klems «.

${ }^{367}$ SHEEAN, Abd el Krims europäische Helfer, 10.11.1925.

${ }^{368}$ WoOLMAN, Rebels in the Rif, S. 152; MANUE, La fin, 21.2.1930. 
cha kurz bevor ${ }^{369}$. Ende 1923 mußte Klems erneut weiter nach Norden fliehen. Diesmal kam er bei den Aït Hassan Bou Kousan unter, einer Fraktion der Aït Youb, wo er als Gast von Taleb Hassan ben Hammou in Tamghilt lebte. Hier trat Klems zum Islam über und heiratete die junge Nichte von Taleb Hassan ${ }^{370}$.

Im Frühjahr 1924 startete er den Versuch, mit den Legionären des 2. Fremdenregiments in Verbindung zu treten und sie zur Desertion aufzufordern. Nachts näherte er sich französischen Posten und ließ beschriebene Papierfetzen zurück ${ }^{371}$. Leutnant Abadie, der Leiter des Nachrichtenbüros von Immouzzer, plante daraufhin, Klems eine Falle zu stellen. Unter dem Namen des wirklich existierenden Legionärs Göhring schrieb Abadie dem Deutschen, daß er desertieren wolle ${ }^{372}$. Ein Marokkaner überbrachte den Brief, und Klems reagierte sofort. "Bin riesig erfreut, noch einige Landsleute zu finden, die noch etwas Herz haben und [...] den Franzosen hassen wie ich «, schrieb Klems und forderte seinen angeblichen Landsmann auf, bei seiner Desertion so viele Gewehre wie möglich zu entwenden. Erstaunlich ist, daß Klems ebenfalls mitteilte: «Mit dem deutschen Consul in Melilla (Herm Ehrlich) stehe ich [...] in Verbindung und habe mehrere Légionnaire fortgeschaff, die heute in Deutschland oder Spanien leben [...]. Wenn du heute Nacht desertierst, bist du in 3 Tagen beim deutschen Consul an der Küste ${ }^{373}$.

Die Frage stellt sich, wie Klems dies behaupten konnte. Es gab kein deutsches Konsulat in Melilla, sondern lediglich in Tetuan, und der dortige Konsul hieß Wilhelm Bohn. Gab es andere Verbindungen nach Melilla, etwa deutsche Kaufleute, die ihm hätten helfen können? Und wie hătte Klems diese Verbindung herstellen sollen? Eine mögliche Erklärung könnte wie folgt aussehen. Zwischen der Region Taza und Melilla befand sich das Rif. Seit dem Sommer 1923 stand Klems mit dem Anführer der Rifkabylen Abdelkrim in Kontakt. Dieser hatte durch Waffenschmuggler, die auf den Märkten der Marmouchas und der Beni Ouarän für das Rif einkauften, von der Existenz des El Haj alemán Kenntnis erhalten. Im Juni und im Juli 1923 erhielt Klems zwei Briefe

${ }^{369}$ Réduction de la Tache de Taza, in: Écho de Paris, 26.4.1923; PA-AA R70636: Botschaft Paris an AA, 28.7.1923.

${ }^{370}$ SHAT 12J3797, 84: Région de Fès, Territoire de Midelt, Cercle de Missour, Affaires indigènes, Bureau des Marmoucha an Substitut commissaire rapporteur près de conseil de guerre, 1.10.1926; SHAT 12J3797: Bericht »Rapport sur l'affaire du caporal Klems Joseph«, 23.12.1926; SHAT 12J3797, 27: Vernehmung von Josef Klems vor dem 2. Kriegsgericht Meknes, 19.6.1927; SHAT 12J3797, 94: Befragung von Taleb Hassen ben Hamou, 18.11.1926; PA-AA R70870: Botschaft Paris an AA, 21.6.1926 mit beiliegendem Bericht "Affaire Klems«.

${ }^{371}$ SHAT 12J3797, 40: Territoire de Midelt, Cercle de Missour an Colonel commandant le territoire, 4.12.1924.

${ }^{372}$ SHAT 12J3797, 39: Lt. Abadie, Chef du bureau des renseignements des Marmoucha an Commandant le cercle, 24.5.1924.

${ }^{373}$ SHAT 12J3797, 38: Grammatikalisch verbesserter Desertionsaufruf von Josef Klems aus Tamghilt o.D. [Mai 1924]. 
von Abdelkrim. Es ist nur bekannt, daß er in ihnen eingeladen wurde, ins Rif zu kommen ${ }^{374}$. Sollte er 1924 weitere Deserteure mit sich führen oder zur Desertion anregen? In diesem Jahr begannen Abdelkrims Rekrutierungen von Überläufern aus den Protektoratsarmeen. $\mathrm{Zu}$ berücksichtigen ist auch, daß zwischen Abdelkrim und Frankreich zu dieser Zeit erste Unstimmigkeiten über den Status des fruchtbaren Ouergha-Tales bestanden. Dies hatte bereits zu bewaffneten Auseinandersetzungen geführt. Es ist daher denkbar, daß zwischen Klems und Abdelkrim eine Vereinbarung bestanden haben könnte, Legionäre abzuwerben.

Im Juni 1924 legte Leutnant Abadie dann den Hinterhalt für den deutschen Deserteur. Klems wurde benachrichtigt, am vereinbarten Treffpunkt desertierte Landsleute anzutreffen. Die auf ihn lauernden 20 bis 30 französischen Soldaten wurden ihrerseits vom vorgewarnten Klems und einem Dutzend Marokkanern überrascht. Nun fühlte er sich in der Region nicht mehr sicher. Ab August 1924 hörten die französischen Truppen nichts mehr von Klems in der Taza-Region. Er war noch im Juni - als unmittelbare Folge des Hinterhaltes - ins Rif aufgebrochen, wobei ihn vier bis fünf weitere deutsche sowie zwei französische Deserteure begleiteten. Mit Hilfe des Waffenschmugglers Mohand Ou Arab erreichte Klems etwa im Juli oder August 1924 die Hauptstadt der »Rif-Republik« Ajdir ${ }^{375}$. Das Kriegsgericht Taza verurteilte ihn daher am 2. Dezember 1924 in Abwesenheit zum Tode ${ }^{376}$.

Für keinen anderen Überläufer interessierte sich Abdelkrim so sehr wie für Klems. Der Deutsche hatte als Fremdenlegionär acht Jahre Kampferfahrung in Nordafrika, hinzu kam noch die zweijährige Unterstützung der >Dissidenten im Atlasgebirge ${ }^{377}$. Abdelkrim hoffte, daß Klems eine ähnliche Rolle im Rif spielen konnte wie Albert Bartels alias Si Hermann während des Ersten Weltkrieges. Bartels hatte an der Seite Abdelmaleks die gegen die französische Zone gerichtete deutsche "Marokko-Aktion geleite $^{378}$. Zudem benötigte Ab-

${ }^{374}$ PA-AA R70870: Botschaft Paris an AA, 21.6.1926 mit beiliegendem Bericht «Affaire Klems«; SHAT 12J3797, 27: Vernehmung von Josef Klems vor dem 2. Kriegsgericht Meknes, 19.6.1927; MANUE, La fin, 21.2.1930.

${ }^{375}$ SHAT 12J3797, 40: Commandant le cercle de Missour an Commandant le territoire, 4.12.1924; SHAT 12J3797: Bericht »Rapport sur l'affaire du caporal Klems Joseph«, 23.12.1926; SHAT 12J3797, 43: Bericht »Notice sur le nommé Joseph Klems«, 5.12.1926; SHAT 12J3797, 89: Befragung von Taleb Mohand Ameziane, Ait Temana, 10.11.1926; SHAT 3H1557: Contrôle civil de Taourirt, Bulletin de renseignements, 16.10.1924; SHAT 3H1102: Bericht "Message téléphonique reçu de Camp Berteaux«, 17.8.1924; SHAT

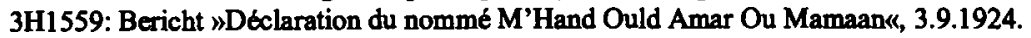

${ }^{376}$ SHAT 12J3797, 12: Commandant $2^{e}$ étranger an Conseil de guerre Taza, 13.12.1924; PAAA R70870: Antoine Paoli an AA, 17.8.1927.

${ }^{377}$ CADN Maroc DAI 199: EMA, $2^{e}$ bureau an RG Rabat, 6.7.1926 mit dem Bericht »Note sur les renseignements fournis par le légionnaire Klems«; MAC ORLAN, La Légion, S. 97.

${ }^{378}$ SHAT 12J3797, 29: Vernehmung von Josef Klems vor dem 2. Kriegsgericht Meknes, 22.6.1926. Siehe zu Bartels Kapitel 2, S. 35. 
delkrim für den kurz zuvor gefallenen Kommandeur der Artillerie Abdallah Serbiano einen Nachfolger. Auch Si Ahmed el Soussi, ein anderer Artillerieeinweiser, wurde im Oktober 1924 bei Sidi Ali Bou Roqba getötet ${ }^{379}$.

Zunächst versuchte Abdelkrim, seinen Neuzugang durch Verheiratung fester zu verwurzeln. Klems' erste Frau Mimouna stammte von den gerade von Abdelkrim unterworfenen Geznaya. Ihr Ehemann war bei den Kämpfen ums Leben gekommen. Bis Januar 1925 verheiratete sich Klems noch mehrmals und wurde Vater eines Sohnes ${ }^{380}$. Er erhielt eine Unterkunft in Ajdir, zwei Pferde, Geld, Handgranaten, Gewehre, Maschinengewehre und - aus Abdelkrims eigenem Harem - die Spanierin Isabella »la rubia« (die Blonde), die seit 1922 in Gefangenschaft war, als Dienerin ${ }^{381}$. Abdelkrim hatte die junge Frau für 20000 Peseten von Hamid ben Dada, einem Caïd der Metalsa, freigekauft und bei sich untergebracht. Dr. Yves Marion-Gallois und die Krankenschwester Mlle Ponzo waren von Isabella im November 1923 als `Hausmädchen` bedient worden. Ihre Heimat Malaga sah sie nie wieder. Kurz vor dem Ende des Krieges starb sie im Rif ${ }^{382}$.

Klems fühlte sich in seiner neuen Heimat sehr wohl und gab sich wie ein echter Rifkabyle ${ }^{383}$. Zunächst lebte er mit seiner Familie in Chaouia direkt vor den Posten der französischen Zone Marokkos ${ }^{384}$. Der Wohnort hatte mit seiner ersten Aufgabe zu tun. Klems sollte noch 1924 zusammen mit etwa einem Dutzend vorwiegend deutscher Überläufer die Front vor der französischen Grenze von Kiffane bis M'Tioua organisieren und MG-Stellungen einrichten. Dies diente zur Verteidigung für den Fall, daß französische Truppen im Zuge ihrer Ouergha-Offensive weiter nach Norden vorrücken sollten. Klems betrieb Spionage und fotografierte die französischen Posten entlang der Ouergha. Für Colonel Huot von der Direction des affaires indigènes in Rabat war schnell klar: "Klems spielt bei Abdelkrim eine vorherrschende Rolle ${ }^{385}$.

379 SHAT 12J3797, 61: Chef de bureau du Cercle de Taza-Nord an Commandant le cercle de Taza-Nord, 24.7.1926.

${ }^{380}$ PA-AA R70870: Botschaft Paris an AA, 21.6.1926 mit beiliegendem Bericht "Affaire Klems«; SHAT 12J3797, 55: Bericht "Déclaration du nommé Allouch Ben Tahar, Iherassen«, 25.7.1926; SHEEAN, An American, S. 275f;; MAC ORLAN, La Légion, S. 97.

${ }^{381}$ SHAT 3H1559: Territoire de Taza, Cercle de Guercif, Bureau de Berkine, SR, Feuille de renseignements, 20.9.1924; SHAT 12J3797, 61: Chef de bureau du cercle de Taza-Nord an Commandant le Cercle de Taza-Nord, 24.7.1926.

${ }^{382}$ SHEEAN, An American, S. 328f.; FONTAINE, L'étrange aventure, S. 61; FURNEAUX, Abdel Krim, S. 92, S. 97; Die Armee Abd el Krims, in: Kölner Tageblatt, 15.1.1925.

${ }^{383}$ SHAT 12J3797, 29: Vernehmung von Josef Klems vor dem 2. Kriegsgericht Meknes, 22.6.1926; SHEEAN, An American, S. 253, S. 277.

334 SHAT 3H1 157: Contrôle civil de Taourirt, Bulletin de renseignements, 13.11.1924.

${ }^{385}$ SHAT 12J3797: DAI Rabat, Bericht von Colonel Huot, 15.11.1924. Vgl. CADN Maroc Direction de l'intérieur 842: Contrôle civil de Taourirt, Bulletin de renseignements, 16.10.1924; SHAT 3H443: Région de Taza, SR, Bericht »Interrogatoire du tirailleur Ottman Mohammed«, 29.9.1925; GABRIELLI, Abd-el-Krim, S. 21. 
Im Anschluß wurde der Deutsche ins Hauptquartier nach Ajdir berufen. Dort arbeitete er einige Zeit als eine Art Sekretär und Übersetzer, der Berichte über militärische Belange des Rifkrieges aus amerikanischen, englischen und deutschen Zeitungen für Abdelkrims Bruder Si M'hammed ins Französische übertrug und auf einer Schreibmaschine briefliche Korrespondenz der Khattabis nach Frankreich, Deutschland, Großbritannien und in die USA ins reine tippte. Über seinen Tisch gingen die Briefe von »Times«-Korrespondent Walter B. Harris, vom politischen Berater Abdelkrims Captain Robert GordonCanning und von Gertrude Arnall aus Tanger. Stets genügte ein Anruf Abdelkrims per Feldtelefon, damit Klems, wo immer er sich aufhielt, sofort nach Ajdir zurückkehrte, um dort Schreibarbeiten zu erledigen. Klems' >Büror war mit Teppichen ausgelegt. Karten, Pläne und Fotos von französischen oder spanischen Posten sowie von Kampfhandlungen hingen an den Wänden ${ }^{386}$.

Kurt Degenkolbe, der Spanisch, Arabisch und ein wenig Französisch sprach, stand Klems auf dessen Empfehlung hin ab dem Frühjahr 1925 bei Verhören spanischer Soldaten als Übersetzer zur Seite. Abdelkrim diktierte ihm auch Briefe, die er an europäische Zeitungen verschickte. Degenkolbe nahm den Namen Abdullah an, wurde zum Caïd ernannt und diente Abdelkrim rund fünf Monate als einflußreicher Sekretär im Hauptquartier von Ajdir $^{387}$.

Ein weiteres Betätigungsfeld für Klems war die Dokumentation der Kampfhandlungen durch Fotografie. Er verfügte über die einzige Kamera im Rif und wurde von Abdelkrim ermutigt, sie so oft wie möglich zu benutzen ${ }^{388}$. Klems folgte Si M'hammeds Generalstab mit dem Vorrücken der Riftruppen und fotografierte den Fall von Chichaouen ${ }^{389}$. Genauso verdingte er sich als Kartenzeichner. Er wurde dem Oberbefehlshaber Si M'hammed an der Westfront zugeteilt und erstellte im Herbst 1924 Karten und Pläne der spanischen Posten zwischen Tetuan und Chichaouen ${ }^{390}$. Mit ihnen konnten die Rifkabylen die Kämpfe im Westsektor im November und Dezember 1924 siegreich gestal-

${ }^{386}$ PA-AA R70870: Botschaft Paris an AA, 21.6.1926 mit beiliegendem Bericht 》Affaire Klems«; SHAT 12J3797, 27: Vernehmung von Josef Klems vor dem 2. Kriegsgericht Meknes, 19.6.1926; CADN Madrid C275: MAE an Ambassade de Madrid, 24.11.1924; CADN Maroc DAI 199: EMA, $2^{e}$ bureau an RG Rabat, 6.7.1926 mit dem Bericht »Note sur les renseignements fournis par le légionnaire Klems«; PRO-FO 371, 12694, 1475, 248: RG Rabat an FO, 15.2.1927; SHAT 12J3797, 98: Befragung von Placide Goux vor dem 2. Kriegsgericht Meknes, 1.12.1926; SHEEAN, Abd el Krims europäische Helfer, 10.11.1925.

${ }^{387}$ DEGENKOLBE, Erlebnisse, 7.3.1926; DERS., Vom Schusterjungen, S. 78, S. 87; CADN Tanger C39: Tabor de police $\mathrm{N}^{\circ}$ 1, Note, 15.7.1925; CADN Maroc DAI 192: Tabor de police $N^{\circ} 1$ Tanger an DAI Rabat, 11.7.1925; PA-AA R71925: Konsulat Tetuan an Botschaft Madrid, 29.6.1925.

${ }^{388}$ SHEEAN, An American, S. 230.

${ }^{389}$ PA-AA R70870: Botschaft Paris an AA, 21.6.1926 mit beiliegendem Bericht »Affaire Klems«.

${ }^{390}$ SheEAN, An American, S. 276; Ders., Chief Raisuli Refuses to Eat, Prays for Death, in: Chicago Tribune, 10.2.1925. 
$\operatorname{ten}^{391}$. Klems empfing Rifbesucher aus Europa und den USA. Zusammen mit Abdelkrims britischem Berater Captain Robert Gordon-Canning fertigte er 1925 Stadtpläne für ein zukünftiges Rif $a^{392}$. Er führte Bergbauingenieure durch das Gebirge, und er beherbergte im Winter 1924 die französischen Kommunisten Lacoste und Couture, die Abdelkrim Briefe von Jacques Doriot überbrachten ${ }^{393}$.

Genauso betreute Klems das Rif besuchende Pressevertreter. Sein erster Gast in Ajdir war Anfang Oktober 1924 der amerikanische Journalist Paul Scott Mowrer von den "Chicago Daily News«. Als Mowrer am 7. Oktober 1924 in Ajdir eintraf, wartete Klems auf ibn. Drei Tage später konnte der Amerikaner Abdelkrim zwei Stunden lang interviewen. Beim Gespräch selbst fungierte dessen Vertrauter Boujibar, der perfekt Englisch sprach, als Übersetzer. Von wichtigen Gesprächen blieb Klems demnach ausgeschlossen. Er versuchte, seine mangelnden Englischkenntnisse vor den Rifkabylen zu verbergen. Mowrer, der einige Tage zusammen mit dem Deutschen verbrachte, fragte sich bisweilen, welchen Unsinn die von Klems übersetzten Briefe nach England enthielten. Der 'Dolmetscher Abdelkrims bat sowohl Mowrer als auch dessen Kollegen Vincent Sheean, mit denen er sich in der Regel in deutscher Sprache unterhielt, ihm ein englisch-deutsches Wörterbuch zuzusen$\operatorname{den}^{394}$. Vincent Sheean von der »Chicago Tribune« traf Klems im Januar 1925. Acht Tage bereisten die beiden das Rif von Ajdir bis Chichaouen. Klems übersetzte ein Interview mit dem von Abdelkrim gefangengenommenen Scherifen Ahmed el Risouni, und Sheean lauschte amüsiert den phantastischen Erzählungen des Deutschen über sein Leben ${ }^{395}$.

Klems' Hauptaufgabe war die Leitung der Artillerie als Nachfolger des getöteten Abdallah Serbiano. Abdelkrim bezeichnete ihn als seinen "großen Artilleristen ${ }^{396}$. Nach dem Chichaouen-Feldzug von 1924 war Klems zum Caïd ernannt worden. Er trug einen roten Turban mit drei Litzen, die seinen Namen und seinen Rang anzeigten. Im November 1924 überprüfte Klems - nun als Caïd el Haj alemán - zusammen mit dem ausländischen Moslem El Haj Tur-

391 WoOLMAN, Rebels in the Rif, S. 152.

${ }^{392}$ SHAT 12J3797, 27: Vernehmung von Josef Klems vor dem 2. Kriegsgericht Meknes, 19.6.1926.

${ }^{393}$ SHAT 3H1558: Commandant du cercle de Guercif an Commandant le territoire de Taza, 6.5.1925; CADN Maroc DAI 199: EMA, $2^{\mathrm{e}}$ bureau an RG Rabat, 6.7.1926 mit dem beiliegenden Bericht »Note sur les renseignements fournis par le légionnaire Klems«; SHAT 12J3797, 28: Vernehmung von Josef Klems vor dem 2. Kriegsgericht Meknes, 19.6.1926; DAOUD, Abdelkrim, S. 192. Siehe zur Rolle Doriots und der kommunistischen Partei Frankreichs (PCF) während des Riflrieges Kapitel 6, S. 259-264.

${ }^{394}$ MOWRER, The House of Europe, S. 467f., S. 477f., S. 483f.; SHEEAN, An American, S. 305; SHAT 3H102: Bericht "Note au sujet du voyage de M. Scott Mowrer dans le Riff" o.D. [Oktober 1924].

${ }^{395}$ SHEEAN, An American, S. 251f., S. 293-301; DERS., Personal History, S. $119 f$.

${ }^{396}$ FLEMING, Primo de Rivera and Abd-el-Krim, S. 225; GODED LLOPIS, Marruecos, S. 98. 
qui im Geznaya-Gebiet die Einsatzfăhigkeit der Gewehre und $\mathrm{MGs}^{397}$. Die beiden Söldner Abdelkrims stellten za dieser Zeit eine nur aus Überläufern bestehende Einheit für die Bedienung von Artilleriegeschützen auf. Nach und nach erhöhten sie die Stärke auf 50 bis 70 Mann - davon waren 15 bis 20 Europäer. Bei Einsätzen übernahm Klems das Kommando. Vom Sold bezahlte er nur einen Teil aus und behielt den Rest für sich. Viele beklagten sich später über seine Brutalität. Auch vor Erschießungen schreckte er nicht zurück ${ }^{398}$.

Während der Offensive auf Tetuan gegen Ende 1924 spielten Klems und seine Artilleristen eine maßgebende Rolle. Einige Kilometer entfernt ließ er auf einer Anhöhe Geschütze postieren, damit von dort die Stadt mit Feuer belegt werden konnte ${ }^{399}$. Für kurze Zeit war der Franzose Abdallah alias Louis Bourhis für den Beschuß zuständig ${ }^{400}$. Diese Situation dauerte bis 1926 an, da die spanische Luftwaffe den Geschützen nicht beikommen konnte. Die Rifartillerie richtete zwar keinen allzu großen Schaden an, die ständige Bedrohung jedoch wirkte auf die Bevölkerung Tetuans zermürbend ${ }^{401}$.

Anfang 1925 erteilte Si M'hammed Klems den Auftrag, eine Verteidigungslinie für die Küste zu entwickeln, um eine spanische Landung zu verhindern $^{402}$. Allein 50 deutsche Überläufer bedienten in der Bucht von Alhucemas Maschinengewehre und zunächst vier Kanonen ${ }^{403}$. Zusammen mit den ausgebildeten Rifkabylen und den indigenen Überläufern bestand Klems' Artillerieeinheit nun nach und nach aus 350 bis 400 Mann, denen Anfang 1925 etwa

${ }^{397}$ CADN Maroc Direction de l'intérieur 842: Contrôle civil de Taourirt, Bulletin de renseignements o.D. [November 1924].

${ }^{398}$ SHAT 12J3797, 61: Chef de bureau du cercle de Taza-Nord an Colonel commandant le cercle de Taza-Nord, 24.7.1926; SHAT 12J3797, 98: Vernehmung von Placide Goux vor dem 2. Kriegsgericht Meknes, 1.12.1926; TERRIER, Les wFrères de la côter 1925, S. 549, Anm. 1; Ex-Prussian Captain Directs Riffians, in: New York Times, 2.11.1925; DEGENKOLBE, Vom Schusterjungen, S. 72; WARD PRICE, In Morocco, S. 246; BLOND, Histoire, S. 204; MAC ORLAN, La Légion, S. 97; BRUSSAC, La Légion, S. 104.

${ }^{39}$ Ál

${ }^{400}$ SHAT 12J3797, 28: Vernehmung von Josef Klems vor dem 2. Kriegsgericht Meknes, 19.6.1926.

${ }^{401}$ Alfred von MIERKA, Die militärische Lage in Marokko IV. Die Einschließung des Rifgebiets im Osten, in: Kölnische Zeitung, 23.10.1925; Die Lage in Marokko, in: Kölnische Zeitung, 1.11.1925; Un canon mystérieux sur Tétouan, in: Petit Journal, 5.3.1926; KUNZ, MÜLLER, Giftgas, S. 167; WOOLMAN, Rebels in the Rif, S. 197f.; CAMPOS MARTíNEZ, Abd-elKrim, S. 236; HARRIS, France, S. 173f.; René de PlanHOL, Skirting the Firing Line in Morocco, in: Living Age 325 (1925) S. 501-505, S. 501f.

${ }^{402}$ PA-AA R70870: Botschaft Paris an AA, 21.6.1926 mit beiliegendem Bericht "Affaire Klems«; Marqués de Estella an Marqués de Magaz, 18.6.1925, in: ARMÑAN (Hg.), Epistolario, S. 205-208, S. 206.

${ }^{403}$ CADN Maroc DAI 188: Tabor de police $N^{\circ} 1$, Note, 16.1.1925 mit Bezug auf Aussagen des spanischen Deserteurs Enrique Larrea Gonzalez; SHAT 3H1557: Territoire de Taza, Cercle de Guercif, SR, Bericht »Renseignements sur le Riff«, 8.2.1925; SABLOTNY, Légionnaire, S. 268f. 
100 bis 200 Kanonen meist spanischer Herkunft zur Verfügung standen. Meist war aber nur die Hälfte einsatzbereit ${ }^{404}$. Maultiere oder auch spanische Gefangene zogen die Geschütze über das von Abdelkrim konzipierte Straßensystem zu den Einsatzorten ${ }^{405}$.

Rifscheichs erinnerten sich später, daß Klems im Generalstab der Rifarmee einer der glühendsten Verfechter für einen Krieg gegen die französische Zone Marokkos gewesen sei $^{406}$. Im Januar 1925 soll er zum französischen Informanten Si Mohammed Jaouen Ameziane gesagt haben, daß es sein Ziel sei, die Franzosen aus Marokko herauszuwerfen, damit Abdelkrim zum Sultan ernannt werde $^{407}$. Unter Umständen hat er also in seinem Haß auf Frankreich dazu beigetragen, daß Abdelkrim den Angriffsbefehl auf Französisch-Marokko gab. Scheich Abdesslam von den Therassen behauptete gar, der Deutsche habe Abdelkrim zum Krieg gegen Frankreich angestachelt ${ }^{408}$. Klems befand sich in unmittelbarer Nähe zu den Entscheidungsträgern. Von März bis Juni 1925 hielt er sich als Mitglied des Generalstabes zumeist im Hauptquartier von Si $M^{\prime}$ 'hammed in Targuist auf ${ }^{409}$. Keinesfalls allerdings war er, wie gelegentlich in der Literatur behauptet wird, der Chef der Rif-Generalstabes ${ }^{410}$.

Klems kannte sich bestens mit den Kampfmethoden der Franzosen aus, und seine Ratschläge haben im Frühjahr 1925 sicher zu den Anfangserfolgen der Rifkabylen während ihres Angriffs auf Französisch-Marokko beigetragen ${ }^{411}$. Anfang April 1925 leitete er die Truppenbewegungen der Geznaya zur Verstärkung der Frontlinie Chaouia-Kiffane ${ }^{412}$. Klems führte Angriffe gegen mit Frankreich verbündete Fraktionen der Beni Zeroual und Ait Mediouna an. In der Region Kiffane-Mçoun fotografierte er französische Stellungen, und im Gebiet der Chaouia befahl er die Sabotage feindlicher Telefonlinien. Den französischen Posten Mediouna beschoß Klems am 11. Juni 1925 mit einer

${ }^{404}$ FLEMING, Primo de Rivera and Abd-el-Krim, S. 224; GaBRIELLI, Abd-el-Krim, S. 50; WOOLMAN, Rebels in the Rif, S. 152; Die Hilfsquellen Abd el Krims, in: Kölnische Zeitung, 25.6.1926; Die Armee Abd el Krims, in: Kölner Tageblatt, 15.1.1925.

${ }^{405}$ USBORNE, The Conquest, S. 269; RUE, News, S. 286.

${ }^{406}$ SHAT 12J3797, 57: Bericht "Déclaration du Cheikh Bel Makoul de Tamjount«, 27.5.1926; SHAT 12J3797, 58: Bericht „Déclarations du nommé Mohand Ould Kaddour«, 27.5.1926.

${ }^{407}$ SHAT 12J3797: Bericht »Déclarations de Si Mohamed Jaouen Ameziane«, 28.7.1926.

${ }^{408}$ SHAT 12J3797, 56: Bericht »Déclaration du Cheikh Abdesslam des Iherassen« O.D.

${ }^{409}$ SHAT 12J3797: Bericht »Rapport sur l'affaire du caporal Klems Josef«, 23.12.1926; SHAT 12J3797, 28: Vernehmung von Josef Klems vor dem 2. Kriegsgericht Meknes, 19.6.1926; PA-AA R70870: Botschaft Paris an AA, 21.6.1926 mit beiliegendem Bericht „Affaire Klems«; CADN Maroc DAI 199: EMA, $2^{\complement}$ bureau an RG Rabat, 6.7.1926 mit dem Bericht »Note sur les renseignements fournis par le légionnaire Klems«.

${ }^{410}$ Z.B. MCLEAVE, The Damned, S. 170; GERAGHTY, La Légion, S. 158.

111 BRUSSAC, La Légion, S. 104.

${ }^{412}$ SHAT 3H1103: Controle civil de Taourirt, Bulletin de renseignements, 8.4.1925; CADN Tanger C38: CG Tanger an RG Rabat, 15.5.1925. 
Kanone. Es folgten weitere Artillerieattacken im Gebiet der Beni Zeroual ${ }^{413}$. Klems' Artillerietruppe war mit etwa 100 Mann an der Offensive der Rifkabylen beteiligt ${ }^{414}$. Die Anzahl der Artilleristen und die Beschränkung auf den Beschuß einzelner belagerter Posten zeigt, daß der Einsatz von Geschützen einen »lediglich zufälligen, sporadischen Charakter ${ }^{415}$ trug, aber die Artillerie war geschickt verteilt. Targuist und Tsouenta dienten als Nachschubdepots ${ }^{416}$.

Viele von Klems' Artilleristen waren deutsche Überläufer ${ }^{417}$. Es handelte sich unter anderem um Walter Hending, Martin Reinhold, Jakob Eugen, Jakob Sauer, Deubsen, Tadler, Lelaczek (allesamt Deserteure aus der französischen Fremdenlegion), die als Artilleristen bei Kiffane kämpften ${ }^{418}$; Johann Kummer und Franz Zunft ${ }^{419}$ (französische Fremdenlegion); Georg Meyer alias Abdallah Islame, der als Deserteur aus der französischen Fremdenlegion zum Caïd ernannt wurde, einen kleinen Kommandoposten innehatte und maßgeblich an der Eroberung eines Postens beteiligt war; Walter vom Scheidt alias Abdelkader (französische Fremdenlegion), der zunächst im Oktober 1924 an der Einnahme von Chichaouen und an den anschließenden Kämpfen bei Tetuan beteiligt gewesen war und nun im Gebiet der Beni Zeroual als Caïd einen Posten kommandierte und Mörserkanonen bediente ${ }^{420}$. Auch ein Berliner namens Federmann alias Caïd Mustafa hatte in der Rifarmee eine höhere Stellung inne. Kurt Degenkolbe alias Caïd Abdullah dirigierte im Juni 1925 einen ganzen Trupp deutscher Deserteure aus der spanischen Fremdenlegion zur Front nach Souk el Sist ${ }^{421}$.

${ }^{413}$ SHAT 12J3797, 56: Bericht "Déclaration du Cheikh Abdesslam, Therassen«, 25.7.1926; SHAT 12J3797, 58: Bericht "Déclarations du nommé Mohand Ould Kaddour, Chaouia", 25.7.1926; SHAT 12J3797, 98: Befragung von Placide Goux vor dem 2. Kriegsgericht Meknes, 1.12.1926; SHAT 12J3797, 55: Bericht „Déclaration du nommé Allouch Ben Tahar, Therassen« o.D. (1926); SHAT 12J3797: Bericht »Rapport sur l'affaire du caporal Klems Josef«, 23.12.1926; SHAT 12J3797, 61: Chef de Bureau du Cercle de Taza-Nord an Commandant le Cercle de Taza-Nord, 24.7.1926.

${ }^{414}$ SHEEAN, Abd el Krims europäische Helfer, 10.11.1925; L'agression des Rifains contre le Maroc français, in: BCAF 35 (1925) S. 307; WOOLMAN, Rebels in the Rif, S. 184.

${ }^{415}$ FrUNSE, Zivilisatoren, S. 523.

${ }^{416}$ USBORNE, The Conquest, S. $269 \mathrm{f}$.

${ }^{417}$ SHAT 3H443: Bericht »Interrogatoire du tirailleur Khelifat Ben Razouk« o.D. (1926).

${ }^{418}$ CRÉMADEILLS, Le Parti communiste français, Bd. 1, S. 211.

${ }^{419}$ PA-AA R70844: Preußisches Innenministerium an AA, 6.2.1928 mit Bezug auf eine Vernehmung von Johann Kummer, 4.1.1928; PA-AA R70980: Regierungspräsident Düsseldorf an AA, 30.7.1935 mit Bezug auf eine Aussage von Max Ranff.

${ }^{420}$ PA-AA R70840: Preußisches Innenministerium an AA, 14.2.1927 mit Bezug auf Aussagen von Walter vom Scheidt; SHAT 3H442: Note de renseignements o.D. [Mitte 1926] mit Bezug auf Aussagen von Karl Ohme; CADN Maroc DAI 192: RG Rabat an EMA, $2^{\mathrm{C}}$ bureau, 13.11.1925 mit dem Bericht »Renseignements fournis par le sergent-fourrier Cucchi« O.D.

${ }^{421}$ DEGENKOLBE, Vom Schusterjungen, S. 99, S. 109f. 
Klems war auch mit der Überwachung der Linie Beni-Berber-Oun-AïchaMetalsa-Guercif beauftragt. An der Grenze zu Französisch-Marokko leitete er die Defensivstellungen, die die französischen Truppen bei deren Gegenattacke lange Zeit aufhielten ${ }^{422}$. Alfred Zaeper aus Klems' früherem 2. Fremdenregiment schilderte den französischen Sturm auf Ain Aïcha vom 24. Mai 1925, der mit schweren Verlusten zurückgeworfen wurde: »Die Rifleute hatten eine schwer verschanzte und gute Stellung und schossen treffsicher mit Geschützen und Maschinengewehren ${ }^{423}$. Klems war gut bewaffnet und stets zu Pferd unterwegs. Eine Eskorte begleitete ihn, wenn er die Front besichtigte und die Moral der Truppen aufrechtzuerhalten versuchte. Er führte außerdem Zählungen durch, er fertigte Pläne und Karten an, er verhörte Gefangene und er fotografierte $^{424}$.

Im Sommer 1925 sollte Klems Abdelkrims Bruder Si M'hammed auf einer Art ,Werbe-Tour ' für das Rif nach Europa und speziell nach Deutschland begleiten. Wegen der sich verschlechternden militärischen Lage mußten beide jedoch im Rif verbleiben ${ }^{425}$. Ende Juni 1925 war Klems, als er den Posten Bab Mizab fotografieren wollte, zudem von drei MG-Kugeln verwundet worden. Die Genesung in Ajdir nahm einen Monat in Anspruch ${ }^{426}$. An ihrer Stelle machte sich Kurt Degenkolbe auf den Weg. Anfang Juli 1925 war er zu Boujibar zitiert worden. Dieser trug ihm auf, dem deutschen Volk mitzuteilen, daß die Rifkabylen die Freiheit wollten wie alle anderen Nationen auch. Ausländer mit Ausnahme von Spaniern könnten jederzeit ins Rif einreisen, um Bergbau zu betreiben, um Fabriken zu errichten oder um Hilfe zu leisten ${ }^{427}$. Abgesehen von einem Artikel in der "Deutschen Zeitung« vom 7. März 1926 bewirkte Degenkolbe aber nichts.

Abdelkrim versuchte, Klems' Kontakte zu den rebellischen Bewohnern des Atlasgebirges zu nutzen, um sich mit diesen gegen die Franzosen zu verbünden. Das Ziel war, die Eisenbahnlinie und die Straße von Taza in Richtung Süden abzuschneiden sowie die Verbindung zwischen Marokko und Algerien

${ }^{422}$ SHAT 12J3797, 69: Befragung von Mohamed Bou Makoul, 20.8.1926; SHAT 3H1559: Région de Taza, Bericht "Note sur l'organisation militaire riffaine« o.D. (1925); MAC ORLAN, La Légion, S. 97.

${ }^{423}$ ZAEPER, Unter der Glutsonne, S. 20.

${ }^{424}$ SHAT 12J3797: Bericht »Rapport sur l'affaire du caporal Klems Josef«, 23.12.1926; SABLOTNY, Légionnaire, S. 267f.

${ }^{425}$ SHAT 12J3797, 27: Vernehmung von Josef Klems vor dem 2. Kriegsgericht Meknes, 19.6.1927; SHAT 12J3797, 29: Vernehmung von Josef Klems vor dem 2. Kriegsgericht Meknes, 22.6.1927.

${ }^{426}$ CAOM Algérie 1CM1: Commune mixte de Remchi an Sous-Préfecture de Tlemcen, 3.7.1925; PA-AA R70870: Botschaft Paris an AA, 21.6.1926 mit beiliegendem Bericht »Affaire Klems«; SHAT 12J3797: Bericht »Rapport sur l'affaire du caporal Klems Joseph«, 23.12.1926.

${ }^{427}$ CADN Tanger C39: Tabor de police $N^{\circ} 1$, Bericht »Déclarations de Degenkalb Kurt«, 15.7.1925; DEGENKOLBE, Erlebnisse, 7.3.1926; DERS., Vom Schusterjungen, S. 110, S. 129. 
zu trennen. Ein ähnlicher Plan war bereits im Zuge der deutschen »MarokkoAktion « des Ersten Weltkrieges verfolgt worden. Abdelkrim schickte Gesandte mit Briefen und Geld zu den Beni Ouaraïn und den Tsoul ${ }^{428}$.

Im Oktober 1925 erhielt Klems den Auftrag, zusammen mit den Tazi-Brüdern den Kontakt zu Aufständischen in Algerien, Tunesien und Tripolitanien herzustellen sowie mit bereits bestehenden Organisationen in Marokko eine allgemeine Erhebung vorzubereiten ${ }^{429}$. Die Tazi-Brüder waren die Söhne von Mohammed Tazi, des früheren Vertreters des Sultans in Tanger. Sie hatten am 2. Oktober 1925 in Targuist angeblich im Namen von Millionen Unterdrückter des Sultans von Marokko eine Treueerklärung für Abdelkrim verlesen und ihn feierlich aufgefordert, keinen Frieden zu schließen, bevor nicht ganz Marokko von französischen Truppen befreit $\mathrm{sei}^{\mathrm{430}}$.

Die von Klems vorbereitete Verteidigungslinie in der Bucht von Alhucemas war mittlerweile auf 20 bis 40 Geschütze angewachsen. Nur noch drei Europäer - zwei Franzosen und ein deutscher Deserteur aus der spanischen Fremdenlegion - hielten sich dort als Einweiser auf. Die Bedienung erfolgte durch 71 Rifkabylen, die Haj Mohammed Chara, sekundiert von zwei Europäern, anführte $^{431}$. Ein deutscher Offizier befehligte im Juni 1925 vier 50-mm-Geschütze, die zwei französische Torpedoboote beschossen, ohne Schaden anzurichten $^{432}$. Der Mangel an Überläufern in die Rifarmee führte dazu, daß Gefangene zum Teil unter Todesandrohung gezwungen wurden, Geschütze auf die spanische Festung Peñon de Alhucemas abzufeuem ${ }^{43}$.

Als die spanischen Truppen am 8. September 1925 westlich der Bucht von Alhucemas landeten, stießen sie auf wenig Gegenwehr, denn der Hauptteil der von Josef Klems vorbereiteten Verteidigungsstellungen war auf die eigentliche Bucht gerichtet. Klems und Abdelkrim hatten sich verspekuliert. Ein Ablen-

${ }^{428}$ Georges R. MANUE, Sur les marches du Maroc insoumis, Paris ${ }^{6} 1930$, S. 123-125; DERS., La fin, 21.2.1930; UsBorNe, The Conquest, S. 270f.; Jacques LADREIT DE LACHARRIÈRE, La Tache de Taza et l'action militaire de la France au Maroc, in: Revue des sciences politiques 49 (1926) S. 486-512, S. 506-508; L'agression des Rifains contre le Maroc français, in: BCAF 35 (1925) S. 353-367, S. 355; Une nouvelle phase de la guerre au Maroc, in: Matin, 5.7.1925; Persönliches über Abd el Krim, in: Deutsche Allgemeine Zeitung, 15.7.1925; Die Initiative bei Abd el Krim, in: Kölnische Zeitung, 14.8.1925; PA-AA Paris 454a: Konsulat Tetuan an Botschaft Madrid, 14.8.1925; VonOT, Sur les traces, S. 149.

${ }^{429}$ AN F7, 13413: MI, Commissariat spécial de Menton an MI, Sưreté géntrale, 2.11.1925.

${ }^{430}$ Vincent SHEEAN, A Declaration from Abd el Kader Tazi, in: Daily Express, 5.11.1925; Ders., Personal History, S. 156; Walter B. HARRIS, The Defection of Tazzi's Sons, in: Times, 19.9.1925; DERs., Gun-Fire Heard in Tangier, in: Times, 17.9.1925.

${ }^{431}$ GODED LLOPIS, Marruecos, S. 98f.; RUE, News, S. 285; SHAT 3H102: EMA, $2^{e}$ bureau, Bericht 'Collaborateurs d'Abd el Krim《, 20.7.1925.

${ }^{432}$ GUY, Le débarquement espagnol, S. 466.

${ }^{433}$ CADN Maroc DAI 192: RG Rabat an EMA, 2 ${ }^{e}$ bureau, 13.11 .1925 mit dem Bericht "Renseignements fournis par le sergent-fourrier Cucchi«; SHAT 3H102: EMA, $2^{\mathfrak{e}}$ bureau, Bericht »Collaborateurs d'Abd el Krim«, 20.7.1925. 
kungsangriff Abdelkrims auf den Posten Kudia Tahar im Westen, der den Weg nach Tetuan öffnen sollte, schlug fehl. Die Artilleristen bei Alhucemas benötigten einige Tage zur Umgruppierung. Nachts tarnte der deutsche Überläufer Karl Ohme mit Gefangenen die Artilleriestellungen ${ }^{434}$. Die Geschütze fügten den Angreifern hohe Verluste zu. Als eine der Stellungen von spanischen Soldaten eingenommen wurde, wurden die drei deutschen Gefangenen aus Rache sofort standrechtlich erschossen ${ }^{435}$. Französischen Überläufern gelangen sechs Treffer auf dem Schlachtschiff »Paris« aus ihrer eigenen Heimat. Der Zerstörer mußte zu Reparaturarbeiten nach Melilla fahren ${ }^{436}$.

Vor Abdelkrims Hauptquartier in Ajdir beobachtete Augenzeuge Vincent Sheean drei Europäer in einheimischer Kleidung. Ajdir selbst wurde von einer rein aus Deutschen bestehenden Artillerie-Einheit verteidigt, die aus sieben Mann bestand und auch das spanische Fort in der Bucht von Alhucemas mit Feuer belegte ${ }^{437}$. Ajdir fiel am 2. Oktober 1925. Abdelkrim flüchtete mit der gesamten Riffiuhnung nach Targuist. Fritz Weinard und andere Deserteure retteten in der Nacht vom 4. auf den 5. Oktober 1925 Kanonen, MGs und Munition etwa 25 Kilometer weit ins Hinterland, von wo sie am Tag darauf von Rifsoldaten weitertransportiert wurden ${ }^{48}$. Klems selbst floh vor den Kämpfen nach Tamasint. Als französische Truppen die Geznaya angriffen, erbat Amar Allouche die Hilfe von Klems' Artillerietruppe. Sie bekämpfte den von Abdelkrim abgefallenen Amar d'Hamidou und französische Hilfstruppen bei Beraber $^{439}$.

Doch dies dürfte ihr letzter Einsatz gewesen sein. Die Fälle, daß Deserteure nun auch aus der Rifarmee fliehen wollten, begannen sich zu häufen. So gab etwa Martin Reinhold alias Ali Anfang Oktober 1925 dem Drängen seiner Kameraden nach, nach Sidi Ali Bou Roqba zu fliehen und sich Caïd Medboh, einem Verbündeten der Franzosen, zu stellen ${ }^{440}$. Kurt Degenkolbe berichtete von Deserteuren aus der französischen Fremdenlegion, die Abdelkrim ein Jahr

${ }^{434}$ ÁlvareZ, Between Gallipoli and D-Day, S. 88, S. 94; WOOLMAN, Rebels in the Rif, S. 188; HARRIS, France, S. 162-164, S. 168.

${ }^{435}$ SHAT 3H102: EMA, 2 $2^{c}$ bureau, Bericht Officiers allemands capturés par les Espagnols«, 25.10.1925.

${ }^{436}$ Hans F. WolfF, Bei den Spaniern in Marokko. Der Sektor von Ajdir, in: Illustrirte Zeitung 165 (1925) S. 694; DERS., Das Gesicht des Rif, Berlin 1927, S. 103f.; ESPAÑA, La actuación, S. 95; Ein französisches Schlachtschiff abgelöst, in: Kölnische Zeitung, 12.9.1925.

${ }^{437}$ Vincent SHEEAN, Vor dem Fall von Aschdir. Unterredung mit Abd-el-Krim, in: Berliner Tageblatt, 21.10.1925; DERS., Die Lage in Marokko, in: Neue Zürcher Zeitung, 16.1 1.1925.

${ }^{438}$ CADN Maroc DAI 192: Tabor de police $N^{\circ} 1$ Tanger an DAI Rabat, 2.11.1925 mit Bezug auf eine Befragung von Fritz Weinard, 30.10.1925.

${ }^{439}$ PA-AA R70870: Botschaft Paris an AA, 21.6.1926 mit beiliegendem Bericht "Affaire Klems«; SHAT 12J3797, 61: Chef de bureau du cercle de Taza-Nord an Colonel Commandant le cercle de Taza-Nord, 24.7.1926.

40 SHAT 3H1154: Bericht »Procès-verbal d'interrogatoire de l'ex-légionnaire Martin Reinhold surnommé Ali«, 24.10.1925. 
gedient hatten und nach ihrem Fluchtversuch in Ketten gelegt wurden ${ }^{441}$. Ein Absetzen Walter Meyers scheiterte, und auch Franz Koberstein versuchte mehrmals erfolglos zu fliehen ${ }^{42}$. Bei vielen Überläufern machte sich Bitterkeit breit, da sie sich das Leben im Rif anders vorgestellt hatten ${ }^{443}$. Abdelkrim war wegen einiger Verräter und Spionagefälle sowie wegen eines Kopfgeldes, das Sultan Moulay Youssef auf ihn ausgesetzt hatte, mißtrauisch geworden. Als Folge ließ er Europäer aus seiner direkten Umgebung entfernen ${ }^{44}$.

Klems hingegen blieb und kämpfte. Im September oder Oktober 1925 wurde er im Gebiet der Branès erneut schwer verwundet. Nach seiner Genesung stand er wieder an der Spitze einer Truppe der regulären Rifarmee, die zwischen den Marnissa und den Beni Amrest eingesetzt wurde ${ }^{445}$. Klems' letzte Aufgabe war die Leitung des militärischen Nachschubparks der Rifkabylen in Bouham. Er wurde dort der Nachfolger von François Gucchi, eines desertierten französischen Unteroffiziers. Wegen seiner arabischen Mutter sprach Gucchi perfekt die Landessprache. Er trug einheimische Kleidung und wurde von allen nur - wie andere Europäer auch - Ali genannt. Gucchi hatte leitende Funktionen inne, aber nach einer durch einen Granatsplitter hervorgerufenen Verletzung am Arm verließ er das Rif im Dezember 1925 in Richtung Tanger $^{446}$. In Bouham gab es Kriegsgerät verschiedenster Art. Allein 40 Kanonen wurden in der Nähe gelagert oder repariert. Dort traf Klems zweimal - am 4. April 1926 und am 13. Mai 1926 - auf Pierre Parent, der als Leiter einer kleinen Delegation von Ärzten für die französischen Gefangenen Abdelkrims humanitäre Hilfe leisten wollte ${ }^{447}$. Als Klems im April 1926 unvorsichtig mit einer Handgranate hantierte, explodierte sie und riß zwei Finger seiner linken Hand ab. Ein dritter Finger verfaulte später ${ }^{448}$.

${ }^{441}$ CADN Tanger C39: Tabor de police $\mathrm{N}^{\circ} 1$, Bericht „Déclarations de Degenkalb Kurt«, 15.7.1925.

${ }^{442}$ MEYER, Dreitausend Kilometer, S. 110-114; SHAT 3H443: Bericht »Renseignements sur les trois légionnaires suspects« o.D. [Mitte 1926].

${ }^{443}$ CADN Maroc DAI 191: Bericht »Renseignements Gabrielli sur le Riff, Renseignements d'ordre militairex, 19.9.1925.

444 SHEEAN, An American, S. 275; ABDELKRIM, Memoiren, S. 98; Die Kämpfe in Marokko, in: Kölnische Zeitung, 18.9.1925.

${ }^{445}$ SHAT 3H1103: Contrôle civil de Taourirt, Bulletin de renseignements, 23.11.1925 und 5.2.1926; CADN Tanger C38: Tanger an RG Rabat, 3.3.1926; SHAT 12J3797, 61: Chef de bureau du cercle de Taza-Nord an Commandant le cercle de Taza-Nord, 24.7.1926.

${ }^{446}$ CADN Tanger C38: Tabor de police $\mathrm{N}^{\circ} 1$, Note, 21.10.1925; SHAT 3H443: EMA, $2^{\mathrm{e}}$ bureau, Fès, Bericht »Interrogatoire du sergeant Ben Ameur Tahar«, 29.12.1925.

${ }^{447}$ PARENT, Au Riff, S. 325, S. 379f.; SHAT 12J3797, 28: Vernehmung von Josef Klems vor dem 2. Kriegsgericht Meknes, 19.6.1926. Siehe zu Parent auch Kapitel 3, S. 86-88.

${ }^{448}$ Abd el Krim zu seiner Übergabe, in: Kölnische Zeitung, 29.5.1926; CADN Maroc DAI 192: Bericht »Rapport du docteur Mosnier«, 1.6.1926. 
Das Verhältnis zwischen Caïd el Haj alemán und Abdelkrim hatte sich unterdessen sehr verschlechtert ${ }^{449}$. Die Moral der Rifkabylen befand sich im Frühjahr 1926 auf dem Tiefpunkt. Nach dem Fehlschlag der Friedensverhandlungen von Oujda wandten sich viele von Abdelkrim ab. Die müden Kämpfer kehrten in ihre Dörfer zurück. Klems betrachtete die Herrschaft seines früheren Mentors zunehmend als tyrannisches Joch, da Exekutionen abgefallener Kabylen-Anführer gehäuft vorkamen. Er verachtete Abdelkrim auch dafür, daß er nicht bis zum Tode kämpfen wollte, sagte er später aus ${ }^{450}$.

Letztmalig traf der Deutsche die Brüder Abdelkrim und Si M'hammed am 19. Mai 1926 in Sidi Abdallah ben Youssef. Als er um Instruktionen bat, soll Abdelkrim geantwortet haben: »Es ist alles vorbei, du kannst gehen ${ }^{451}$. Der Emir des Rifs behielt Klems in schlechter Erinnerung, denn - so heißt es in seinen Erinnerungen - »er war [...], nebenbei bemerkt, ein widerlicher Mensch ${ }^{452}$. Am 27. Mai 1926 kapitulierte Abdelkrim. Die wenigen übriggebliebenen europäischen Überläufer verstreuten sich in alle Richtungen ${ }^{453}$. Viele wurden verhaftet und vor ein Kriegsgericht gestellt. Bis zum November 1926 handelte es sich um 44 Fälle $^{454}$. Im Glauben, als Rifkabyle ein Anrecht auf das »aman« - eine Art Amnestie - zu haben, begab sich Klems zu seinen Geznaya-Verwandten. Deren Anführer Caïd Medboh war längst ein Verbündeter der Franzosen. Er lieferte Klems an seinen jahrelangen Verfolger, den Elsässer Capitaine Charles Maurice Schmitt, aus, der ihn am 30. Mai 1926 in Aknoul verhaftete ${ }^{455}$.

${ }^{449}$ SHEEAN, Abd el Krims europäische Helfer, 10.11.1925; GABRIELLI, Abd-el-Krim, S. 21; DEGENKOLBE, Vom Schusterjungen, S. 73, MAC ORLAN, La Légion, S. 97; SHAT 12J3797, 56: Bericht „Déclaration du Cheikh Abdesslam, Therassen«, 25.7.1926; SHAT 12J3797, 57: Bericht »Déclaration du Cheikh Bel Makoul de Tamjount", 25.7.1926; AN 475 AP 193: Bericht »Notes sur les affaires indigènes au Maroc, La campagne riffaine« (1927); SHAT 3H1558: Commandant du cercle de Guercif an Commandant le territoire de Taza, 6.5.1925.

${ }^{450}$ SHAT 12J3797, 66: Conseil de guerre de Meknes, Bericht „Compte rendu de Klems«, 8.9.1926.

${ }^{451}$ CADN Maroc DAI 199: EMA, $2^{e}$ bureau an RG Rabat, 6.7.1926 mit dem Bericht $» N o t e$ sur les renseignements fournis par le légionnaire Klems«.

${ }^{452}$ ABDELKRIM, Memoiren, S. 96.

${ }^{453}$ SHAT 12J3797, 61: Chef de bureau du cercle de Taza-Nord an Colonel commandant le cercle de Taza-Nord, 24.7.1926.

454 PA-AA R70857: Botschaft Paris an AA, 16.11.1926.

45s SHAT 12J3797, 23: Befragung von Josef Klems vor dem 2. Kriegsgericht Meknes, 8.6.1926; PA-AA R70870: Botschaft Paris an AA, 21.6.1926 mit beiliegendem Bericht "Affaire Klems«; SHAT 12J3797, 64: Befragung von Capitaine Charles Maurice Schmitt o.D. [1926]; AN 475 AP 193: Bericht »Notes sur les affaires indigenes du Maroc, La campagne riffaine« o.D. [1927]; SHAT 12J3797: Bericht "Rapport sur l'affaire du caporal Klems Joseph«, 23.12.1926; CADN Madrid C261: Région de Fès, Quotidien, 31.5.1926. Zu Caïd Medboh: Deux de nos partisans, Amar d'Hamidou, Caïd Medboh, in: BCAF 36 (1926) S. 280-283, S. 282f. 
Klems' Prozeß, der am 9. Februar 1927 vor dem Kriegsgericht Meknes begann, war eine lokale Sensation. Der Gerichtssaal war voll besetzt, als der gichtgeplagte deutsche Deserteur auf einer Bahre hereingetragen wurde. Die deutsche Presse berichtete ausgiebig. Das Auswärtige Amt hatte Klems - wie in solchen Fällen üblich - Rechtsanwalt Antoine Paoli aus dem algerischen Oran als juristischen Beistand zugewiesen. In diesem Fall jedoch verschleierten die Diplomaten die bereitgestellten Gelder für den Anwalt so, daß es schien, als stammten sie von gemeinnützigen Organisationen. Im Auswärtigen Amt befürchtete Ministerialdirektor Köpke Ärger mit der französischen Regierung, weil »Klems im Heere Abd-el-Krims eine wichtige Rolle gespielt hat und sein Fall in einigen französischen Sensationsblättern als Beweis für die unsinnige Behauptung angeführt worden ist, daß die deutsche Regierung bei den Marokkowirren die Hand im Spiel gehabt habe ${ }^{456}$.

Die Anklage - Desertion, Waffentragen gegen Frankreich, Verrat, Diebstahl - bezog sich explizit nicht auf den Berater Abdelkrims, sondern auf den Fahnenflüchtigen Klems. Nach nur halbstündiger Beratung fallte das Gericht am 10. Februar 1927 das Todesurteil ${ }^{457}$. Seine Identität als Rifkabyle legte Klems in der Folgezeit genauso schnell ab wie die islamische Religion. Er kehrte zur Neuapostolischen Kirche, der seine Eltern in Düsseldorf angehört hatten, zu-

${ }^{456}$ PA-AA R70870: Aufzeichnung, 22.1.1927.

${ }^{457}$ SHAT 12J3797, 128f.: Bericht "Notes d'audience, séance du 9 février 1927, séance du 10 février 1927 «. Die Auswahl an Zeitungsberichten verdeutlicht den Sensationscharakter des Prozesses: Der Prozeß gegen Abd-el-Krims Artilleriechef, in: Berliner Tageblatt, 19.1.1927; Der Prozeß gegen den Legionär Klems, Abd-el-Krims Artilleriechef, in: Berliner Tageblatt, 8.2.1927; Der Prozel gegen den Legionär Klems, in: Berliner Tageblatt, 9.2.1927; Der Prozeß Klems, in: Berliner Tageblatt, 10.2.1927; Das Todesurteil gegen Klems, in: Berliner Tageblatt, 11.2.1927; Der Pressechef von Abd el Krim, in: Düsseldorfer Nachrichten, 9.2.1927; Die Verhandlungen gegen Klems, in: Disseldorfer Nachrichten, 10.2.1927; Der Fremdenlegionär Klems bei Abd el Krim, in: Tägliche Rundschau, 10.2.1927; Klems zum Tode verurteilt, in: Tägliche Rundschau, 12.2.1927; Das Todesurteil gegen Klems, in: Kölnische Zeitung, 11.2.1927; Ein deutscher Abenteurer bei Abd el Krim, in: Berliner BörsenCourier, 9.2.1927; Fremdenlegionär Klems zum Tode verurteilt, in: Berliner Börsen-Courier, 11.2.1927; Klems zum Tode verurteilt, in: Deutsche Allgemeine Zeitung, 12.2.1927; Todesurteil gegen Klems, in: Kölnische Volkszeitung, 11.2.1927; Fremdenlegionär, dann Helfer Abd el Krims, in: Vossische Zeitung, 11.2.1927; L'existence aventureuse du traitre Klems, que va juger le conseil de guerre de Meknes, in: Matin, 9.2.1927; Le deserteur allemand Joseph Klems, in: Vigie marocaine, 10.2.1927; Le légionnaire déserteur Klems devant le conseil de guerre de Meknes, in: Écho du Maroc, 10.2.1927; Les wFrères de la Côteর du Rif. Le caporal deserteur Klems devant le Conseil de guerre de Meknes, in: BCAF 37 (1927) S. 104-106; Klems est condamné à l'unanimité à la peine de mort, in: Écho du Maroc, 11.2.1927; Klems savait trop de choses sur les visées de l'imperialisme français, il est condamné à mort«, in: Humanité, 11.2.1927; L'affaire Klems devant le Conseil de guerre, in: Vigie marocaine, 12.2.1927; Death Sentence on Deserter, in: Times, 11.2.1927; Un desertor de la Legion condenado a muerte, in: A.B.C., 11.2.1927. 
rück $^{458}$. Die französische und die deutsche Regierung einigten sich unter der Hand auf einen Handel. Als dem französischen Agenten August Dreyer, der 1921 in Münster militärische Spionage betrieben hatte, per Dekret des Reichspräsidenten vom 30. April 1928 drei Jahre seiner Haftstrafe erlassen wurden, wandelte der französische Präsident drei Monate später die Todesstrafe von Klems in lebenslange Zwangsarbeit um ${ }^{459}$.

Dies bedeutete die Verschiffung nach Französisch-Guayana ins dortige Straflager, dem »Bagnoк. Am 1. Februar 1930 legte das Häftlingsschiff »Martinière« mit 600 Sträflingen in Algier $a b^{460}$. Auf der berüchtigten Teufelsinsel $\mathrm{saB}$ Klems - einer der bekanntesten Gefangenen seiner Zeit ${ }^{461}$ - in einer Schreibstube, da er wegen seiner verkrüppelten Hand nur leichte Arbeiten verrichten konnte ${ }^{462}$. Franz Zunft, ein Gefährte aus dem Rif, wurde ebenfalls auf die Teufelsinsel verbannt. Ihm gelang 1937 die Flucht nach NiederländischGuayana $^{463}$. Nachdem mehrere Gnadengesuche abgelehnt worden waren und er keine Möglichkeit mehr sah, nach Deutschland zurückzukehren, nahm sich Josef Klems am 9. Oktober 1938 mit einem von einem Wärter entwendeten Revolver das Leben ${ }^{464}$.

${ }^{458}$ CAOM Colonies H4417, Mle. 50321: Paul Dach, Leiter der Neuapostolischen Gemeinde Düsseldorf an Josef Klems, 29.7.1927.

${ }^{459}$ PA-AA R70870: Aufzeichnung, 26.1.1928; PA-AA R70966: AA an Reichsjustizministerium, 9.5.1928; PA-AA R70966: Anklageschrift des Oberreichsanwalts Leipzig gegen August Dreyer, 16.2.1925; PA-AA R70870: Botschaft Paris an AA, 8.8.1928; MAC ORLAN, La Légion, S. 98; MILES, Devil's Island, S. 180.

${ }^{400}$ PA-AA R70871: MAE an Botschaft Paris, 14.6.1930; Das tragische Schicksal des Deutschen Peter Klems. Die graue Eminenz des Rifrebellen Abd-el-Krim, in: Berliner Zeitung, 19.2.1930; Abd el Krims Adjutant, der Deutsche Josef Klems, wurde zu lebenslanger Zwangsarbeit begnadigt, in: Der Weltspiegel, 23.2.1930.

${ }^{461}$ PIERRE, La terre, S. 291; BELBENOiT, Dry Guillotine, S. 152.

${ }^{462}$ PA-AA R70977: PreuBisches Innenministerium an AA, 31.8.1932 mit Bezug auf eine Aussage von Karl Wilhelm; PA-AA R70979: Konsulat Paramaribo an AA, 28.1.1935 mit Bezug auf eine Aussage von Max Ranff.

${ }^{463}$ PA-AA R70975: Polizeipräsident Berlin an AA, 18.3.1931 mit Bezug auf eine Aussage von Walter Fuckert; PA-AA R70976: Preußisches Innenministerium an AA, 31.7.1931 mit Bezug auf eine Aussage von Johann Malsy, 16.5.1931; PA-AA R102941: AA an Leitung der Auslandsorganisation der NSDAP, 28.3.1938.

${ }^{464}$ CAOM Colonies H4417, Mle. 50321: Billet de décès, Administration pénitentiaire, Service de santé, Îles du salut; Îles du salut an Pénitentiaire Saint-Laurent, 10.10.1938; MiCHELS, Deutsche in der Fremdenlegion, S. 83. Michel Pierre nennt als falsches Todesdatum den 27.12.1938 [PIERRE, La terre, S. 293]. Paul Scott Mowrer setzte die Legende in die Welt, Klems sei zurück nach Deutschland gelangt und habe sich in einer Berliner Gefängniszelle erhängt [MOWRER, The House of Europe, S. 521; Angeklagt in Moabit. Der Generalstabschef Abd-el-Krims, in: Berliner Tageblatt, 16.8.1929; vgl. VAIDON, Tangier, S. 198; MCLEAVE, The Damned, S. 172; GeraGHTY, La Legion, S. 161; ANDERSON, Devils, S. 63; MERCER, Legion, S. 240; WARD PRICE, In Morocco, S. 246]. Hierbei handelte es sich jedoch um einen Bruder, nämlich Peter Klems, der wegen Diebstahls in Moabit einsaB [PA-AA R70870: Generalstaatsanwalt beim Kammergericht Berlin an AA, 13.9.1929]. Rupert Furneaux schreibt wahrheitswidrig, Josef Klems sei 1963 in Wien gestorben [FUR- 
Klems hatte als einziger Europäer beratende Funktionen im Generalstab der Rifarmee, der sonst ausschließlich aus Rifkabylen bestand, inne. Fast alle Offiziere und Unteroffiziere der regulären Armee kamen aus dem Rif. Die Grundprinzipien der militärischen Strategie und Taktik stammten von $\mathrm{Si}$ M'hammed und seinem Bruder Abdelkrim. Die beiden trafen praktisch alle wichtigen Entscheidungen selbst. Neben Klems gab es im Rif nur wenige andere Europäer, die eine ähnliche Bedeutung als militärische Berater oder Kommandanten erringen konnten. Zu nennen sind im Grunde genommen nur sein Vorgänger Abdallah Serbiano sowie mit starken Abstrichen Kurt Degenkolbe und Walter vom Scheidt. Abdelkrim benötigte keine europäischen Kommandeure. Dies war Sache der Rifkabylen selbst - vor allem deswegen, weil sie sich im Gelände viel besser auskannten ${ }^{465}$.

Die militärische Bedeutung der europäischen Kämpfer, Berater und Instrukteure war eher gering. Kurzfristige Erfolge der zumeist mit Überläufern besetzten Maschinengewehr- und Artillerieabteilungen sowie die Ausgestaltung des Straßen- und Telefonnetzwerks konnten die Aussichtslosigkeit des Rifkampfes gegen zwei hochgerüstete Kolonialmächte nicht verdecken.

NEAUX, Abdel Krim, S. 234]. Nach dem deutschen Einmarsch in Frankreich wurde 1940 zwei Jahre nach seinem Tod - eine Liste mit etwa $100 \mathrm{zu}$ begnadigenden Personen nach Guayana geschickt, auf der auch Klems' Name verzeichnet war [MILES, Devil's Island, S. 179].

${ }_{465}$ PRO-FO 371, 11080, 39, 155: Embassy of Madrid an FO $23.10 .1925 \mathrm{mit}$ dem beigefügten Bericht des Militärattachés W.W.T. Torr »Interview with Mr. W.B. Harris, the >Times, Correspondent at Tangier«, 10.10.1925; Walter B. HARRIS, The Warfare in the French Zone. A Difficult Campaign, in: Times, 10.6.1925; FrAUENHOLZ, Det spanische Krieg, S. 108. 